\title{
Next Generation Nuclear Plant Methods Technical Program Plan
}

The INL is a

U.S. Department of Energy

National Laboratory

operated by

Battelle Energy Alliance

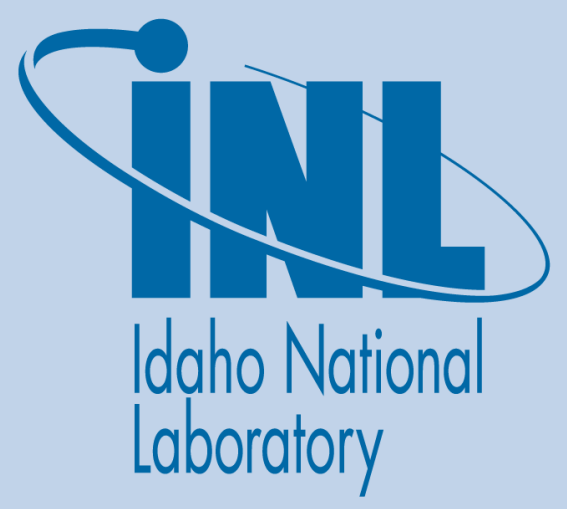

\section{December 2010}

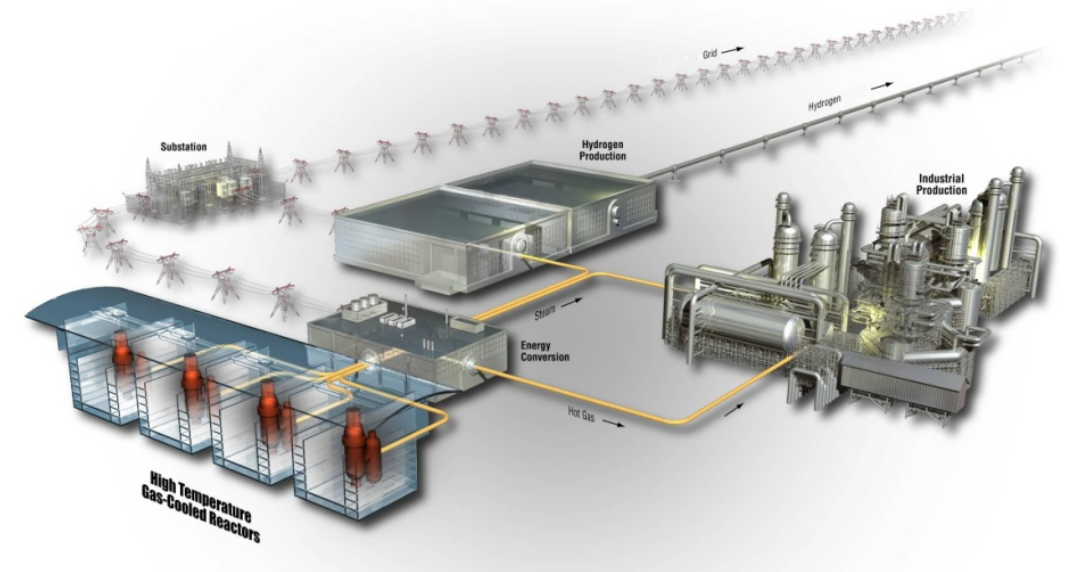


INL/EXT-06-11804

PLN-2498

Rev. 3

\title{
Next Generation Nuclear Plant Methods Technical Program Plan
}

December 2010

\author{
Idaho National Laboratory \\ Next Generation Nuclear Plant \\ Idaho Falls, Idaho 83415
}

http://www.inl.gov

Prepared for the

U.S. Department of Energy

Office of Nuclear Energy

Under DOE Idaho Operations Office

Contract DE-AC07-05ID14517 
Form 412.09 (Rev. 10)

Idaho National Laboratory

NEXT GENERATION NUCLEAR PLANT METHODS TECHNICAL

PROGRAM PLAN

Identifier: $\quad$ PLN-2498

Revision: $\quad 3$

NGNP Project

Plan

eCK Number: 587682

Approved by:
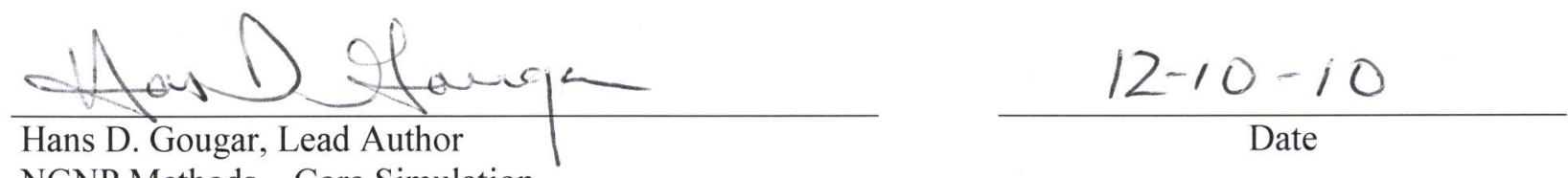

NGNP Methods - Core Simulation

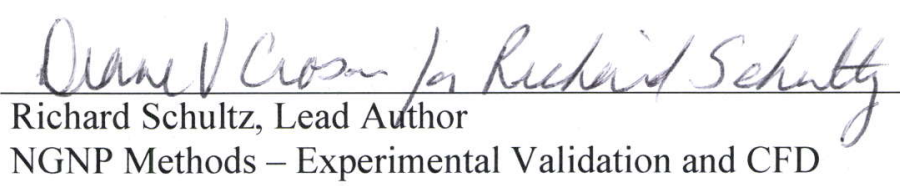

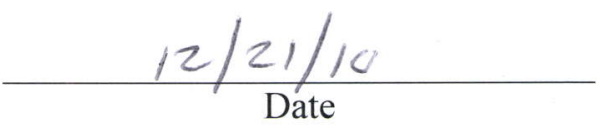

deane Clos

Diane V. Croson

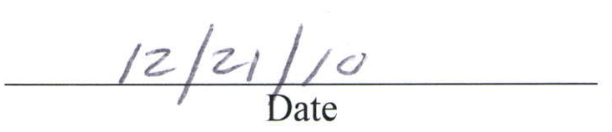

VHTR TDO Deputy Director

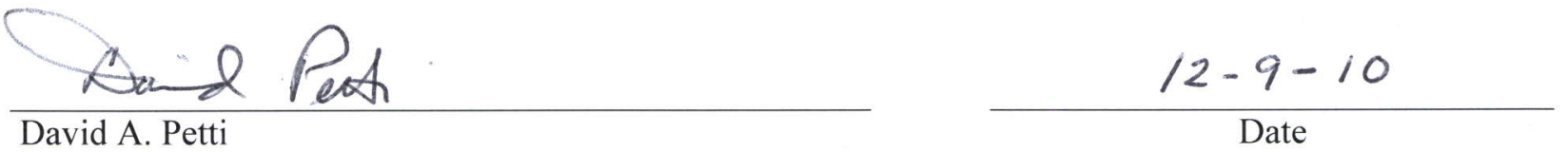

VHTR TDO Director 


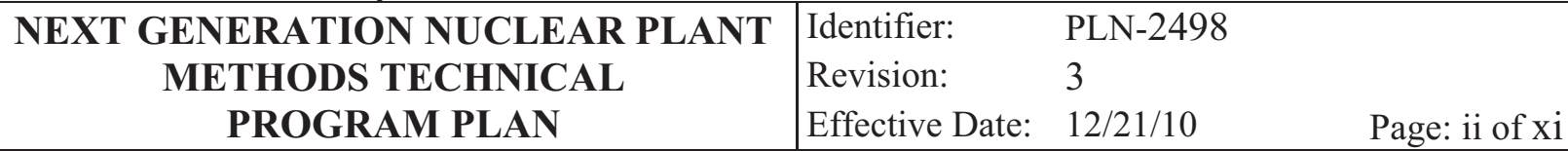

\section{REVISION LOG}

\begin{tabular}{|c|c|c|c|}
\hline Rev. & Date & Affected Pages & Revision Description \\
\hline 0 & $10 / 25 / 07$ & All & Newly issued document \\
\hline 1 & $9 / 26 / 08$ & Section 5 & $\begin{array}{l}\text { Section 5,"neutronics and Reactor Kinetics Analysis } \\
\text { Development" has been completely rewritten to } \\
\text { emphasive the needs for new or enhanced neutronic } \\
\text { methods such as PEBBED-THERMIX-COMBINE } \\
\text { and RELAP-CYNOD-COMBINE. } \\
\text { Minor editorial and grammatical changes throughout } \\
\text { the document. }\end{array}$ \\
\hline 2 & $08 / 26 / 10$ & All & $\begin{array}{l}\text { Goals, Assumptions, and Requirements added. } \\
\text { Program divided into two major elements: } \\
\text { Experimental V\&V and Core Simulation. High } \\
\text { Temperature Test Facility and potential dust/fission } \\
\text { product testing facilities added to the Experimental } \\
\text { V\&V section. Multiphysics simulations and } \\
\text { developments and needs for cross section generation } \\
\text { added to the Core Simulation section. Overall } \\
\text { condensation of technical detail along with editorial } \\
\text { and grammatical changes. }\end{array}$ \\
\hline 3 & $12 / 21 / 10$ & All & $\begin{array}{l}\text { Overall Goals revised. Core Simulation section } \\
\text { revised substantially. }\end{array}$ \\
\hline & & & \\
\hline & & & \\
\hline & & & \\
\hline & & & \\
\hline & & & \\
\hline & & & \\
\hline
\end{tabular}




\begin{tabular}{|c|lll|}
\hline NEXT GENERATION NUCLEAR PLANT & Identifier: & PLN-2498 & \\
METHODS TECHNICAL & Revision: & 3 & \\
PROGRAM PLAN & Effective Date: & $12 / 21 / 10$ & Page: iii of xi \\
\hline
\end{tabular}

\section{EXECUTIVE SUMMARY}

One of the great challenges of designing and licensing the Next Generation Nuclear Plant (NGNP) is to confirm that the intended analysis tools can be used confidently to make decisions and to ensure that all the reactor systems are safe and meet the performance objectives of the Generation IV Program. The research and development (R\&D) projects defined in the NGNP Design Methods Development and Validation Program will ensure that the tools and data used to perform the required calculations and analyses are validated and verified. The Methods R\&D tasks are designed to ensure that the calculational envelope of the tools used to analyze high temperature gas-cooled reactor (HTGR) systems encompasses the operational and transient envelope of the HTGR itself. The methods to be developed and employed for HTGRs with historical outlet temperatures $\left(700\right.$ to $\left.850^{\circ} \mathrm{C}\right)$ may also be used for reactors with higher temperatures, i.e., the so-called very high temperature reactor (VHTR) identified in the Generation IV Roadmap as a viable nuclear technology (Generation IV 2002).

Methods research and development focuses on the development and validation of tools to assess the neutronic and thermal fluid behavior of the plant. The fuel behavior and fission product transport models are discussed in the Advanced Gas Reactor Fuel Development and Qualification program plan. Fuel particle performance and dimensional changes in graphite are also directly related to the neutronic and thermal fluid behavior of the fuel and are being addressed as part of the long-term core simulation effort described in this plan.

The calculational envelope of the neutronics and thermal-fluids software tools intended to be used on the NGNP is defined by the scenarios and phenomena that these systems are expected to experience. The software tools can only be used confidently when the results they produce have been shown to be in reasonable agreement ${ }^{\mathrm{a}}$ with first-principle results, thought-problems, and data that describe the highly ranked phenomena inherent in all operational conditions and important accident scenarios for the HTGR.

The R\&D process is informed by Regulatory Guide 1.203 of the U.S. Nuclear Regulatory Commission. It is a well-established process by which key safety scenarios and phenomena are identified and ranked according to their importance to safety and the analysts' state of knowledge of their defining parameters. The calculational envelope of the model must fully encompass the operating envelope of the plant, including accident conditions. The code must be shown to reproduce both the individual physics (flow patterns, heat transfer, reaction rates) and the integral behavior of the plant. If the code is incapable of modeling some of the physics with sufficient fidelity, further code development is warranted. The full range of validation studies must be completed prior to performing the required analyses so that there is confidence in the result.

A design for the demonstration HTGR has not yet been selected. Consequently, the R\&D process is focused on scenarios and highly ranked phenomena that have already been identified as important by the advanced gas-cooled reactor community for all the designs being considered as candidates for the HTGR. This approach has resulted in an HTGR-specific Phenomenon Identification and Ranking Table (PIRT) from which the methods R\&D is being defined using the following assumptions:

1. The selected NGNP design could be either a pebble-bed or a prismatic reactor.

a. Reasonable agreement is achieved when the calculation generally lies within the uncertainty band of the data used for validation and always shows the same trends as the data. Code deficiencies are minor. 


\begin{tabular}{|c|lll|}
\hline NEXT GENERATION NUCLEAR PLANT & Identifier: & PLN-2498 & \\
METHODS TECHNICAL & Revision: & 3 & \\
PROGRAM PLAN & Effective Date: & $12 / 21 / 10$ & Page: iv of xi \\
\hline
\end{tabular}

2. The calculational and experimental needs, and consequently the required $R \& D$, are focused in six distinct areas based on the relative state of the software and data in each:

a. Basic differential and integral nuclear cross-section data measurements and evaluations, including mathematically rigorous sensitivity studies of the effects of uncertainties in the differential nuclear data and other independent design variables on key integral reactor properties (the task of characterizing the effects of the nuclear fuel, fission products, moderator, and other relevant materials on the system reactivity, neutron flux distribution, and power production). It is anticipated that existing cross section data is sufficient for the licensing of the NGNP. If the sensitivity studies indicate large uncertainties in key safety parameters arising from uncertainties in the cross sections of specific nuclides (such as $\mathrm{Pu}-240$ ) then new measurements will need to be conducted.

b. Reactor assembly cross-section preparation (the task of translating the fundamental data characterized in area (a) into formats and states useful for core burnup and dynamic analysis).

c. Reactor core simulation (the task of computing the $k_{\text {eff, }}$, reactivity, core flux, power, temperature, coolant flow, and burnup profiles for all anticipated steady-state operating scenarios).

d. Reactor kinetics (calculation of spatial changes in flux, power, and temperature level as functions of time during postulated transients).

e. Fuel and material behavior (calculation of the effect of neutronic and thermal fluid behavior on the fuel and core structures).

f. Fission product transport (determination of fission product movement once fission products have escaped from the confines of the fuel).

Methods R\&D is tailored to follow the guidance and timelines defined by the Energy Policy Act of 2005. Through 2013, Methods R\&D will be performed to enable analyses to be performed that can characterize the behavior of candidate NGNP designs. Phase 1 covers the period beginning from the passage of the Energy Policy Act until the design is selected. Phase 2 will begin when Phase 1 is completed. During Phase 2, software will be developed and the software tools will be validated using data directly scaled to the NGNP design. The operational, off-normal, and accident behavior of the design will also be analyzed.

The commercial companies such as AREVA, General Atomics, and Westinghouse, which are currently designing the future gas-cooled reactors, are still in varying degrees, using decades-old legacy analysis tools to describe the operational and accident characteristics of their designs and intend to use them, or potentially modified versions, for licensing purposes once they are validated. Likewise, the U.S. Nuclear Regulatory Commission is developing its own evaluation models using modifications or enhancements of available tools for the purposes of evaluating an NGNP license application. The levels of uncertainty in the accuracy and fidelity of these tools have yet to be quantified. However, considerable fundamental physics in the HTGR designs is either ignored or approximated in the legacy software to the degree that it would be very difficult, and potentially impossible, to license the NGNP without this comprehensive development and validation program. The role of the NGNP Methods program is therefore to provide an independent and accessible validation, verification, and high fidelity simulation capability against which all NGNP stakeholders can benchmark their tools.

This role is carried out by (1) conducting or coordinating thermal fluid experiments that provide data for validating computational fluid dynamics and system codes; (2) developing high-fidelity core and plant simulation tools specifically geared toward the modeling of scenarios and phenomena with large uncertainties or that exhibit complex neutronic, thermal-hydraulic, and material interaction; and 


\begin{tabular}{|c|lll|}
\hline NEXT GENERATION NUCLEAR PLANT & Identifier: & PLN-2498 & \\
METHODS TECHNICAL & Revision: & 3 & \\
PROGRAM PLAN & Effective Date: & $12 / 21 / 10$ & Page: v of xi \\
\hline
\end{tabular}

(3) integrating the diverse but dispersed high-temperature reactor knowledge base through frequent communication with stakeholders. This communication includes:

- Regular telephone conversations with the NRC to discuss HTGR Methods issues

- Steering committees for thermal fluid experiments that include representatives from the NRC, vendors, national labs, and academia

- Leadership of, or full participation in, code benchmark or comparison activities

- Workshops for exchanging ideas and results and for developing strategy.

Methods activities to support project objectives and the overall project schedule will follow the schedule shown in Table ES-1.

Table ES-1. High level methods development and experiment schedule.

\begin{tabular}{|c|c|c|c|}
\hline Activity & Start & Finish & 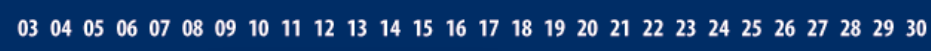 \\
\hline METHODS & 10/15/08 & $10 / 1 / 17$ & $\square$ \\
\hline $\begin{array}{l}\text { Fundamental Experiments and } \\
\text { Separate Effects Tests }\end{array}$ & 10/15/08 & 10/30/16 & Fundamental Experiments and Separate Effects Tests \\
\hline $\begin{array}{l}\text { Integral Testing - } \\
\text { Heat and Mass Transfer inside Vessel }\end{array}$ & 10/1/09 & 9/30/14 & Integral Testing - Heat and Mass Transfer inside Vessel \\
\hline Integral Testing - Ex-Core Heat Transfer & $3 / 1 / 10$ & $9 / 30 / 14$ & Integral Testing - Ex-Core Heat Transfer \\
\hline Development of Core Simulation Tools & 10/15/08 & $9 / 30 / 13$ & Development of Core Simulation Tools \\
\hline Validation of Core Simulation Tools & $10 / 1 / 09$ & $10 / 1 / 17$ & Validation of Core Simulation Tools \\
\hline
\end{tabular}

The highest-priority Methods activities for FY 2011 through 2013 will include: conducting integral experiments in the High Temperature Test Facility, refurbishing and operating the Natural Convection Shutdown Test Facility for investigation of ex-core heat removal, performing bypass and air ingress experiments with associated computational fluid dynamics model validation, and completing the development of three-dimensional core simulation tools for analyzing complex core behavior under anticipated normal and off-normal conditions, including a range of loss-of-forced-cooling events.

In subsequent years, these tools will be validated and verified using experimental data and used to investigate complex phenomena as required for the understanding and licensing of HTGR systems. 


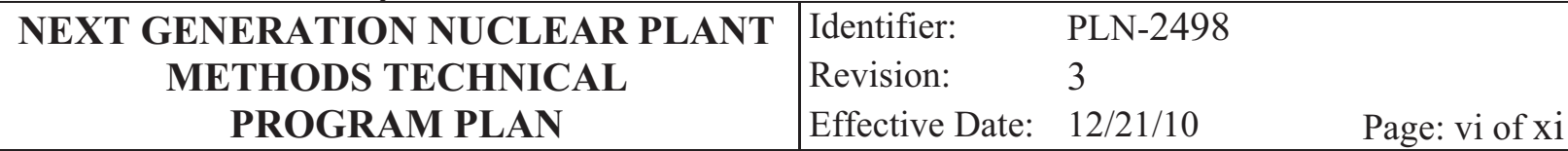

\section{CONTENTS}

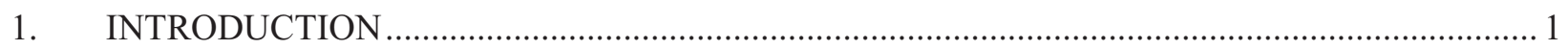

1.1 The Need for NGNP Analysis Methods Development and Qualification .............................. 1

1.2 Categories of and General Approach to Core Simulation.....................................................2

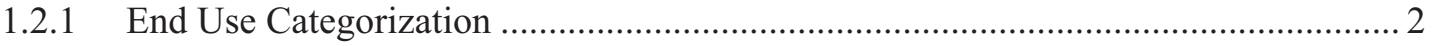

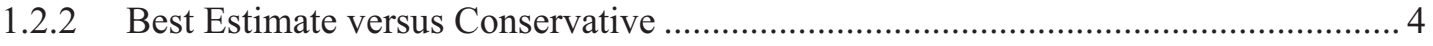

1.3 Addressing Calculational Uncertainties ......................................................................... 5

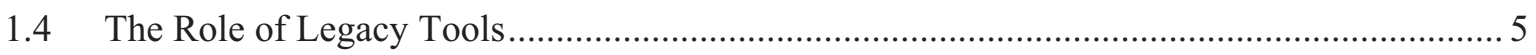

1.5 The Role of Multiphysics and Higher Order/High Fidelity Simulations ................................ 6

1.6 Differences between the HTGR Concepts that Must Be Addressed in Methods.................... 6

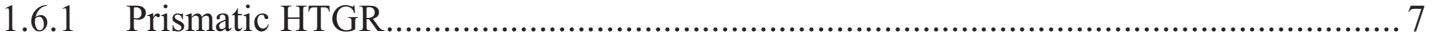

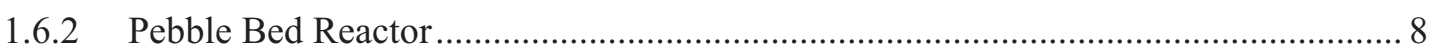

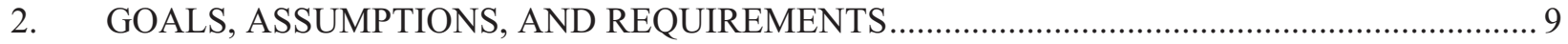

3. QUALIFICATION OF CODES AND MODELS .............................................................. 11

3.1 Analysis Methods Research, Development, and Qualification Process................................. 11

3.2 Qualification of Evaluation Models (Regulatory Guide 1.203) ......................................... 12

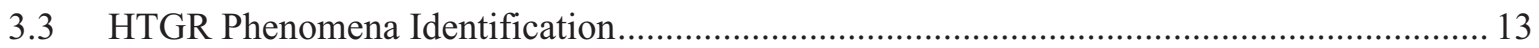

3.3.1 Phenomena Identification and Ranking Tables................................................... 14

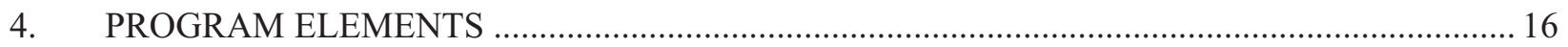

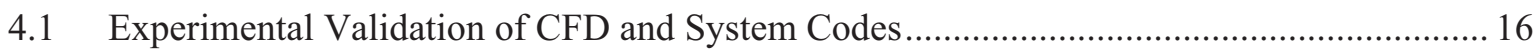

4.1.1 Goals, Assumptions, and Requirements............................................................... 16

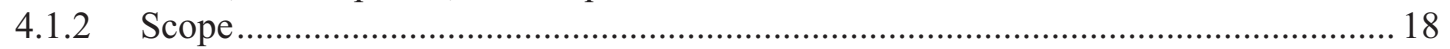

4.1.3 Accomplishments and Status of Experimental V\&V and CFD Studies ................... 34

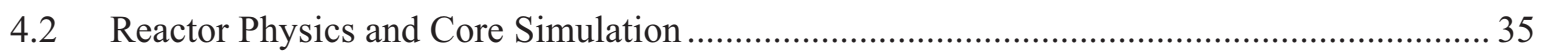

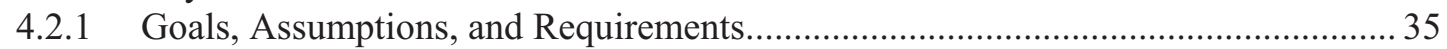

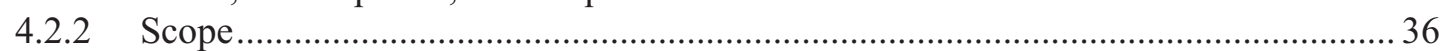

4.2.3 Reactor Physics and Core Simulation Code V\&V ............................................... 61

4.2.4 Benchmarks, Data, and Computational Activities used for Reactor Physics

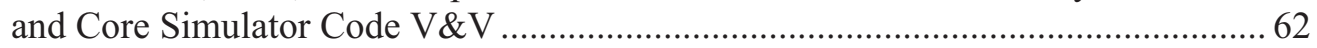

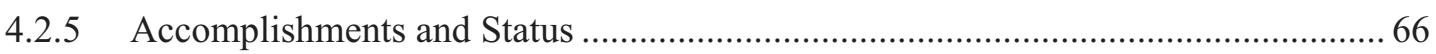

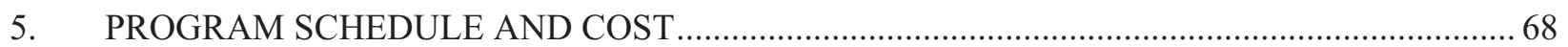

Appendix A Qualification, Selection, Validation, and Verification of Thermal Fluid Codes and Models 76

\section{FIGURES}

Figure 1. Uncertainties and margins in conservative and best estimate analyses. .................................... 5

Figure 2. Prismatic block and reactor (left) and a PBR (right). ..................................................... 8 


\begin{tabular}{|c|lll|}
\hline NEXT GENERATION NUCLEAR PLANT & Identifier: & PLN-2498 & \\
METHODS TECHNICAL & Revision: & 3 & \\
PROGRAM PLAN & Effective Date: & $12 / 21 / 10$ & Page: vii of xi \\
\hline
\end{tabular}

Figure 3. Methods R\&D process. 11

Figure 4. Potential apparatus to obtain benchmark to obtain turbulence data in heated channels. 22

Figure 5. Schematic diagram of miniature five sensor probe by Vukoslavcevic and Wallace [2002], the dimensions are in millimeters. .22

Figure 6. Examples of some possible flow paths in the lower plenum of a typical HTGR prismatic reactor concept. .23

Figure 7. Reactor cavity cooling system configuration. .25

Figure 8. Convection flow regimes at various operating pressures for both helium and $\mathrm{CO}_{2}$ (from Williams et al. 2003). .25

Figure 9. Schematic of ANL Natural Convection Shutdown Heat Removal Test Facility...... .26

Figure 10. SNU water-cooled RCCS experiment. 27

Figure 11. Cross-section view of ANL Zero Power Reactor (ZPR) Cell 5. .27

Figure 12. Rendition of the OECD-THAI Facility for investigating fission product and dust transport [Poss 2009]. .29

Figure 13. Schematic of HTR-10 (from HTGR Proceedings, Beijing, China, March 2001).................... 30

Figure 14. Schematic of HTTR. 30

Figure 15. Planned experiment campaign in the HTTR. 32

Figure 16. The HTTF integral experiment: a one-quarter-scale experiment based on the MHTGR.........34

Figure 18. Heterogeneity within a single prismatic fuel block. 41

Figure 19. Partial core (SuperCell) model of a prismatic reactor used for cross section generation.......... 42

Figure 20. Extent of domain beyond a single block needed to capture leakage spectra. .42

Figure 21. 3-Stage homogenization process in COMBINE. .44

Figure 22. Absorber locations in prismatic blocks. 45

Figure 23. Radial flux profiles in the simplified PBMR-268. 48

Figure 24. Comparison of core power (normalized to steady state) assuming three different fuel temeprature models in CYNOD-THERMIX. .52

Figure 25. Comparison of the temperature and stress histories of $\mathrm{UO}_{2}$ and deep burn pebbles...............53

Figure 26. Snapshots of PBR loading cones during an earthquake as simulated using PEBBLES........... 54

Figure 27. Core power trajectory and pebble packing fraction during an earthquake.............................55

Figure 28. Core reactivity as a function of steam density. 57

Figure 29. Input and results from a PEBBED analysis of Peak temperature during a PBMR400 depressurized conduction cooldown: distributions of core power and inlet temperature (top); distribution in peak fuel temperature (bottom).

Figure 30. Information flow in a SUSA analysis.

Figure 31. Measured temperature profile in the SANA experiment vs. profile predicted by PRONGHORN. 


\begin{tabular}{|c|lll|}
\hline NEXT GENERATION NUCLEAR PLANT & Identifier: & PLN-2498 & \\
METHODS TECHNICAL & Revision: & 3 & \\
PROGRAM PLAN & Effective Date: & $12 / 21 / 10$ & Page: viii of xi \\
\hline
\end{tabular}

Figure 32. High level schedule of experimental thermal fluid V\&V tasks. 69

Figure 33. High level schedule of core simulation activities 70

Figure A-1. VHTR system design software: elements of adequacy evaluation and acceptance testing practices. .78

Figure A-2. Validation process - including participation by experts from the national laboratories, universities, vendors, and the community specific to software undergoing validation. 81

Figure A-3. Flow chart to evaluate applicability of analysis software. .83

\section{TABLES}

Table ES-1. High level methods development and experiment schedule ................................................

Table 1. PIRT results for normal operation and conduction cooldown scenarios. ................................... 15

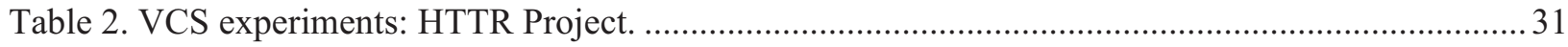

Table 3.Test data to be acquired from 2010 HTTR experiments under a Proposed Data

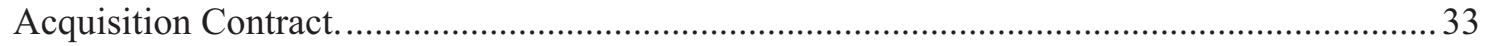

Table 4. Comparison of $k_{\text {eff }}$ and runtimes for HEXPEDITE and various DIF3-D solvers........................50

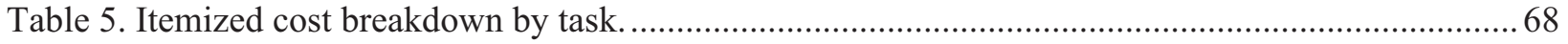

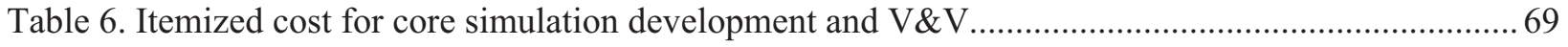

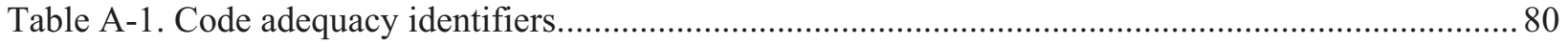




\begin{tabular}{|c|c|c|}
\hline $\begin{array}{c}\text { NEXT GENERATION NUCLEAR PLANT } \\
\text { METHODS TECHNICAL } \\
\text { PROGRAM PLAN }\end{array}$ & $\begin{array}{l}\text { Identifier: } \\
\text { Revision: } \\
\text { Effective Date: }\end{array}$ & $\begin{array}{l}\text { PLN-2498 } \\
3 \\
12 / 21 / 10\end{array}$ \\
\hline
\end{tabular}

\section{ACRONYMS}

AGR Advanced Gas Reactor

ANL Argonne National Laboratory

ASME American Society of Mechnical Engineers

AVR Arbeitsgemeinschaft Versuchsreaktor

BDBA beyond design basis accident scenarios

BISO bi-structural isotropic

BOC beginning of cycle

CFD computational fluid dynamics

CFR Code of Federal Regulations

DBA design basis accidents

DCC depressurized conduction cooldown (event)

DLOFC depressurized loss of forced cooling

DOE Department of Energy

EMDAP evaluation model development and assessment process

EOC end of cycle

FTE full-time equivalent

FY fiscal year

GEN IV Generation IV

GIF Generation IV International Forum

HTGR high temperature gas-cooled reactor

HTR high-temperature reactor

HTR-10 Chinese High Temperature Gas-Cooled Reactor

HTTF High Temperature Test Facility

HTTR high-temperature engineering test reactor

IAEA International Atomic Energy Agency

INET Institute of Nuclear Energy Technology

INL Idaho National Laboratory

JAEA Japan Atomic Energy Agency (formerly JAERI)

LOCA loss of coolant accident

LOFC loss of forced cooling (event)

LWR light water reactor

MCNP Monte Carlo Neutral Particle 


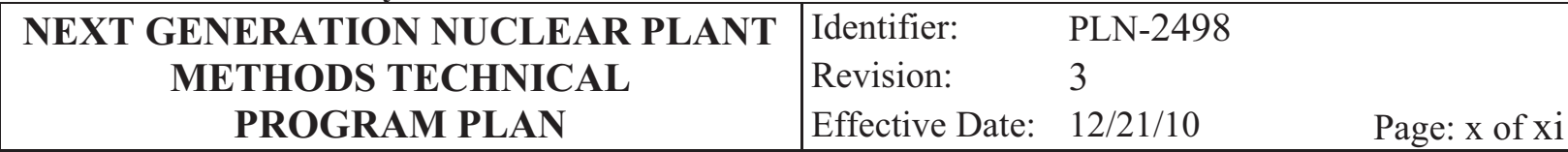

MHTGR modular high temperature reactor

MIR matched-index-of-refraction

NEUP Nuclear Energy University Program

NGFM Nodal Green's Function Method

NGNP Next Generation Nuclear Plant

NQA Nuclear Quality Assurance

NRC U.S. Nuclear Regulatory Commission

NSTF Natural Convection Shutdown Heat Removal Test Facility

OECD Organization of Economic Cooperation and Development

PASTA PArticle STress Analysis

PBMR pebble bed modular reactor

PBR pebble bed reactor

PCC pressurized conduction cooldown scenario

PIRT Phenomena Identification and Ranking Table

QA Quality Assurance or quality assurance

QL Quality Level

QSHo quasistatic homogeneous

QWHe heterogeneous fuel

R\&D research and development

RCCS reactor cavity cooling system

SNU Seoul National University

SUSA Software for Sensitivity and Uncertainty Analysis

TDHe time-dependent heterogeneous

TDO Technology Development Office

TPAC tritium permeation analysis code

TPP Technical Program Plan

TRISO tristructural-structural isotropic (ceramic-coated-particle fuel)

$\mathrm{V} \& \mathrm{~V} \quad$ verification and validation

V\&V30 Verification and Validation Standards Committee

VCS vessel cooling system

VHTR Very High Temperature Reactor

VHTRC very high temperature reactor critical

ZPR Zero Power Reactor 
NEXT GENERATION NUCLEAR PLANT

METHODS TECHNICAL

PROGRAM PLAN
PLN-2498

Revision: $\quad 3$

Effective Date: $12 / 21 / 10$ 


\begin{tabular}{|c|c|c|}
\hline NEXT GENERATION NUCLEAR PLANT & Identifier: & PLN-2498 \\
\hline METHODS TECHNICAL & Revision: & 3 \\
\hline PROGRAM PLAN & Effective Date: & $12 / 21 / 10$ \\
\hline
\end{tabular}

\section{INTRODUCTION}

The Energy Policy Act of 2005 was signed into law on August 8, 2005. As summarized in the September 2005 issue of Nuclear News, page 15, in the article, "Compromise Energy Bill Becomes Law," the nuclear provisions specific to the Next Generation Nuclear Plant (NGNP) are:

The DOE shall establish the Next Generation Nuclear Plant project, with a prototype to be sited at Idaho National Laboratory. The centerpiece is to be the development of reactor, fuel, and associated technology for the production of hydrogen as well as electricity. The DOE and the NRC are to submit jointly a licensing strategy to Congress within three years after enactment. Hydrogen production technology and initial reactor design parameters are to be chosen by September 30,2011, or an alternative date is to be submitted to Congress by that time. The reactor is to begin operation by September 30, 2021, or an alternative date is to be submitted to Congress by that time. The project is authorized to receive $\$ 1.25$ billion over fiscal years 2006 through 2015, and such sums as are necessary thereafter.

Research and development (R\&D) specific to the NGNP mentioned in the Energy Policy Act and conducted to date is based on the gas-cooled very high temperature reactor (VHTR) concept promulgated in the Generation IV Technology Roadmap [Generation IV International Forum 2002]. Presently, the most likely VHTR candidates are the helium-cooled prismatic reactor and pebble bed reactor (PBR) designs. Consequently, the R\&D described in this document is focused on these types of gas-cooled thermal reactors.

The purpose of this revision is to describe the updated plan for the development and validation of the methods used to analyze and license the NGNP and incorporates the experience and knowledge gained from ongoing and completed work since the release of the original technical plan in April 2007 [Schultz 2007]. This revision also summarizes the progress made in the program to date and the activities remaining to complete the program.

In the Generation IV (GEN-IV) analyses, two high temperature gas-cooled reactor (HTGR) concepts excelled in meeting program goals: the prismatic reactor and PBR. The overall layout, functionality, and behavior of the concepts are quite similar with the primary difference being the geometry and mobility of the fuel. The general approaches used in the simulation of core neutronics and thermal fluid behavior, therefore, are the same. The differences do impact the specific steps taken, so they are briefly discussed in this plan.

\subsection{The Need for NGNP Analysis Methods Development and Qualification}

The status of methods currently available for designing and analyzing the HTGR can be summarized with the following statements:

- State-of-the-art software and advanced, detailed methods are not ready to perform design and analysis to the standard required by the HTGR. Considerable validation, and limited development of the necessary software tools, is required.

- The above conclusion also applies to present software capabilities to perform NGNP licensing calculations.

The practices and procedures acceptable for both validating and developing the necessary software tools for the HTGR must be defined and implemented to a standard defined by the engineering 


\begin{tabular}{|c|c|c|}
\hline NEXT GENERATION NUCLEAR PLANT & Identifier: & PLN-2498 \\
\hline METHODS TECHNICAL & Revision: & 3 \\
\hline PROGRAM PLAN & Effective Date: & $12 / 21 / 10$ \\
\hline
\end{tabular}

community. Standards for software validation have been developed by the American Society of Mechanical Engineers (ASME) and are summarized in Appendix A. The NGNP Project is sponsoring the development of HTGR-specific ASME standards for computational fluid dynamics (CFD) and safety analysis software.

These statements are true because (a) the computational tools developed under the early HTGR programs were subject to limitations and assumptions that were required of the computing and simulation capabilities available decades ago but can now be relaxed or refined, and (b) these methods do not account for some of the detailed characteristics and complex phenomena anticipated for these reactors (as discussed below) and thus yield results with significant uncertainties, (c) software tools that have a low calculational uncertainty will be required to analyze the behavior of the HTGR to enable the plant to operate safely at a high efficiency with a competitive economic margin, and (d) most of the software tools that will be used have not been validated for the scenarios and phenomena that must be analyzed for licensing. For example, although systems analysis software has been validated for selected cases, a full validation has not been performed nor are the data available that will enable a full validation to be performed. Also, computational fluid dynamics (CFD) software, which will be widely used to analyze the HTGR thermal fluid behavior, have never been used in large measure to perform auditing, design, or licensing calculations for a nuclear plant. If a license application were to be submitted today using the existing tools, it is anticipated that the regulator would request a considerable amount of additional information and validated quantification of the uncertainties associated with the reported results. There is therefore considerable risk that the NGNP could not be licensed within a reasonable cost and schedule using the legacy codes and methods.

Finally, the risks involved with a complex engineering project of this nature can be greatly reduced with a rigorous, front-loaded modeling effort that can resolve key performance and safety issues early in the design process. The cost of design changes increases exponentially as the project matures and the licensing process has begun. A comprehensive evaluation model with a low degree of calculational uncertainty can facilitate the design process and increase the confidence in the results obtained by the designers and regulators.

\subsection{Categories of and General Approach to Core Simulation}

For licensing purposes, the complete set of codes and models used to analyze a nuclear plant is called the evaluation model. Other codes may supplement these for purposes of core and plant design. Codes and models may be categorized by their ultimate use or by how the uncertainty in their results is treated. These are described in the following subsections.

\subsubsection{End Use Categorization}

As is the case with light water reactors (LWRs), reactor core simulation entails the use of neutronics calculations to determine the reactivity, neutron flux, power, and burnup (transmutation) profiles and thermal fluid calculations to obtain the temperature and coolant mass flow distributions at selected times during a fuel cycle. The specific type of calculation depends upon the parameter(s) of interest, and the objective of the analysis and the tools to be used will vary in functionality and fidelity. The types of calculations needed may be categorized as follows:

- Design (optimization, sensitivity analyses, economics, proliferation resistance)

- Benchmarking and verification and validation $(\mathrm{V} \& \mathrm{~V}$; fundamental and separate effects phenomena, integral experiments)

- Safety analysis (normal and off-normal transients, fission product transport, cliff-edge behavior). 


\begin{tabular}{|c|c|c|}
\hline NEXT GENERATION NUCLEAR PLANT & Identifier: & PLN-2498 \\
\hline METHODS TECHNICAL & Revision: & 3 \\
\hline PROGRAM PLAN & Effective Date: & $12 / 21 / 10$ \\
\hline
\end{tabular}

\subsubsection{Thermal Hydraulic Analysis}

For prismatic designs, the engineered coolant channels in the blocks enable one-dimensional (1-D) subchannel analysis of coolant temperature inside the fuel columns, which is adequate for many design and safety calculations. In pebble bed analysis, the bed is assumed to be a homogeneous but porous medium in which the bulk coolant temperature is coupled to the solid temperature through a heat transfer correlation. Validated empirical heat transfer and pressure drop correlations exist for such geometries. The flow distribution in the core is determined from a common core pressure drop between the upper and lower plenum. The local coolant temperatures, combined with the power profile obtained from the neutronics calculations, can be used to compute the temperature distribution within the prismatic reactor or PBR. The system codes that perform such calculations (e.g., RELAP5 [Bayless 2009] and TINTE [Reitsma 2005]) run fast enough to support extensive design calculations and larger plant simulations that explore the time-dependent coupling between the core and the balance-of-plant.

Errors and uncertainties arise with certain phenomena and scenarios. The flow of hot helium out of the core, into the lower plenum, and into the hot duct is not captured well using system codes like RELAP5, especially in one-dimensional components such as pipes. The helium jets emerging from the core may exhibit large variations $\left( \pm 100^{\circ} \mathrm{C}\right)$ in temperature and velocity and this stratification may continue through the cross duct and into the heat exchanger. The effect of this temperature variation upon the mechanical integrity of the graphite core support structures of the lower plenum is uncertain. The turbine blades and other metallic components of the power conversion system operate closer to design limits and will not tolerate large temperature fluctuations (NGNP 2010-1). The graphite core and reflector blocks in the prismatic core shrink and swell as complex functions of irradiation and temperature. This leads to the formation of gaps between the blocks through which coolant will flow. The nature of this bypass flow is still under study in order to assess the impact on temperature profiles within the fuel blocks. Computation of the flow and temperature distribution in the lower (outlet) plenum or for a given gap geometry is possible with the use of CFD codes. CFD calculations are computationally demanding and thus not yet practical for routine whole core simulations. Standards and practices for their use in reactor analyses are still being developed, so CFD is still considered as much an art as it is a science. Still, CFD may play an important role in the understanding and licensing of HTGRs. However, the system codes will still need to be used for identification of operational and accident extremes.

\subsubsection{Neutronic Analysis}

Neutronics codes can also be segregated into low-order tools suitable for whole-core design and transient analysis and high resolution, high fidelity tools for benchmarking and separate effects studies. Monte Carlo Neutral Particle (MCNP) transport code [Briesmeister] is the workhorse of the high fidelity category because of its extensive user base, ability to model geometry exactly, and continuous energy treatment of neutron interactions. Like CFD, Monte Carlo simulations are, at least for now, computationally too demanding to be used for extensive design optimization, whole-core fuel management, and transient analysis. They are, however, the preferred option for investigating detailed neutronic behavior in specific components. When coupled to a suitable depletion code like ORIGEN, burnup and irradiation damage in small components or for specific core conditions can be studied in considerable detail. Monte Carlo calculations can yield very accurate results for critical experiments in which burnup and temperature variations are negligible or well-characterized. More recently, deterministic transport codes have progressed to the point in which whole core calculations are possible in limited cases. These codes offer the fidelity of Monte Carlo simulations but can also generate detailed point-wise flux and power profiles.

Low-order (usually multigroup diffusion) approximations to the neutron transport equation are still preferred for fuel management and transient analysis of a large HTGR core, because of their 


\begin{tabular}{|c|c|c|c|}
\hline $\begin{array}{c}\text { NEXT GENERATION NUCLEAR PLANT } \\
\text { METHODS TECHNICAL } \\
\text { PROGRAM PLAN }\end{array}$ & $\begin{array}{l}\text { Identifier: } \\
\text { Revision: } \\
\text { Effective Date: }\end{array}$ & $\begin{array}{l}\text { PLN-2498 } \\
3 \\
12 / 21 / 10\end{array}$ & Page: 4 of 84 \\
\hline
\end{tabular}

computational efficiency. The use of such codes requires the generation of multigroup diffusion parameters (cross sections, diffusion coefficients, and kinetic parameters) using a procedure called spatial-homogenization. Higher-order transport codes are used to simulate local regions with high fidelity and generate spectrum and spatial average values that are then used in the whole core diffusion code. The challenge in HTGRs is to generate these nodal parameters in such a way that captures the physics of the fuel and core geometry and scattering in graphite. Well-established techniques and codes used for LWR simulation and the early HTGR programs do not do this with sufficient accuracy to address current design and licensing needs.

Fuel management codes must compute the local flux, power, and temperature profiles and then use this information to compute the varying composition in the blocks or pebbles as a function of time. The fuel management module must be able to compute and store composition data for each block or batch of pebbles as they are burned during, and shuffled between, each cycle. The power profiles at each specified burnup step provide an initial condition for transient analyses. Thermal fluid analyses generate the coolant and fuel temperature data that determine if the core is operating within design specifications. These analyses are dominated by the thermal coupling between the solid structures and the coolant, and neutronic feedback is captured with reactivity coefficients or quasi-static kinetic modules to generate time-dependent power data.

\subsubsection{Best Estimate versus Conservative}

Figures-of-merit for the present fleet of LWRs were traditionally calculated using conservative assumptions and approaches that were guaranteed to yield calculated results with very large safety margins. Models of this sort were based on prescription of sometimes arbitrary restrictions (for example, neglecting heat transfer for certain phases of a scenario) to ensure a large safety margin was present in the licensing calculations. The approach codified in Title 10 of Part 50.46, Appendix K of the Code of Federal Regulations is the most widely known example. The major drawback to the Appendix K approach is that the calculational uncertainty, while known to be large and conservative, is not quantified.

Subsequent to the Appendix K approach, best-estimate approaches were developed and have been used to perform some plant license reevaluations. The best estimate approaches have the advantage of enabling the calculational uncertainties to be defined and quantified. However, 1-D fluid flow models were almost exclusively used to calculate average or bulk values of the figures-of-merit in the various regions of the plant. Thus, to account for potential deviations from 3-D behavior in the 1-D model results, safety factors have been used to provide a sufficient margin from the limiting value.

The concepts discussed in the above two paragraphs are illustrated in Figure 1. The best estimate approach for calculating the safety margin gives more operational latitude to the plant operator than using a conservative approach with prescribed arbitrary models. 


\begin{tabular}{|c|c|c|}
\hline NEXT GENERATION NUCLEAR PLANT & Identifier: & PLN-2498 \\
\hline METHODS TECHNICAL & Revision: & 3 \\
\hline PROGRAM PLAN & Effective Date: & $12 / 21 / 10$ \\
\hline
\end{tabular}

Safety Limit (damage to a barrier)

Regulatory Limit (acceptance)

Calculated Value (conservative model)

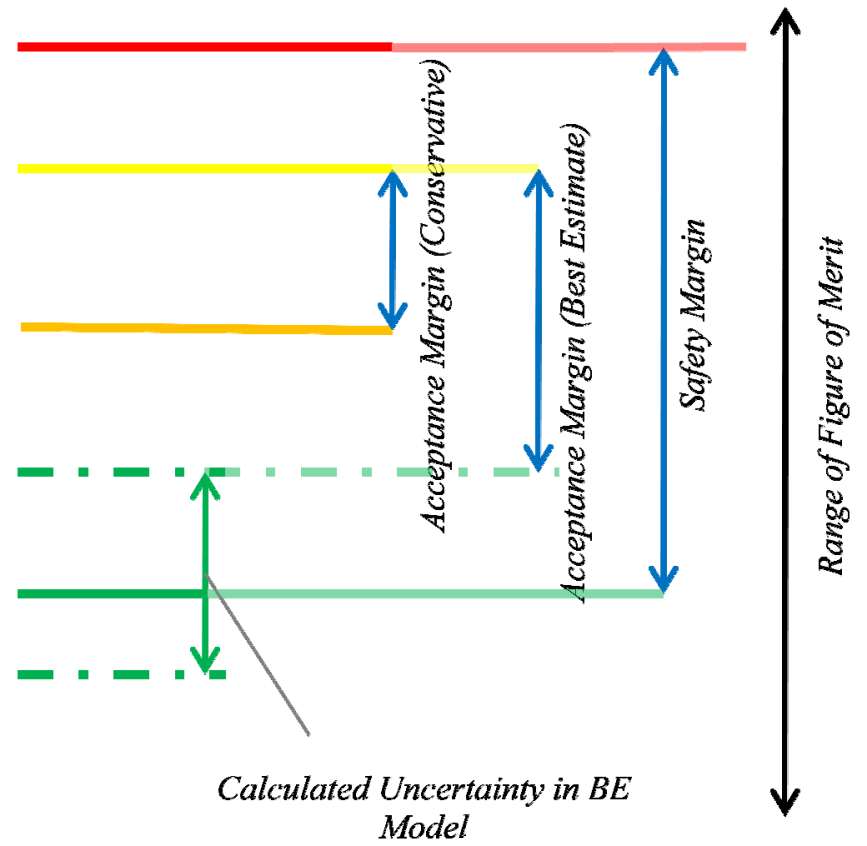

Calculated Value (Best Estimate) (actual value is unknown)

Model

Figure 1. Uncertainties and margins in conservative and best estimate analyses.

\subsection{Addressing Calculational Uncertainties}

The calculational uncertainties for NGNP methods V\&V will be determined using an approach that is compatible with the code scaling, applicability, and uncertainty (CSAU) methodology that has been accepted by the U.S. Nuclear Regulatory Commission. Examples are embodied in the commercial light water reactor community by AREVA's realistic large break loss-of-coolant-accident (LOCA) methodology and also the approach taken by the Nuclear Energy Advanced Modeling and Simulation team.

\subsection{The Role of Legacy Tools}

The vendors often use tools that were developed for the early (circa 1970s and earlier) HTGR program to calculate the plant operational and accident behavior for licensing purposes. This legacy software relies mostly on low-order, low-dimension, approximate methods that would run efficiently on the computers of the day. For example, the core temperature distribution for a prismatic reactor would be generated using a rigorous 1-D calculation of the bulk temperatures, which did not have the capability to calculate localized hot spots or cross flow between blocks. Similarly, the few-group cross sections used in the core simulation are generated at the compact (pincell) level and homogenized for use in block lattice calculations. The calculations do not account for the interpenetration of spectra from the surrounding fuel and reflector blocks, nor can they accurately treat large asymmetrically-placed control rods and burnable poisons. To allow room for the uncertainty in the power and temperature fields, prescribed safety factors are used to ensure that local material temperatures do not exceed material property limits. Consequently, since the prescribed safety factors account for the large uncertainties inherent in the use of legacy tools to calculate the localized core power distributions and maximum outlet-jet temperatures, the NGNP would have to operate at a degraded power condition or with larger design margins as a function of the magnitude of the prescribed safety factor. These tools still have value in design and scoping calculations; however, greater accuracy and precision is needed and can be achieved with modern lattice, nodal 


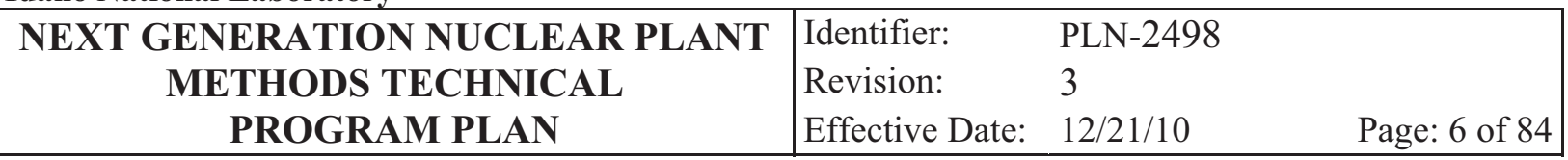

diffusion, and multidimensional thermal fluid and CFD tools that can capture the physics with far greater fidelity and accuracy.

\subsection{The Role of Multiphysics and Higher Order/High Fidelity Simulations}

Advances in computing power and algorithms for efficiently solving large systems of partial differential equations have enabled the development of high resolution, multiscale, and multiphysics analysis tools. Whereas 1-D or 2-D neutron diffusion or transport is used in legacy evaluation models for generating local reaction rates and cross sections, 3-D discrete ordinates or Monte Carlo transport calculations of entire cores is now possible in some cases, particularly for confirming the ability of lower order tools to capture the important physics behavior. High fidelity neutron transport and CFD calculations can be used to homogenize complex structures and localized phenomena to generate coarse mesh parameters that can be solved quickly with core simulation codes with a minimal loss of accuracy.

'Multiphysics' in this case refers to the ability to solve simultaneously a system of equations that governs the behavior of more than one major distributed parameter. For core analyses this usually means the simultaneous solution of neutron flux, heat transfer, and coolant transfer through the core, but fuel stress equations, photon transport, and other physics are also under consideration. The ability to solve these systems simultaneously avoids the introduction of errors that often arise from solving the equations separately and coupling them explicitly via 'split- operator' techniques. Multiphysics codes can be used to investigate phenomena too complex for system codes such as power and temperature peaking near the pebble bed reflector interface. The large change in porosity of the bed near the wall enhances cooling, which is counteracted by power peaking caused by the additional thermalization of neutrons near the reflector. The conduction of heat from the pebble bed into the reflector is not described well by the correlations used in systems codes. Since the highest power densities, and thus the highest fuel stresses, occur near this boundary, it is desirable to be able to model this region with full neutronic and thermal fluid feedback. Current thermal fluid codes do not address the change in porosity near the walls. The anisotropic scattering is not captured fully by neutron diffusion codes. A fully coupled CFD-transport calculation with an explicit representation of pebbles near the boundary can capture the physics and simulate power peaking and heat transfer far better than system codes.

Similarly, system codes do not explicitly model the change in the dimensions of graphite blocks under irradiation. This deformation is a complex function of irradiation and temperature history and thus the bypass flow is constantly changing over the life of the core. In modeling the core with system codes, a certain fraction and distribution of bypass flow is usually assumed based on empirical knowledge. A fully-coupled, neutronic-CFD, mechanical model of the core can be used to simulate and predict bypass flow and reduce the uncertainty in core temperature analyses.

\subsection{Differences between the HTGR Concepts that Must Be Addressed in Methods}

As mentioned previously, the prismatic and pebble bed versions of the HTGR possess the same general functionality and bulk design. Tristructural isotropic (TRISO) fuel particles are embedded in a graphite matrix to form fuel elements that occupy a tall annular or cylindrical region inside the vessel and are surrounded by graphite reflector blocks. Helium is circulated through cooling pathways in the core to carry off the fission energy and gamma heating and be converted into the desired energy product. Reactivity control is affected by either helium inventory variations or with control rods inserted into the side reflector in the annular core design. The material, neutronic, and thermal fluid behavior of the concepts are largely the same and can thus be addressed with the same general modeling approach. There are, however, key differences in the fuel geometry requiring different spatial homogenization techniques, 


\begin{tabular}{|c|lll|}
\hline NEXT GENERATION NUCLEAR PLANT & Identifier: & PLN-2498 & \\
METHODS TECHNICAL & Revision: & 3 & \\
PROGRAM PLAN & Effective Date: & $12 / 21 / 10$ & Page: 7 of 84 \\
\hline
\end{tabular}

heat transfer correlations, fuel management techniques, and other modeling assumptions that prohibit a prismatic core simulator from being used to model a PBR core and vice versa. Thus the NGNP Design and Safety Methods Validation program (Methods program) has developed two simulation code capabilities in parallel but with largely the same functionality and underlying physics. The differences are described below.

\subsubsection{Prismatic HTGR}

In the prismatic reactor, cylindrical fuel compacts are stacked firmly inside channels drilled into graphite blocks in the shape of right hexagons (blocks). Surrounding the fuel channels are a number of open channels through which the helium coolant is directed. These fuel blocks are stacked firmly against each other in columns (red region of the left core in Figure 2). The columns form an annulus between an inner reflector and an outer reflector, both of which consist of rings of unfueled graphite blocks. The fuel blocks are loaded and reshuffled at regular intervals (18 to 24 months) to distribute the fuel burnup and power peaking, much like a LWR. Because prismatic reactors are batch-loaded, additional fuel must be loaded into the blocks to maintain criticality through the burnup cycle. This results in excess reactivity at the beginning of the cycle that has to be held down by burnable poisons or control rod insertion. Burnable poisons are also used to flatten the power profile and achieve a more uniform fuel burnup. Neutronic codes are geared toward solving the transport or diffusion equation in hexagonal geometry with special accommodation for cylindrical burnable poison pins and control rods. Cylindrical coolant channels are drilled vertically through the blocks and between the columns of compacts. Most of the coolant flows through these engineered coolant passages. They are not connected except at the upper and lower plena. In the simplest thermal fluid analysis, the coolant can be modeled as 1-D flow through a set of independent, parallel pipes by assuming no bypass flow (flow between the blocks). This can yield a first order map of temperatures within the core for fuel management studies and transient analysis. More sophisticated thermal fluid codes must model the radial and axial flow in the gaps between the blocks to get a firmer picture of the temperature distribution within the fuel and core. Such analyses have only recently been attempted with CFD codes (Sato 2010, Tak 2008) but they indicate that the presence of bypass flow can increase the temperature of the coolant leaving a block by as much as $60^{\circ} \mathrm{C}$. The increase in the maximum fuel temperature can be as high as $80^{\circ} \mathrm{C}$. 


\begin{tabular}{|c|lll|}
\hline NEXT GENERATION NUCLEAR PLANT & Identifier: & PLN-2498 & \\
METHODS TECHNICAL & Revision: & 3 & \\
PROGRAM PLAN & Effective Date: & $12 / 21 / 10$ & Page: 8 of 84 \\
\hline
\end{tabular}

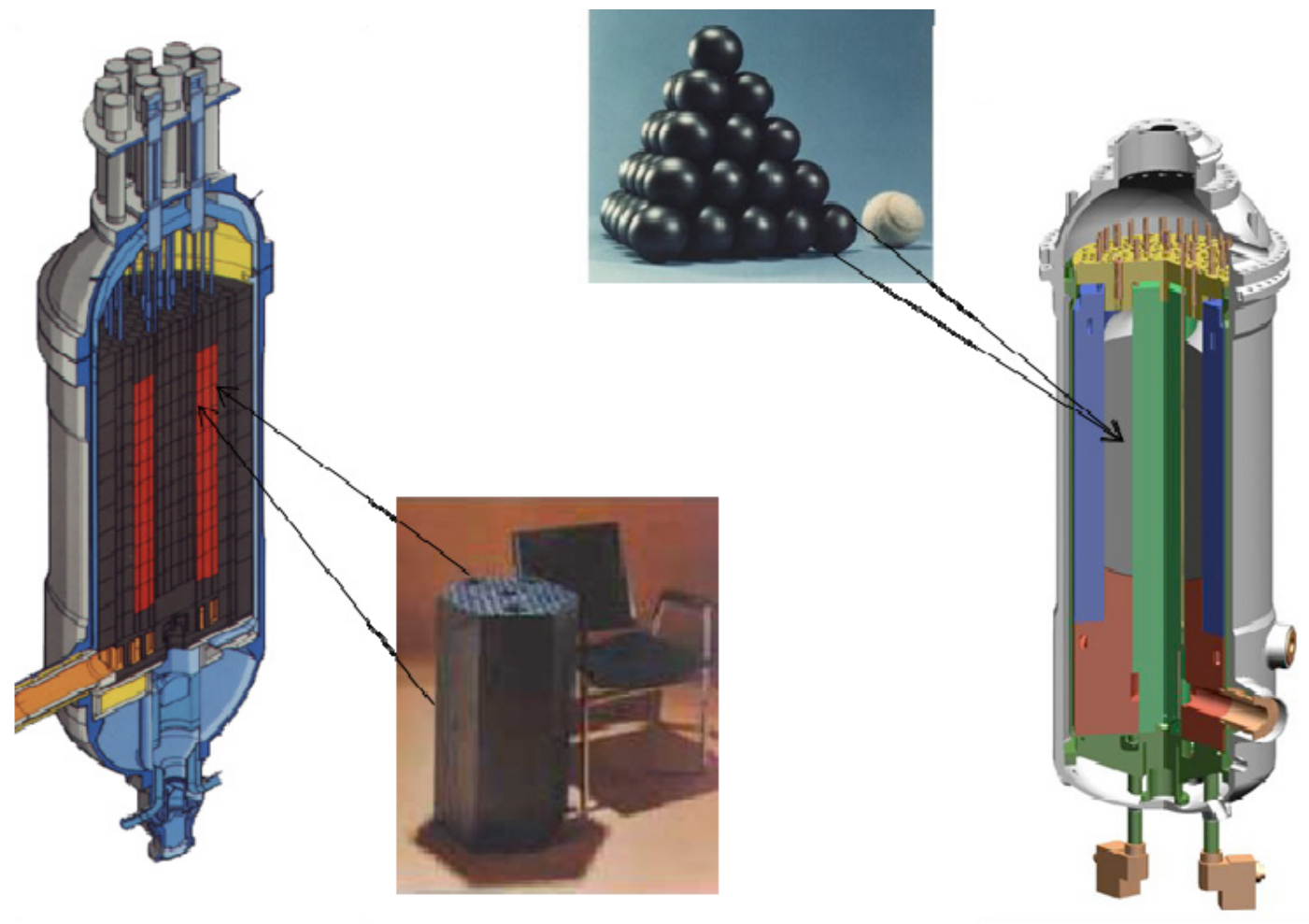

Figure 2. Prismatic block and reactor (left) and a PBR (right).

\subsubsection{Pebble Bed Reactor}

The core in the PBR consists of a bed of randomly ordered fuel pebbles. A pebble consists of TRISO particles embedded in the central fuel region (usually $5.0 \mathrm{~cm}$ in diameter) and surrounded by a $0.5 \mathrm{~cm}$ thick pure graphite shell. Helium coolant is blown through the interstitial void that makes up about 39\% of the pebble bed volume. The PBR has the unique characteristic of continuous fueling and pebble movement through the core during operation. Fresh pebbles dropped onto the top of the bed work their way down through the core region and out through one or more discharge chutes at the bottom of the core. After measuring its burnup, the pebble is either reloaded for another pass through the core or discharged to a spent fuel storage container. Pebbles pass through the core a number of times before being discharged. Neutronic codes solve the transport or diffusion equations in spherical (pebble) or cylindrical (core) geometry. Burnable poisons are not required, as the online addition and removal of pebbles eliminates the need for excess reactivity. Fuel management is a unique challenge because of the semicontinuous movement and reloading of the fuel. 2-D or 3-D thermal fluid codes model the bed as a porous medium with known pressure drop and heat transfer correlations for pebble beds. Coolant flow can be in any direction, but analyses indicate that the axial flow assumption is a reasonable first order approximation for the bulk flow. PBRs do experience bypass flow when the coolant is redirected through channels in or between the reflector blocks rather than through the pebble bed itself. High fidelity thermal fluid analyses must account for this phenomenon. 


\begin{tabular}{|c|lll|}
\hline NEXT GENERATION NUCLEAR PLANT & Identifier: & PLN-2498 & \\
METHODS TECHNICAL & Revision: & 3 & \\
PROGRAM PLAN & Effective Date: & $12 / 21 / 10$ & Page: 9 of 84 \\
\hline
\end{tabular}

\section{GOALS, ASSUMPTIONS, AND REQUIREMENTS}

The overall goal of the NGNP Methods program is to produce a set of validated physics and thermal fluid methods and experimental data for HTGR design and licensing to support near-term deployment of the NGNP for industrial energy production by reducing risks and barriers to market entry from neutronic and thermal-hydraulic technical uncertainties.

To achieve this goal, the Methods program seeks to:

- Define the calculational envelope required to be able to analyze the candidate HTGR reactor systems.

- Define an NGNP evaluation model that should be capable of performing all the required calculations encompassed by the calculational envelope developed in the above bullet. This evaluation model shall provide reference results with estimated uncertainties against which licensee and regulator simulation results can be compared.

- Design and execute a matrix of thermal fluid experiments that will produce a comprehensive data set that can be used to validate and verify NGNP evaluation models developed by the Department of Energy (DOE), Nuclear Regulatory Commission (NRC), and vendors.

- Define and qualify the components of the NGNP evaluation model using an approach that conforms with NRC's Regulatory Guide 1.203.

Overall Methods Program assumptions are as follows:

- A stable, long-term, disciplined methods development and code qualification effort offers the greatest probability of success.

- Proposed NGNP designs will impose more demanding service conditions than the German High Temperature Reactor module and require codes that simulate plant scenarios and phenomena with greater accuracy and lower uncertainties than can be achieved with legacy tools.

- It is technically feasible to develop and qualify codes and models for licensing purposes at reasonable cost and on a schedule consistent with the proposed NGNP demonstration plant deployment schedule(s).

- Adequate DOE funding will be available to support the methods development and qualification activities outlined in this Technical Program Plan (TPP).

- CFD models of thermal fluid phenomena can simulate complex flow and heat transfer phenomena with a level of fidelity and reproducibility that is acceptable to a regulator.

- Nodal diffusion, depletion, and assembly homogenization techniques can be developed that generate reaction and leakage rates in HTGR fuel with uncertainties comparable to, or better than, state-of-theart LWR simulation tools.

- Dedicated physics critical facilities for the NGNP will not be constructed; validation of neutronic codes will rely upon data from critical facilities that operated in the past and on existing HTGR engineering scale reactors (Japan High Temperature Test Reactor [HTTR] and Chinese HTR-10) and code-to-code comparisons that can serve as benchmarks.

- Activities relating to the qualification of a reactor vendor's evaluation model by the NRC Office of Nuclear Reactor Regulation and meeting the NRC mandate of 10 CFR 50, Appendix B, Quality Assurance (QA) and control are outside the scope of this program. As appropriate, however, software QA requirements will be applied to the codes and methods developed under NGNP. 


\begin{tabular}{|c|lll|}
\hline NEXT GENERATION NUCLEAR PLANT & Identifier: & PLN-2498 & \\
METHODS TECHNICAL & Revision: & 3 & \\
PROGRAM PLAN & Effective Date: & $12 / 21 / 10$ & Page: 10 of 84 \\
\hline
\end{tabular}

- No major difficulties that could significantly impact the schedule are encountered during the experiment execution and development and validation of HTGR analysis tools.

- Experimental data and simulation results will be made available to all U.S.-based NGNP stakeholders for qualification of their own methods and tools. Data will be made available to non-U.S. entities through appropriate exchange mechanisms such as the Generation IV International Forum (GIF) or other bilateral or multilateral agreements.

Overall Methods Program requirements are as follows:

- Establish an HTGR methods development and qualification program that will:

- Address safety and performance issues identified in the NGNP Phenomena Identification and Ranking Tables (PIRTs) as being both important in terms of safety and having a high degree of uncertainty with regard to behavior and ability to model

- Produce standards for using CFD codes in analyzing and licensing HTGRs

- Provide high quality (Nuclear Quality Assurance (NQA)-1 qualified) data to NGNP stakeholders for validating system and CFD codes

- Improve understanding of thermal fluid behavior in components and during both normal and offnormal scenarios

- Establish a capability to perform 3-D simulations of core burnup and transients in both pebble bed and prismatic reactors

- Design, or inform the design of, thermal fluid experiments that are scaled properly to envelope conditions anticipated in the NGNP

- Develop pertinent technical information that supplements the NGNP reactor vendor's own licensing/qualification data in the topical report supporting NGNP licensing.

- Implement this plan such that it supports both prismatic and pebble-type fuel designs. The effort dedicated to each design will be proportionate with its associated level of industry interest and commitment. Current stages of the program should support both designs by concentrating on integral, separate effects, fundamental tests, and lattice physics improvements common to both designs.

- Implement this TPP in accordance with the DOE QA requirements specified in 10 CFR 830, "Nuclear Safety Management," Subpart A, "Quality Assurance Requirements," and in DOE Order 414.1B, "Quality Assurance." All activities that have direct input to the fuel, material, and code qualification will be conducted in accordance with national consensus standard NQA-1-2000, "Quality Assurance Requirements for Nuclear Facility Applications," published by the ASME. Each participating organization shall prepare specific QA plans for its assigned scope of work and may prepare additional project-specific plans for individual work breakdown structure elements as appropriate. 


\begin{tabular}{|c|lll|}
\hline NEXT GENERATION NUCLEAR PLANT & Identifier: & PLN-2498 & \\
METHODS TECHNICAL & Revision: & 3 & \\
PROGRAM PLAN & Effective Date: & $12 / 21 / 10$ & Page: 11 of 84 \\
\hline
\end{tabular}

\section{QUALIFICATION OF CODES AND MODELS \\ 3.1 Analysis Methods Research, Development, and Qualification Process}

To ensure that the analysis software is capable of calculating the NGNP plant behavior for the scenarios of interest, a rigorous approach is required that starts from a definition of needs and concludes with a demonstration of the capabilities of the software to fulfill those needs. Such an approach has been adopted by the NGNP Project. Once the software is demonstrated to be adequate for performing representative plant behavior calculations, plant behavior analyses are initiated.

The process of identifying R\&D needs and then formulating plans is straightforward, although there are many unknowns and the process itself is iterative. In essence, it is a five-stage process that consists of (1) identifying the scenarios of importance, (2) identifying the key phenomena for the scenarios of importance, (3) verifying and validating to determine whether the tools are adequate to analyze the scenario progressions, (4) correcting or completing existing software and carrying out any software development that may be needed to ensure that the analysis tools are adequate, followed by verification and validation of the new/modified tools, and finally, (5) performing the required analyses. This process is illustrated by the yellow boxes in Figure 3 (Steps 1, 2, 6, and 7). The other boxes illustrate the multinational, multiorganizational nature of the activities under the GIF and the NGNP Project.

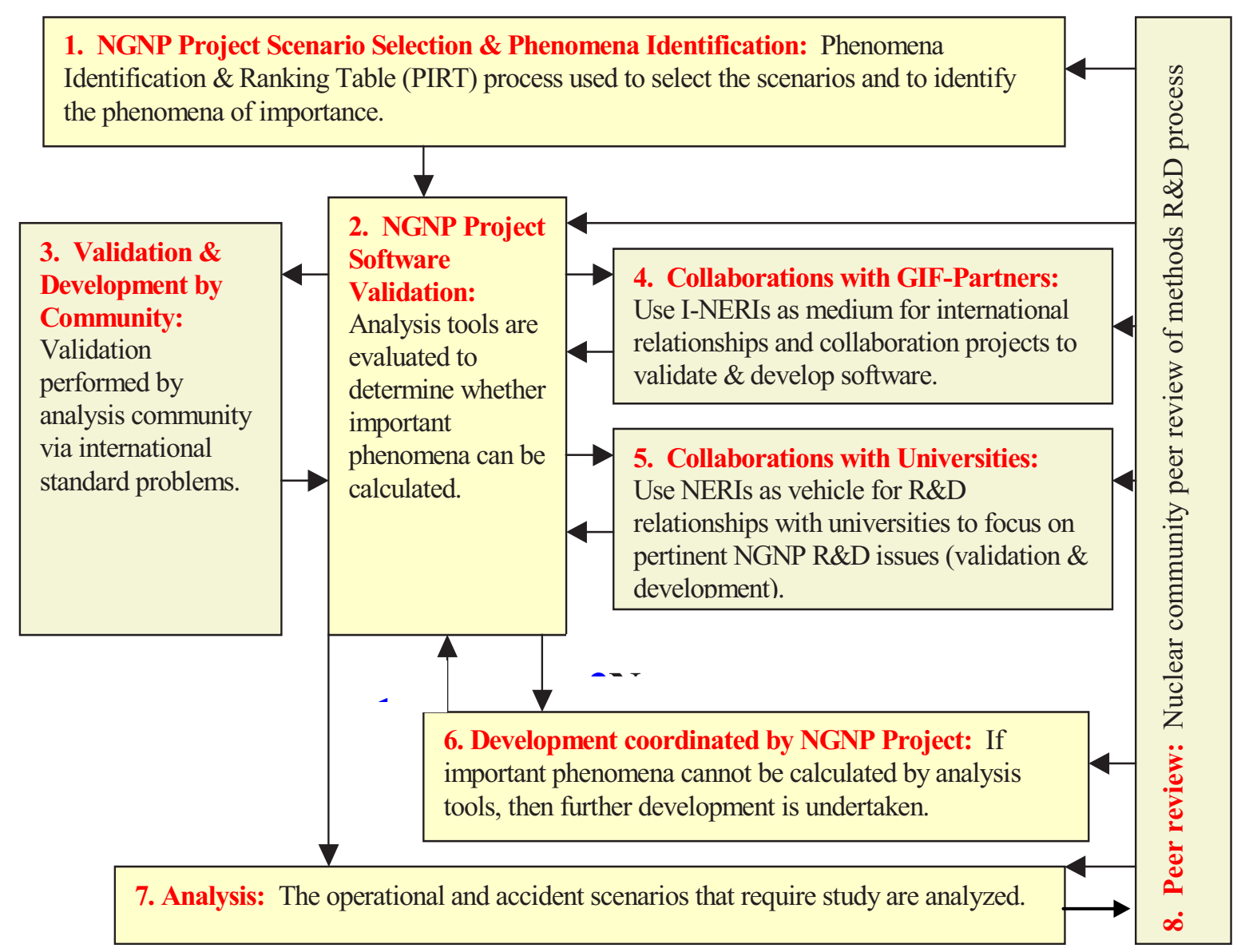

Figure 3. Methods R\&D process. 


\begin{tabular}{|c|lll|}
\hline NEXT GENERATION NUCLEAR PLANT & Identifier: & PLN-2498 & \\
METHODS TECHNICAL & Revision: & 3 & \\
PROGRAM PLAN & Effective Date: & $12 / 21 / 10$ & Page: 12 of 84 \\
\hline
\end{tabular}

The Methods R\&D process consists of eight interacting activities or steps:

1. Selecting the most challenging scenarios together with the dominant phenomena in each.

3. Internally validating the software tools and data required to calculate the NGNP behavior in each scenario.

4. Externally validating the software tools via non-NGNP Project nuclear engineering community participation in international standard problems.

5. Performing R\&D through GIF member and NGNP Project collaborations centered in International Nuclear Engineering Research Initiatives.

6. Performing R\&D through university and NGNP Project collaborations sponsored by DOE or GIF Project Management Board agreements.

7. Developing software, when validation findings show that certain models are inadequate.

8. Analyzing the operational and accident scenarios.

9. Reviewing the global process and the process ingredients using expert peers outside the program.

The first iteration of Step 1 has been completed and the results are discussed in Section 3.3 as they are specific to the NGNP. The PIRT process will be repeated at major steps in the design and licensing phases as knowledge and maturity of the design increases. Standard practices for the selection, validation, and verification of software have been adopted for the NGNP Methods Program. As these are not specific to the NGNP, they are described in detail in Appendix A.

\subsection{Qualification of Evaluation Models (Regulatory Guide 1.203)}

The NRC describes a process, in Regulatory Guide 1.203 [NRC 2005], which they consider acceptable for use in developing and assessing evaluation models that may be used to analyze transient and accident behavior that is within the design basis of a nuclear power plant. In general the Evaluation Model Development and Assessment Process (EMDAP), described in Regulatory Guide 1.203, consists of: (1) determining the requirements for the evaluation model, ${ }^{b}(2)$ developing an assessment base ${ }^{c}$ consistent with the determined requirements, (3) developing the evaluation model, (4) assessing the adequacy of the evaluation model, (5) following an appropriate quality assurance (QA) protocol during the EMDAP, and (6) providing comprehensive, accurate, up-to-date information.

Although a specific NGNP design has not been selected, the NGNP Methods development effort has proceeded by examining and postulating the evaluation model requirements in conjunction with making a preliminary formulation of the required assessment base [Lee, Wei, and Schultz 2005], i.e., Steps 1 and 2. Because the NGNP will likely be either a prismatic or a pebble-bed type gas-cooled thermal reactor with known general characteristics, the various steady-state and transient characteristics are known in general. The assessment base (benchmark experiments) cannot be defined and selected until the final design selection because many of the thermal-fluids experiments are very geometry specific and very dependent on initial conditions that would reflect initial operating and accident conditions. The most probable HTGR design basis scenarios are described in Section 3.3.

b. An evaluation model is the calculational framework for evaluating the behavior of the reactor system during a postulated transient or design-basis accident.

c. That is, either certifying existing experimental data as being adequate or designing physical experiments that will provide high-quality, acceptable data. 


\begin{tabular}{|c|lll|}
\hline NEXT GENERATION NUCLEAR PLANT & Identifier: & PLN-2498 & \\
METHODS TECHNICAL & Revision: & 3 & \\
PROGRAM PLAN & Effective Date: & $12 / 21 / 10$ & Page: 13 of 84 \\
\hline
\end{tabular}

The evaluation models have been selected (Step 3) as will be noted in Section 3.3. A different suite of methods software is required to calculate the reactor physics behavior for the prismatic as opposed to the pebble bed gas-cooled reactor. However, the software used to calculate the thermal-fluids behavior is the same for both reactor types.

In essence, much of this plan deals with defining the appropriate experiments to enable methods software validation to meet NRC Regulatory Guide 1.203 requirements and the practices and procedures that must be developed and used to ensure the evaluation models are deemed adequate. Thus, much of this plan addresses Steps 2 and 4 of the EMDAP; these topics are discussed in Sections 4, 5, and 6.

In summary, the NGNP Methods development program's R\&D are being planned and executed in conformance with the approach, practices, and methodologies recommended in NRC Regulatory Guide 1.203.

\subsection{HTGR Phenomena Identification}

To show that the NGNP meets all safety requirements, proven analysis capability must be available to model not only the normal operational conditions, but also the accident conditions. Also, various aspects of the core behavior must be modeled, including:

1. Operational characteristics of the TRISO fuel throughout the NGNP's life cycle, e.g., the power, burnup, flux, fluence, fuel temperature profile, migratory characteristics of the fuel kernel within the fuel microsphere, shrinkage and swelling of the various pyrolytic carbon coatings, and stress distributions in the coating layers. All of these operational characteristics are modeled numerically in the PARFUME software [Miller, Petti, Maki, and Knudson 2004; Petti, Hobbins, Kendall, and Saurwein 2005].

2. Fuel power distribution as a function of exposure in both the fuel compacts or pebbles and in the microspheres.

3. Thermal-fluid conditions during both operating and transient conditions, including the fuel temperature profiles and maximum temperatures of plant structural members such as the core barrel, core support plate, vessel wall, etc.

4. Mixing characteristics of the fluid inventory in the plena - the lower plenum during operating conditions since the hot exit gases are delivered to the turbine and both plena during a loss of forced-flow scenario.

5. Potential for air ingress, water ingress, and graphite oxidation subsequent to a depressurized loss of forced cooling (DLOFC) event, also known as a depressurized conduction cooldown (DCC).

6. Fission product release and transport as a function of projected TRISO fuel failure rates.

The full spectrum of possible accident scenarios of importance is not fully defined, since it is dependent on the presently undefined NGNP design. ${ }^{\mathrm{d}}$ As a starting point, however, the following events postulated for Fort St. Vrain and the German Arbeitsgemeinschaft Versuchsreaktor Reactor (AVR), as indicated in the Fort St. Vrain Final Safety Analysis Report, can be used. The applicability of these to the candidate NGNP designs must be established.

d. While the NGNP design is being formulated, the modular high temperature gas-cooled reactor (MHTGR) is serving as the reference reactor to define methods validation experiments for the prismatic design. A place-holder pebble bed reactor design has not been specified to serve as the basis for defining methods validation experiments. 


\begin{tabular}{|c|lll|}
\hline NEXT GENERATION NUCLEAR PLANT & Identifier: & PLN-2498 & \\
METHODS TECHNICAL & Revision: & 3 & \\
PROGRAM PLAN & Effective Date: & $12 / 21 / 10$ & Page: 14 of 84 \\
\hline
\end{tabular}

1. Anticipated operational occurrences:
a. Main loop transient with forced core cooling
b. Loss of main and shutdown cooling loops
c. Accidental withdrawal of a group of control rods followed by reactor shutdown
d. Small break loss of coolant accident LOCA ( 1/2 inch area break).

2. Design basis accidents (assuming that only safety-related systems can be used for recovery):

a. Loss of heat transport system and shutdown cooling system (similar to scenario $1 \mathrm{~b}$ above)

b. Loss of heat transport system without control rod trip

c. Accidental withdrawal of a group of control rods followed by reactor shutdown

d. Unintentional control rod withdrawal together with failure of heat transport systems and shutdown cooling system

e. Pressurized loss of forced cooling without scram

f. Earthquake-initiated trip of heat transport system

g. DLOFC event in conjunction with water ingress from failed shutdown cooling system or steam generator tube rupture

h. Large break DLOFC

e. Small break DLOFC.

On the basis of the prior experience of gas-cooled reactor designers and experimentalists (Ball 2003; Krüger et al. 1991), Scenarios 2a and 2g (hereafter referred to as the pressurized conduction cooldown $[\mathrm{PCC}]$ and DCC scenarios, respectively) are considered to be the most demanding and most likely to lead to maximum vessel wall and fuel temperatures. Hence, first-cut R\&D specifications are based on calculation of the hot-channel temperatures and mixing characteristics in the lower plenum during normal operation, and the PCC and the DCC scenarios from the accident envelope.

\subsubsection{Phenomena Identification and Ranking Tables}

The PIRT process entails carefully identifying the most demanding scenarios, followed by prioritizing the phenomena that are found in the most demanding scenarios. Key phenomena are those exerting the most influence on the path taken during the most demanding scenarios. Thus, as discussed in the previous paragraphs, the key phenomena for the PCC and DCC scenarios, or most highly ranked phenomena, are those that exert the greatest influence on the peak core temperatures and peak vessel wall temperatures. During normal operation, other key phenomena such as stresses or irradiation-induced dimensional changes may be important.

Because the specific NGNP design has yet to be selected, a detailed PIRT cannot be completed. However, during the interim, first-cut PIRTs have been used instead as a guide for the initial R\&D work and planning for both prismatic and pebble-bed-type gas-cooled reactors. The first-cut PIRTs are based on observations from seasoned gas-cooled reactor experts and engineering judgment; these factors were used by a team assembled to define the first PIRT for both the prismatic and PBRs and described in Appendix A of Schultz et al. [2008] and is documented in detail in Lee, Wei, and Schultz [2005] and Ball et al. [2008]. These scenarios and the experiments and modeling used in the investigation of them are listed in Table 1 and described in Section 4. 


\begin{tabular}{|c|lll|}
\hline NEXT GENERATION NUCLEAR PLANT & Identifier: & PLN-2498 & \\
METHODS TECHNICAL & Revision: & 3 & \\
PROGRAM PLAN & Effective Date: & $12 / 21 / 10$ & Page: 15 of 84 \\
\hline
\end{tabular}

Table 1. PIRT results for normal operation and conduction cooldown scenarios.

\begin{tabular}{|c|c|c|c|c|}
\hline Scenario & Upper Plenum & Core & RCCS & Lower Plenum \\
\hline $\begin{array}{l}\text { Normal } \\
\text { operation }\end{array}$ & $\begin{array}{ll}\text { i. } & \text { Flow } \\
\text { distribution } \\
\text { ii. } & \text { Pressure drop }\end{array}$ & $\begin{array}{ll}\text { i. } & \text { Reactivity feedback behavior } \\
\text { ii. } & \text { Core configuration (bypass) } \\
\text { iii. } & \text { Pressure drop } \\
\text { iv. } & \text { Heat transfer } \\
\text { v. } & \text { Flow distribution } \\
\text { vi. } & \text { Power distribution } \\
\end{array}$ & 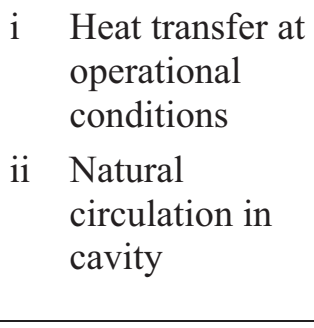 & $\begin{array}{ll}\text { i } & \text { Flow } \\
& \text { distribution } \\
\text { ii } & \text { Heat transfer } \\
\text { iii } & \text { Thermal } \\
& \text { striping } \\
\text { iv. } & \text { Jet behavior }\end{array}$ \\
\hline DCC & $\begin{array}{ll}\text { i. } & \text { Mixing and } \\
& \text { stratification } \\
\text { ii. } & \text { Hot plumes } \\
\text { iii. } & \text { Thermal } \\
& \text { resistance of } \\
& \text { structures }\end{array}$ & $\begin{array}{l}\text { i. Thermal radiation and } \\
\text { conduction of heat across the } \\
\text { core } \\
\text { ii. Axial heat conduction and } \\
\text { radiation } \\
\text { iii. Natural circulation in the } \\
\text { reactor pressure vessel } \\
\text { iv. Air and water ingress } \\
\text { v. Potential fission product } \\
\text { transport } \\
\text { vi. Power distribution } \\
\text { vii. Core configuration } \\
\text { viii. Decay heat } \\
\text { ix Flow distribution } \\
\text { x } \text { Material properties } \\
\text { xi. Pressure drop }\end{array}$ & 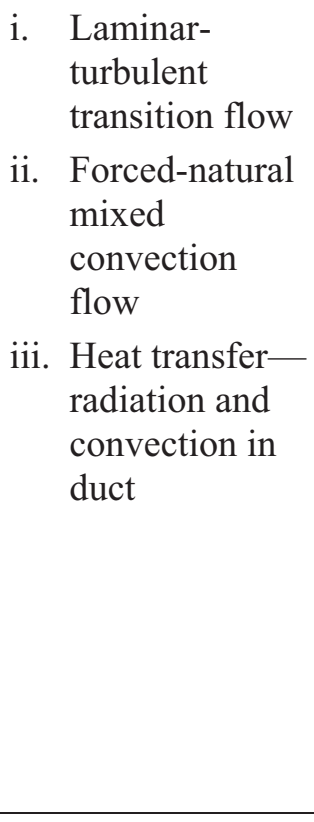 & 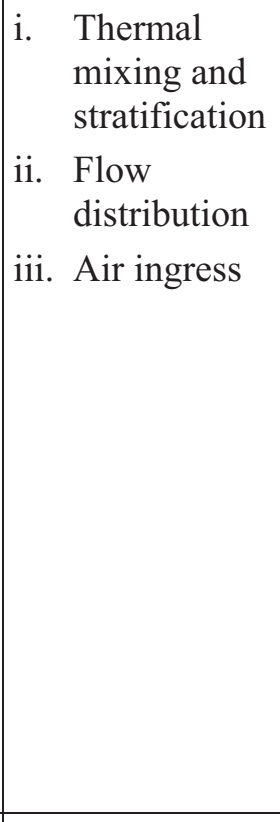 \\
\hline PCC & $\begin{array}{ll}\text { i. } & \text { Mixing and } \\
& \text { stratification } \\
\text { ii. } & \text { Hot plumes } \\
\text { iii. } & \text { Thermal } \\
& \text { resistance of } \\
& \text { structures }\end{array}$ & $\begin{array}{l}\text { i. Thermal radiation and } \\
\text { conduction of heat across the } \\
\text { core } \\
\text { ii. Axial heat conduction and } \\
\text { radiation } \\
\text { iii. Natural circulation in the } \\
\text { reactor pressure vessel } \\
\text { iv. Power distribution } \\
\text { v. Core configuration } \\
\text { vi. Decay heat } \\
\text { vii. Flow distribution } \\
\text { viii. Material properties } \\
\text { ix Pressure drop }\end{array}$ & 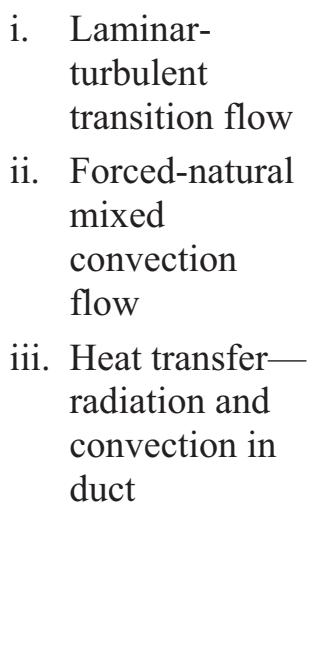 & $\begin{array}{ll}\text { i. } & \text { Thermal } \\
& \text { mixing and } \\
& \text { stratification } \\
\text { ii. } & \text { Flow } \\
& \text { distribution }\end{array}$ \\
\hline
\end{tabular}




\begin{tabular}{|c|lll|}
\hline NEXT GENERATION NUCLEAR PLANT & Identifier: & PLN-2498 & \\
METHODS TECHNICAL & Revision: & 3 & \\
PROGRAM PLAN & Effective Date: & $12 / 21 / 10$ & Page: 16 of 84 \\
\hline
\end{tabular}

\section{PROGRAM ELEMENTS}

\subsection{Experimental Validation of CFD and System Codes}

The challenges associated with understanding and simulating the neutronic and thermal fluid behavior of the HTGR arise mainly from the complexity of helium flow phenomena through specific core structures or under various normal and off-normal conditions. The high outlet temperature that makes this reactor suitable for driving a number of industrial processes can also impose unacceptable thermal stresses on candidate plant materials and components. An understanding of, and ability to simulate, the exit flow behavior and its variability is essential for economic and safe operation. Variability in core coolant flow paths and in the local power density also contributes greatly to the uncertainty in the temperatures attained in the fuel elements.

The key phenomena and scenarios identified in the PIRT (Section 3.3.1) are the subjects of experimental investigation. These experiments will provide the data needed to validate the CFD and system codes used for the design and analysis of NGNP. CFD codes have limited history in the licensing of nuclear reactors and have yet to be qualified for high temperature reactor applications. The NGNP Project therefore sponsors this process through the ASME. A Verification and Validation Standards Committee (V\&V30) has been established to qualify CFD codes for HTR applications. V\&V30 will issue a set of 'Standard Problems' based upon the NGNP thermal fluid experiments that will define a set of reference problems and techniques approved for HTGR code and model qualifications.

\subsubsection{Goals, Assumptions, and Requirements}

The goal of the CFD and system code experimental validation task is to demonstrate that thermalfluids analysis software are capable of calculating the HTGR plant behavior for typical operational conditions and for those accident scenarios identified in the PIRT review process using the approach outlined in Regulatory Guide 1.203.

In order to achieve this goal, the Methods program seeks to:

- Sponsor a series of key experimental programs at High Temperature Test Facility (HTTF), NSTF, and perhaps other facilities to produce qualified experimental data with which to carry out CFD and system code validation.

- Create a spectrum of standard problems ${ }^{\mathrm{e}}$ centered on the NGNP thermal-fluids experiments, which will form the backbone of the HTGR thermal-fluids analysis software qualification/certification for both DOE and Generation IV (GEN IV).

- Define the validation matrix to provide the basis for validating the thermal-fluids analysis software using the spectrum of standard problems that will make up the NGNP experiment V\&V matrix.

- Prescribe the methodology for qualifying thermal-fluids software (both systems analysis and CFD) for performing HTGR plant behavior analyses that meet the standards required by NRC licensing.

- Demonstrate that the methodology for qualifying thermal-fluids software is feasible and conforms to NRC recommended guidelines.

- Develop and use an uncertainty quantification method to evaluate the calculational uncertainties of the above plant behavior calculations.

e. A standard problem is an experimental data set that has undergone a rigorous review to ensure the data have achieved the desired quality level, have acceptable measurement uncertainties, are demonstrated to be scalable to the reference reactor system, and have been distilled to a useable format to enable comparison to software validation calculations. 


\begin{tabular}{|c|lll|}
\hline NEXT GENERATION NUCLEAR PLANT & Identifier: & PLN-2498 & \\
METHODS TECHNICAL & Revision: & 3 & \\
PROGRAM PLAN & Effective Date: & $12 / 21 / 10$ & Page: 17 of 84 \\
\hline
\end{tabular}

Assumptions for validating CFD and system codes are as follows:

- The validation approach most likely to be acceptable to NRC is outlined in Regulatory Guide 1.203. A working example of this approach is the methodology developed at the Idaho National Laboratory (INL) to qualify the thermal-hydraulic analysis software for the NRC Westinghouse AP600 auditing effort.

- The validation approach and the approach for accepting software outlined in Regulatory Guide 1.203 will be used to accept the NGNP thermal-fluids software prior to performing NGNP-certified calculations that describe the HTGR plant behavior for operational and accident conditions.

- The Phenomena Identification and Ranking Tables generated to identify the most challenging scenarios, the figures of merit, and the dominant phenomena for each phase of each scenario will be periodically updated as the NGNP design is first identified and then matures.

- A standard for developing and using a validation matrix as a tool to demonstrate that the software is acceptable, will be developed, and will be used as the means for demonstrating the capabilities of the thermal-fluids software that is part of the NGNP evaluation model. The standard will be developed within the ASME V\&V30 Standard Committee.

- All experiments used to generate data will be scaled to the reference HTGR reactor system using the acceptable scaling approach [Zuber 1991].

- A set of standard practices and procedures for performing validation calculations for both systems analysis and CFD will be demonstrated and approved. The NGNP thermal-fluids software will be validated using the approved standard practices and procedures before NGNP-generated HTGR plant calculations for operational and accident conditions will be completed.

Requirements for validating CFD and system codes are as follows:

- The experimental data generated in the NGNP experimental V\&V program will meet the NQA-1 requirements necessary for the data to be used as a validation reference to validate software that may be used to perform licensing calculations for submittals in licensing documents to the NRC. The quality of legacy data will be evaluated on a case-by-case basis and its suitability for code validation will be weighted accordingly and annotated in the data management system

- The validation matrix developed in the NGNP experimental V\&V program will be comprehensive enough that the software calculational envelope can be shown to encompass the NGNP operational and accident envelopes using the required standard.

- The scaling studies performed to design the experiments used to generate data for the thermal-fluids validation matrix will be accomplished using the approach defined in the Hierarchical, Two-Tiered Scaling Methodology [Zuber 1991].

- The validation matrix and NGNP calculational matrix will be updated periodically to reflect both updates in the reference reactor design and the iterations performed to ensure the PIRT evaluations are consistent with the updated reference reactor design.

- It is required that core and plant calculations performed by the NGNP Project in support of trade studies, vendors in support of design and licensing, and the NRC in support of a license evaluation must adhere to the calculational requirements imposed by Regulatory Guide 1.203 using the validation matrix and that standard practices and procedures will have been executed to qualify the NGNP thermal-fluids analysis software. 


\begin{tabular}{|c|lll|}
\hline NEXT GENERATION NUCLEAR PLANT & Identifier: & PLN-2498 & \\
METHODS TECHNICAL & Revision: & 3 & \\
PROGRAM PLAN & Effective Date: & $12 / 21 / 10$ & Page: 18 of 84 \\
\hline
\end{tabular}

\subsubsection{Scope}

The following sections summarize the phenomena under investigation and the facilities used for that purpose. Bypass flow is considered the most important contributor to uncertainty in fuel temperatures but, due to the lack of knowledge of detailed design features and uncertainties in helium flow behavior, the other phenomena discussed below will also be investigated until mitigating design features or additional knowledge cause the uncertainty to be reduced.

\subsubsection{Bypass Flow}

A series of experiments is envisioned that will test the various theories regarding factors that influence the quantity of bypass (in either the prismatic or PBR) as a function of various factors, including manufacturing tolerances and core configuration changes from irradiation or thermal expansion. It is envisioned that executing the work scope will be a DOE laboratory-university partnership.

The bypass is the core flow that moves through the core via the interstitial passages and noncooling passages in a prismatic reactor, through unanticipated zones of low resistance in a PBR, and through the reflector regions in both designs. The bypass may vary from 10 to $25 \%$ or more of the total core flow and will vary during the lifetime of the reactor as a function of the local temperature and the changes in the dimensions of the prismatic reactor's graphite blocks because of irradiation damage or changes in the pebble-bed axial bed fraction because of lifetime variations in the loading patterns [Yoon et al. 2007]. Because the bypass flow exerts considerable influence on the core temperatures and the peak exit cooling channel jet temperature and thus the temperature distribution in the lower plenum at operational conditions, identification of the NGNP core bypass characteristics and its influence on the reactor's peak temperatures is crucial.

The resolution for this phenomenological issue will likely be a statistical approach similar to that used for the classical hot spot/hot channel factors. A high-level stochastic structure involving a combination of materials modeling, first-principles and correlations, thermal-hydraulics R\&D, and manufacturing practice will need to be put in place early. This will guide the R\&D. It is anticipated that researchers will investigate the various factors that influence the bypass and develop preliminary models. These factors include gap size and variations in temperature and power profiles. Single or few-block models will be the subject of CFD investigations. Feedback effects upon and due to other core phenomena (e.g., fluence) will be investigated as part of the longer term core simulation plan. For the case of the prismatic reactor, small-scale experiments encompassing both thermal-hydraulics and materials phenomena will be performed (some at INL and some at universities). To fully resolve and characterize the prismatic bypass flow, at least three R\&D stages are needed as given below.

Stage 1: Characterize isothermal bypass flow and its relationship to the flow in the core coolant channels in the following steps:

a. Characterize flow in the bypass slots as a function of slot width

b. Characterize slot flow relative to the central vertex that connects the adjacent three slots

c. Characterize slot flow as a function of local distortion resulting from expansion and/or contraction of block surface

d. Characterize radial cross flow (leakage) as a function of expansion and/or contraction of block surface in conjunction with potential seal failures.

Stage 2: Characterize heated bypass flow and its relationship to the flow in the core coolant channels in the following steps:

a. Build on the isothermal experiments to study effects of heating on flow in the slots. 


\begin{tabular}{|c|lll|}
\hline NEXT GENERATION NUCLEAR PLANT & Identifier: & PLN-2498 & \\
METHODS TECHNICAL & Revision: & 3 & \\
PROGRAM PLAN & Effective Date: & $12 / 21 / 10$ & Page: 19 of 84 \\
\hline
\end{tabular}

b. Conduct supporting separate-effects (fundamental physics) and integral-effects experiments.

Stage 3: Characterize the relationship between the changes in the bypass flow as a function of irradiation, graphite type, and block configuration considering:

a. Graphite material thermal effects such as thermal conductivity, capacitance, and thermal expansion - all as a function of direction and temperature

b. Graphite structural deformation for selected graphite types as a function of irradiation and fuel loading history

c. Prismatic block seal deformation at the upper and lower end of prismatic blocks as function of irradiation, fuel loading history, and structural loading.

Stages 1, 2, and 3 are presently underway.

The R\&D effort for the PBR will be planned to complement available data already recorded during extensive experimental programs at the Pebble Bed Modular Reactor (PBMR) Pty. Assuming the PBMR Pty data will be made available through the GIF via the Computational Methods Validation and Benchmark Project Management Board, supplementary experiments will be planned to complement the PBMR Pty data. It is envisioned that the experiments may be performed at INL, universities, and industrial facilities such as those built for the PBMR project.

\subsubsection{Water/Air Ingress and Graphite Oxidation}

\section{Air Ingress}

Subsequent to a leak in the hot duct or at other locations on the reactor vessel such as the control rod drive flanges, the reactor vessel is postulated to depressurize. Although the fission reaction will cease either from thermal feedback or control rod insertion, any air (oxygen) entering the core after depressurization has the potential to lead to degradation of the graphite structure. The rate of depressurization is important because a large break will trigger the opening of 'blow-out' panels in the reactor building and push primary loop helium into more parts of the building. Thus, the size of the leak and the functioning of the blow-out panels will greatly influence the amount of air available for seepage into the core. The trajectory of an air ingress event therefore becomes a design issue as the different NGNP vendors may propose different techniques for mitigating the flow of air into the primary.

A related scenario is the ingress of air into the confinement vessel after depressurization of the building. Vendor designs possess blow-out panels (valves) that will open to vent the primary loop helium in the event of a larger break. The valves are meant to close after depressurization but a licensing analysis would have to assume that one or more of them would remain stuck open. Air can then flow into the confinement and subsequently into the primary if the broken seal or pipe remains open. The rate at which this occurs is a strong function of the building geometry and confinement boundary conditions.

$R \& D$ for the scenarios summarized above is ongoing. Plans are to study (a) stratified flow of air into the reactor vessel via the leakage site, (b) stratified flow of air into the confinement via blowout passage ports, (c) the rate of mixing between air and helium in the confinement as a function of leak size and the influence of these, and (d) secondary factors on the rate of air movement into the reactor vessel.

Isothermal air ingress experiments are presently under way. Heated air ingress experiments will be performed using the High Temperature Test Facility (HTTF) as discussed in Section 4.1.2.8.

Isothermal experiments will be ongoing throughout fiscal year (FY) 2011 to provide the data required to accurately treat heat transfer and wall friction of air-helium mixtures during air ingress events. Some of these experiments can be conducted by university partners, and the Very High Temperature Reactor 


\begin{tabular}{|c|lll|}
\hline NEXT GENERATION NUCLEAR PLANT & Identifier: & PLN-2498 & \\
METHODS TECHNICAL & Revision: & 3 & \\
PROGRAM PLAN & Effective Date: & $12 / 21 / 10$ & Page: 20 of 84 \\
\hline
\end{tabular}

(VHTR) Technology Development Organization (TDO) is working with Nuclear Energy University Program (NEUP) management to include this work in the Call for Proposals. Key experiments not performed at the universities will be conducted at INL and other DOE labs. Air ingress experiments will be performed in the HTTF for at least one year, starting in 2012.

Graphite oxidation experiments (in both the kinetic and diffusion-limited regimes) are being performed as part of the NGNP Graphite Characterization program. The data from these experiments will be used in multiphysics air ingress simulations using the GAMMA code.

\section{Water Ingress}

Water is normally present in the air in the form of humidity, but if the shutdown cooling system suffers a pipe break, it may enter the core in greater quantities, thereby having greater potential for affecting reactivity. There is presently a high probability that the reference HTGR design will be based on a Rankine cycle with the secondary side designed to operate at a considerably higher pressure than the primary side. It is anticipated that this design will use a set of steam generators where the secondary side is segregated from the primary side by only the wall of a number of steam generator tubes designed to operate with a defined operational differential pressure across them.

For such a reference reactor design, the NGNP will be vulnerable to a new set of scenarios called steam-generator tube rupture events, for which it is assumed that occasional off-normal events and operational occurrences may cause a single tube to rupture. The single tube, as it undergoes depressurization, may be responsible, via pipe whip, for producing ruptures in adjacent tubes. Hence a set of steam generator tubes may rupture almost simultaneously and lead to a depressurization of the water-filled secondary system into the helium-filled primary system.

Water ingress was not identified in the original PIRT to be a high frequency scenario, but the shift to water as a secondary loop working fluid poses a substantially higher risk of water ingress. A preliminary PIRT exercise will be performed in 2011 to assess the need for a full-scale PIRT process. Water Ingress was investigated as part of the Fuel and Source term PIRTs so that the effect on the fuel is being addressed. The reactivity, system pressure, and source term transport effects of water ingress will thus be the focus of any PIRT analyses in the Methods program. The flow of wet helium in and out of the primary will be analyzed with existing CFD and system tools. Reactivity and source term transport will be modeled with the tool being developed in the Core Simulation effort. Significant graphite degradation arising from oxygen in the steam is considered well beyond design basis and this will not be analyzed as part of this effort.

\subsubsection{Core Heat Transfer and Plenum-to-Plenum}

The characteristics of the hottest cooling channels at operational conditions are considered a key calculational result, since the hot channel temperature distribution defines the hottest initial condition for the fuel and surrounding materials. Hence, preliminary neutronics and CFD studies have been initiated and validation data are sought from core heat transfer experiments. Under low-flow conditions such as can occur after the primary blowers have tripped, conduction, radiation, and buoyancy-driven flow become the dominant heat transfer mechanisms. This flow can be a mixture of turbulent and laminar flow and thus may be subject to considerable instability. Codes used to analyze this scenario may not capture the heat transfer mechanisms with correlations that are valid in the turbulent or laminar regimes. Also, CFD codes presently do not have a well-developed capability to distinguish whether flow is laminar, in transition, or turbulent. Simulations in the transition flow range are challenging, yet important because the ability of the core to reject heat under these circumstances is tied closely to peak temperatures and the stress on the fuel. 


\begin{tabular}{|c|lll|}
\hline NEXT GENERATION NUCLEAR PLANT & Identifier: & PLN-2498 & \\
METHODS TECHNICAL & Revision: & 3 & \\
PROGRAM PLAN & Effective Date: & $12 / 21 / 10$ & Page: 21 of 84 \\
\hline
\end{tabular}

\section{Prismatic HTGR}

Core heat transfer experiments will provide documented temperature, velocity, and turbulence field data for forced and mixed convection (buoyancy effects) and gas property variations in HTGR prismatic reactor cooling channels in order to validate the turbulence models at reactor conditions for which benchmark data are not available. The proper calculation of turbulence directly influences cooling flow and temperature. Instrumentation will include miniaturized multisensor hot-wire probes developed as a task in a recent Nuclear Energy Research Initiative project for gas-cooled reactors [McEligot et al. 2002]. Both down-flow (normal operation) and up-flow (pressurized cooldown) will be considered.

The distribution of the flow between the various coolant channels in a prismatic reactor (and the complementary behavior in both the upper and lower plena) is important in determining the warmest part of the core and also the location of potential hot spots in the plena. It is necessary to know the flow distribution for both operational and transient conditions.

During normal operation, the core power profile can produce an array of coolant jets that may have large differences in temperature moving into the lower plenum. Potentially large temperature variations may lead to hot spots or "hot streaks" in the lower plenum structures that consist of particularly hot jets that do not mix well with the surrounding gases prior to reaching downstream components such as intermediate heat exchangers or turbine blades.

During transients initiated by a trip of the helium recirculator, natural convection patterns are driven by the temperature distributions in the core and the plena. These are characterized by upward flow through part of the core and downward flow through other core regions. Hence, hot plumes will emerge from the upward flowing core cooling channels and impinge on the upper plenum ceiling and the control rod hardware located there. Unacceptably large thermal gradients may result in structural failure.

An experiment designed to investigate core heat transfer is shown in Figure 4. The experiment will support the efforts of the current computational task concerning the hot channel issue by providing benchmark data for detailed assessment of its turbulence models for forced and mixed convection with helium property variation. Miniature multiple-sensor hot-wire probes will be inserted through the open exit as shown in Figure 5 (as indicated by the four red and one blue lines) to obtain point-wise temperature and velocity measurements. The objectives are to measure the fundamental turbulence structure and obtain benchmark data to assess CFD codes for high temperature gas flows that are in the forced and mixed convection regions, for a range of conditions important in HTGRs. To achieve these objectives, the experiment will provide an approximately uniform wall heat flux boundary condition in a tube for helium, either ascending or descending and entering with a fully-developed turbulent velocity profile at a uniform temperature as in coolant channels after passing through an end reflector. 


\begin{tabular}{|c|lll|}
\hline NEXT GENERATION NUCLEAR PLANT & Identifier: & PLN-2498 & \\
METHODS TECHNICAL & Revision: & 3 & \\
PROGRAM PLAN & Effective Date: & $12 / 21 / 10$ & Page: 22 of 84 \\
\hline
\end{tabular}

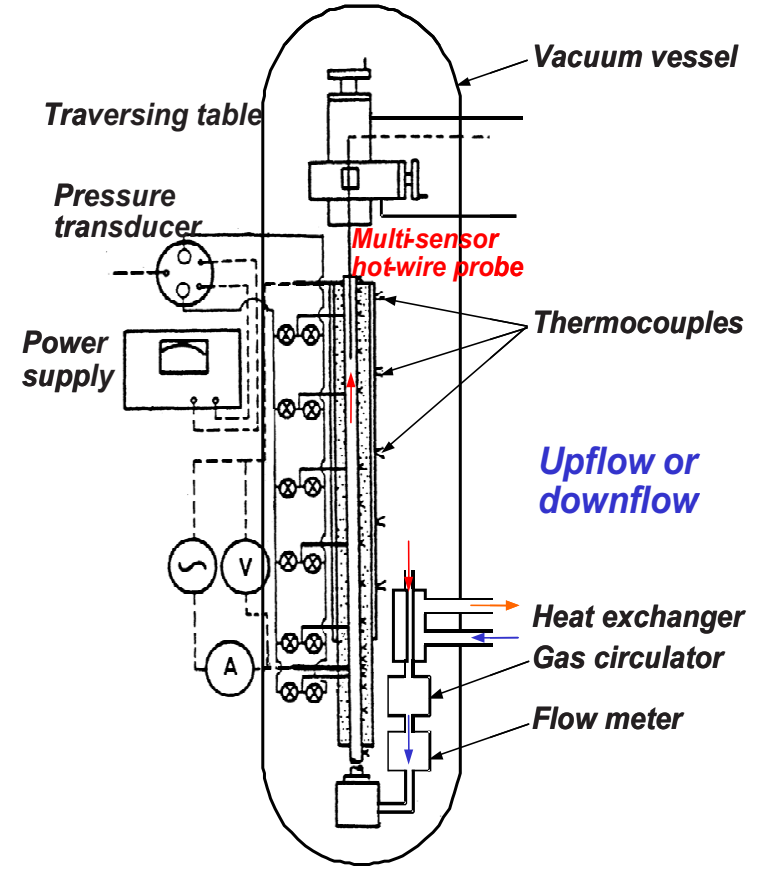

Figure 4. Potential apparatus to obtain benchmark to obtain turbulence data in heated channels.

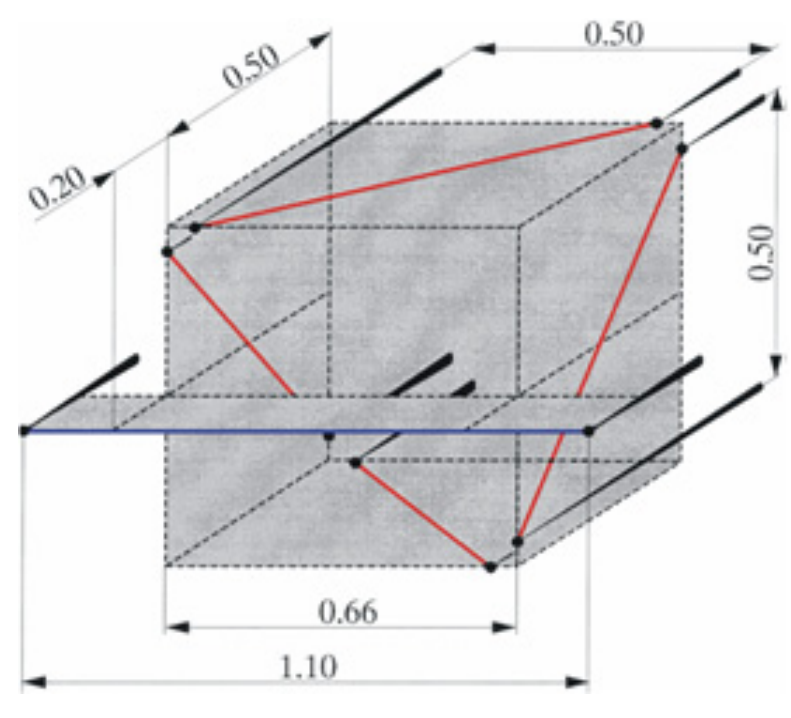

Figure 5. Schematic diagram of miniature five sensor probe by Vukoslavcevic and Wallace [2002], the dimensions are in millimeters.

\section{Pebble Bed HTGR}

A matched-index-of-refraction (MIR) experiment is planned to examine flows near outlets in PBRs. A key difficulty in analyzing the safety of PBR systems is predicting the maximum fuel temperatures and chemical reaction rates locally in the coolant outlet region (e.g., hot spots) where the temperature field is generally high. 1-D system codes have been applied for transient safety analyses and parameter studies during preliminary design. A 1-D calculation predicts quantities that are averaged across the flow (e.g., the core diameter) and does not predict the highest temperatures or their locations. The THERMIX and TINTE codes developed for the early HTGR program in Germany use a 2-D porous medium model (Reitsma 2005). Further, since chemical reaction rates vary nonlinearly with temperature, the average reaction rate is not the reaction rate at an average temperature. While these systems codes are needed, it is desirable to supplement them with 3-D calculations for final design and for estimating hot spot factors to improve their predictions. Potentially, 3-D CFD codes can be applied using a porous medium approximation to find the coolant velocity and temperature in localized macroscopic regions. Then direct numerical simulations can be used to identify the point-wise peak temperatures and their locations (microscopic treatment). The goal of this research is to develop accurate techniques for predicting maximum temperatures in HTGR concepts that use pebble bed technologies by coupling CFD calculations with experiments in the unique INL MIR flow system.

The flow through a pebble bed core is not unidirectional as in experiments to derive flow correlations. The general flow converges and diverges, in addition to the localized changes in direction at the porescale. However, it is well known to fluid physicists that a convergence stabilizes flows [Schlichting 1979]; in a turbulent flow, the turbulence levels can be reduced below expectations and the flow can even be laminarized [Satake et al. 2000]. A consequence is a reduction in convective heat transfer coefficient and, hence, an increase in surface temperatures. While criteria for this occurrence have been hypothesized 


\begin{tabular}{|c|lll|}
\hline NEXT GENERATION NUCLEAR PLANT & Identifier: & PLN-2498 & \\
METHODS TECHNICAL & Revision: & 3 & \\
PROGRAM PLAN & Effective Date: & $12 / 21 / 10$ & Page: 23 of 84 \\
\hline
\end{tabular}

for turbulent boundary layer flows [Murphy, Chambers, and McEligot 1983], none is known to us for converging flows in porous media. Appropriate measurements are needed to quantify this phenomenon and, hence, to determine its importance in PBR technology.

Under accident conditions (no forced flow) heat is transported by radiation, heat conduction of the pebbles (through the contact points), and convection. An integral simulation can only be done using the porous medium approach. Several parameters are needed for this treatment, such as pressure loss and volumetric heat transfer coefficient between gas and pebbles. A model that accounts for the turbulent mixing, caused by the complex path of the gas through the pebble array, will be important. Such models have so far been developed based on intuition, so experiments are needed. An additional difficulty for predictive techniques near a converging outlet region is that, as the radius of the bed decreases, the effects of the surrounding wall increase relatively. In the interior an isotropic approach seems to be appropriate, but near the boundaries of the pebble bed, the porosity becomes strongly anisotropic where the average porosity increases and the flow resistance decreases, resulting in channeling along the boundaries. Little is known about the current macroscopic models that take account of this effect (e.g., what is their accuracy?). A similar problem becomes important in the context of flow with heat transfer, because the boundary between pebble bed and a plane wall may act as an insulation layer. The combined effect of the convergence and wall effect is another unknown that needs study. Measurements are needed to examine the validity of any models employed and their related constitutive theories. The INL MIR flow system is well-suited to investigate these difficulties in detail.

\subsubsection{Upper and Lower Plenum}

In typical prismatic HTGR concepts, the complicated transition from coolant channels to the lower plenum provides the inlet conditions for the coolant jets into the lower plenum (see Figure 6); measurements of turbulence distributions and pressure drop (loss coefficients) are needed for CFD predictions and design. Depending on the reactor designs, comparable problems may appear for the upper plenum. Also, at the geometric transition from a lower plenum to its outlet duct, the convergence may cause laminarization of the turbulent flow, leading to reduced thermal mixing [McEligot and McCreery 2004]. Experiments on fluid dynamics of geometric transitions conducted from FY 2009 through FY 2010 have employed the INL MIR facility (McCreery and Condie 2006)) and gas flow experiments to address the key geometry problems identified in NGNP conceptual designs to that time, both for prismatic and pebble-bed approaches.

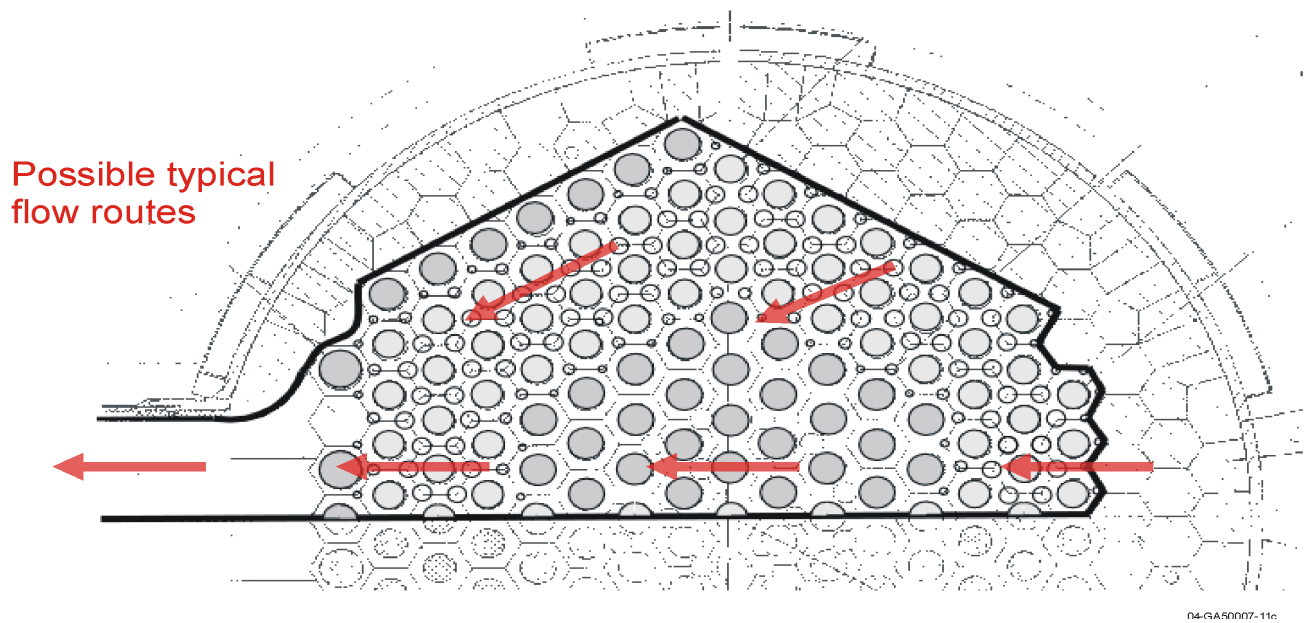

Figure 6. Examples of some possible flow paths in the lower plenum of a typical HTGR prismatic reactor concept. 


\begin{tabular}{|c|lll|}
\hline NEXT GENERATION NUCLEAR PLANT & Identifier: & PLN-2498 & \\
METHODS TECHNICAL & Revision: & 3 & \\
PROGRAM PLAN & Effective Date: & $12 / 21 / 10$ & Page: 24 of 84 \\
\hline
\end{tabular}

In addition, a series of scaled bench-top experiments may prove essential for validation of multidimensional and/or multiphysics predictive computational simulation tools for the evaluation of design-specific local features specific to the core region such as insulation, baffles, and mixing plates, which improve the performance of the system. As candidate designs are developed, it is anticipated that a list of important local features that are likely to have a limiting effect on system performance will be developed for each design. At this stage, two such features that require simulation tool development and/or validation and can be identified as important to all potential designs are (1) the prediction of isothermal flow-induced vibration of plate or sheet components (e.g., insulation or thermal radiation shielding), and (2) the prediction of flow-induced vibration and thermal distortion of plate or sheet components for heated systems (e.g., insulation or thermal radiation shielding). In both cases, the wear and fatigue associated with these fluid-structure interactions may have significant implications on the expected life and probabilistic failure rates of these components, which impact the safety case for the system as a whole. Other important local features may be identified as potential designs mature. Local structural effects because of large depressurization accidents could be such a possibility.

A number of experiments focused on analyzing typical behavior in the lower and upper plenums are planned and some have been completed. Although the specific lower and upper plenum geometries have not yet been specified in detail, it is known that the reactor will most probably have both a lower and upper plenum. The final lower and upper plenum geometry designs, whether the reactor is a pebble-bed or a prismatic-type configuration, will probably have features similar to the baseline design being used to define the preliminary experiments. That is, the upper plenum will probably have accommodations for inserting control rods and a number of flow channels will be available for the working fluid to proceed through the core. Although the aspect ratio (height to diameter) will probably be different than that chosen, it is likely safe to assume that the flow making the transition in the plenum to the core will not be developed flow. For the lower plenum, there will probably be various flow obstructions in place whose function is to provide structural support for the core hardware, and the flow will likely exit through a duct such that the core flow will be required to shift from a downward to a horizontal direction. Finally, the flow characteristics will likely be quite different on one side of the lower plenum versus the other side because of the siting of an exit duct on the side of the reactor vessel. Thus, the validation data produced in the experiments described below are envisioned as scalable, to a degree, to the final design geometry.

The mixing of hot plumes in the upper plenum of a gas-cooled reactor is of concern during pressurized cooldown [McEligot et al. 2002]. These plumes come from up-flow in the hot coolant channels during natural circulation in the core and may impinge on the reactor vessel upper plenum structure and control rod apparatus causing localized hot spots that may lead to structural failure. The flow rates and temperatures of the plumes may be affected by laminar flow instability caused by variations in the viscosity with temperature [Reshotko 1967] at the low Reynolds numbers in these channels and may possibly cause choking. An experiment is planned to investigate interactions between hot plumes and parallel flow instabilities.

The envisioned experiment will produce a scaled fluid behavior simulation of plumes moving upwards from the hot core cooling channels, of the natural circulation development in the upper plenum, and of the downward movement of upper plenum inventory into the cooler channels in route to the lower plenum. Sufficient instrumentation will be used to characterize the flow behavior for CFD validation data sets. 


\begin{tabular}{|c|lll|}
\hline NEXT GENERATION NUCLEAR PLANT & Identifier: & PLN-2498 & \\
METHODS TECHNICAL & Revision: & 3 & \\
PROGRAM PLAN & Effective Date: & $12 / 21 / 10$ & Page: 25 of 84 \\
\hline
\end{tabular}

\subsubsection{Ex-Core Heat Transfer}

Figure 7 shows a likely layout for the NGNP with the reactor pressure vessel and the vessel containing the intermediate heat exchanger and primary coolant system circulator sited below grade. During the PCC scenario in the core region and during both the PCC and DCC scenarios in the reactor cavity cooling system (RCCS), there is the potential for having convective cooling in the transition region as shown in Figure 8, where an example is shown of convection flow regimes along the heater (reactor core) and cooler (heat exchanger providing ultimate heat sink) at various pressures in a simplified Reynolds-Rayleigh number map [Williams et al. 2003]. Although Figure 8 was generated for a typical gas fast reactor core having hexagonal blocks with circular coolant holes, analogous behavior may occur in the NGNP in various locations and should be investigated. Because the convective cooling contribution is an important ingredient in describing the total heat transfer from the core and thus the ultimate peak core and vessel temperatures, these heat transfer phenomena are potentially important.

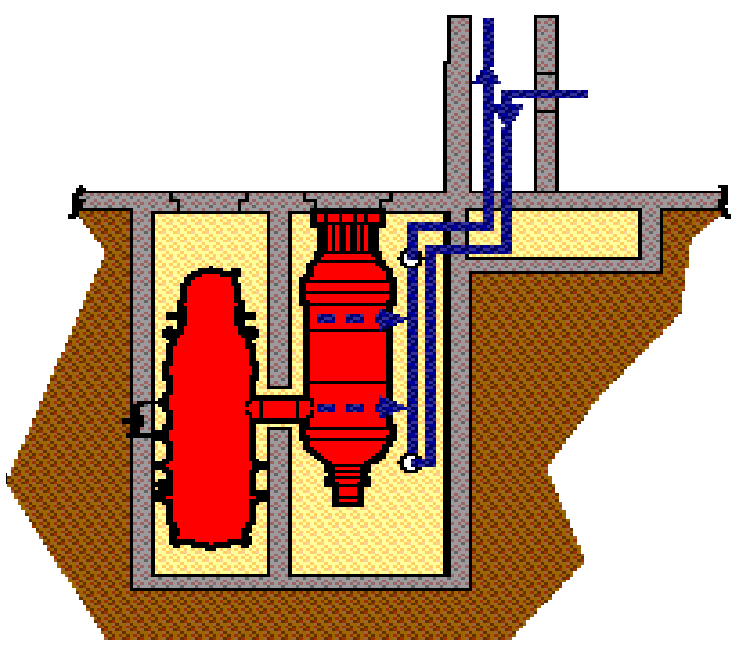

Figure 7. Reactor cavity cooling system configuration.

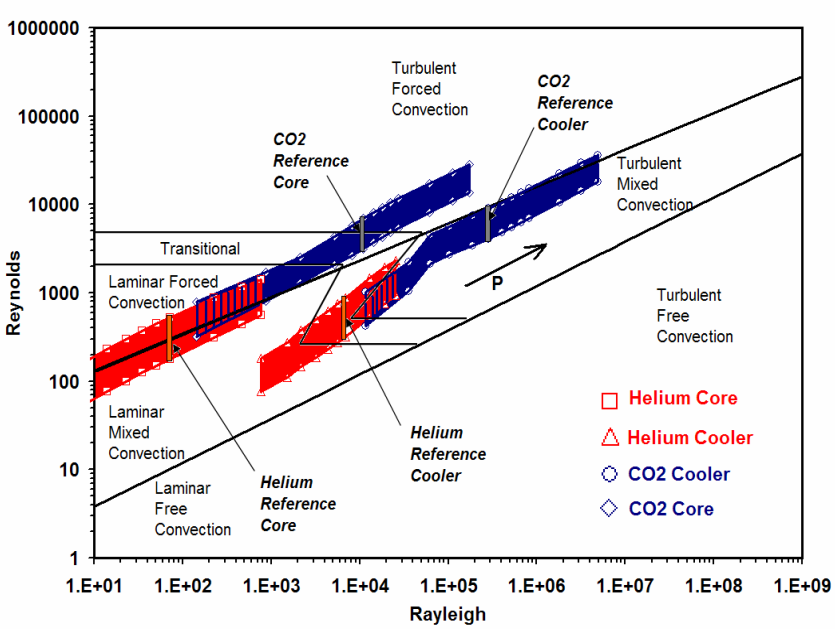

Figure 8. Convection flow regimes at various operating pressures for both helium and $\mathrm{CO}_{2}$ (from Williams et al. 2003).

The objective of this task is therefore to acquire the model/code validation data for natural convection and radiation heat transfer in the reactor cavity and the RCCS by performing experiments in the Argonne National Laboratory (ANL) Natural Convection Shutdown Heat Removal Test Facility (NSTF). The NSTF (see schematic in Figure 9) will be used as an experiment simulator. The first step will be to determine scalability of the existing data and configuration of the ANL RCCS simulator to the RCCS designs. The scaling studies will identify the important nondimensional parameters for each separateeffects study for both air-cooled and water-cooled systems. Based on the results of the scaling/feasibility study, the range of experiment conditions will be determined as well as the appropriate experiment scale and fluids to be used that most effectively simulate full-scale system behavior. R\&D will include the identification of RCCS design candidates from both the prismatic and PBR options. The range of thermalhydraulic conditions for normal operating and accident events will be evaluated. An instrumentation strategy will be developed to assure that adequately detailed velocity and turbulence profiles are obtained, as well as temperature distributions for the validation of multidimensional simulation tools. Based on the results of these scaling/feasibility studies and the associated analyses, a detailed engineering modification plan for the ANL RCCS facility will be developed. 


\begin{tabular}{|c|lll|}
\hline NEXT GENERATION NUCLEAR PLANT & Identifier: & PLN-2498 & \\
METHODS TECHNICAL & Revision: & 3 & \\
PROGRAM PLAN & Effective Date: & $12 / 21 / 10$ & Page: 26 of 84 \\
\hline
\end{tabular}

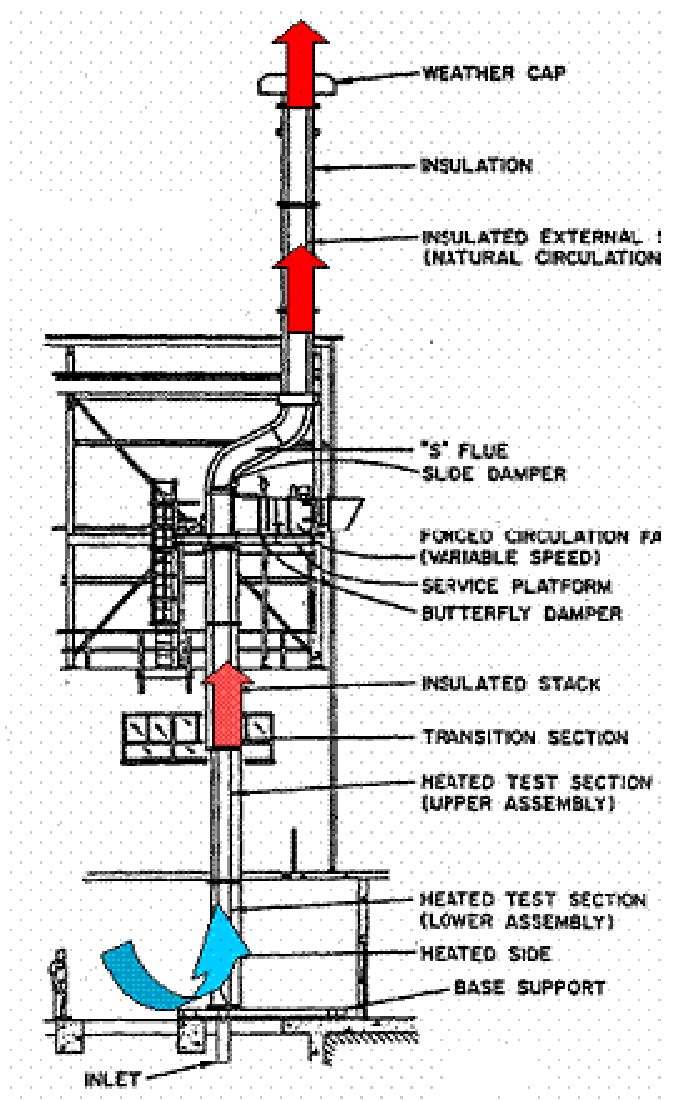

Figure 9. Schematic of ANL Natural Convection Shutdown Heat Removal Test Facility.

A test matrix will be developed, and the indicated test program will be performed. The ANL RCCS experimental results will capture key phenomena expected to be present in the RCCS and provide data of sufficient resolution for development and assessment of applicable CFD (STAR-CD/Fluent) and system codes (RELAP5-3-D/ATHENA). Both air and water-cooled RCCSs will be included in the NSTF test plan. The work scope for the modification of the NTSF to perform experiments for the NGNP RCCS has been completed. Refurbishment of the NSTF will commence in FY 2010, with final construction in FY 2011.

A complementary experiment has been constructed at the Seoul National University (SNU) RCCS facility in Korea. It consists of three parts shown in Figure 10: the reactor vessel, an air cavity, and a water pool. The SNU experiments are being performed using various gas mixtures in the gap and with various water pool elevations. The temperatures on the various surfaces are measured together with the surface emissivities and water pool characteristics (temperature as a function of position, elevation, etc.). Heat from the reactor vessel is transferred to the RCCS by radiation, natural convection, and conduction. The data provided by these experiments are the basis for validation of CFD calculations specific to the behavior of a water-cooled RCCS. 


\begin{tabular}{|c|lll|}
\hline NEXT GENERATION NUCLEAR PLANT & Identifier: & PLN-2498 & \\
METHODS TECHNICAL & Revision: & 3 & \\
PROGRAM PLAN & Effective Date: & $12 / 21 / 10$ & Page: 27 of 84 \\
\hline
\end{tabular}

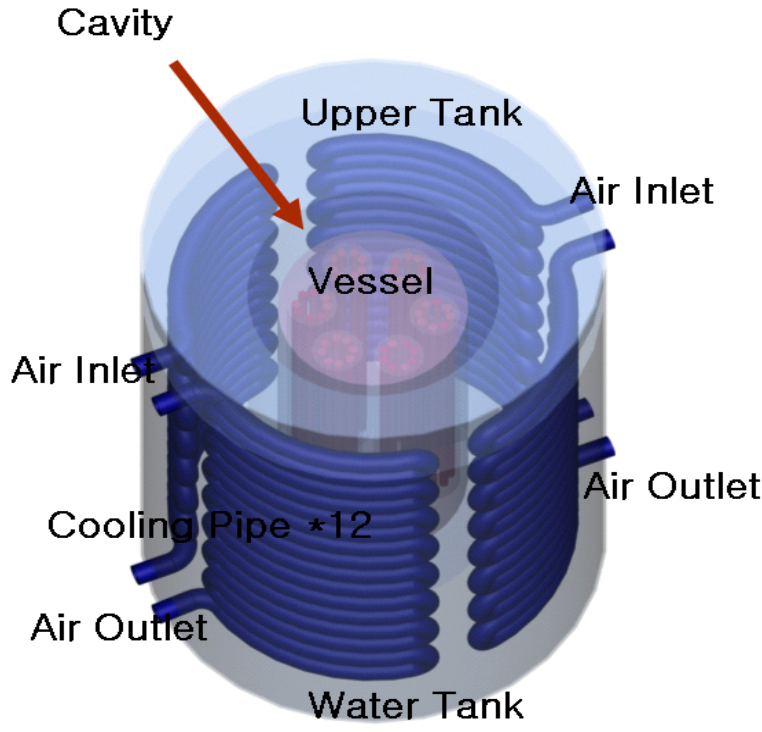

a. Schematic of test facility

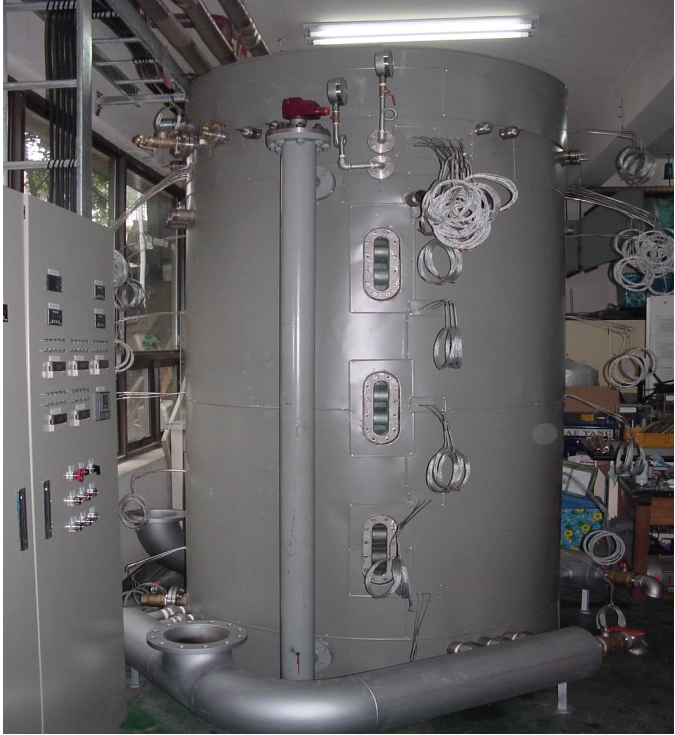

b. Photograph of test facility

Figure 10. SNU water-cooled RCCS experiment.

Work accomplished from FY 2006 through FY 2010 included initiating preliminary design of the apparatus, cost and schedule estimation, complementary CFD modeling of the system, and initial reconfiguration of the NSTF. Final design, reevaluation of costs and schedules, and initiation of fabrication are planned for later years with equipment operation, measurements, and documentation occurring from FY 2011 to FY 2013.

\subsubsection{Fission Product and Dust Transport}

The "Technical Program Plan for the Next Generation Nuclear Plant/Advanced Gas Reactor (AGR) Fuel Development and Qualification

Program" [Petti 2010] discusses the need for experimental facilities for fission product and source term experiments in Section 3.5.1. The AGR Fuel Qualification Program addresses the generation and transport of fission products out of the fuel and block matrix, a largely material issue. The transport of fission products out of the primary system and into the reactor building is addressed in Methods, as this phenomena is better described with fluid dynamics. Specific experiments are outlined for fission product transport in the vented low-pressure containment. The compartment and spaces in the reactor silo building are connected together to

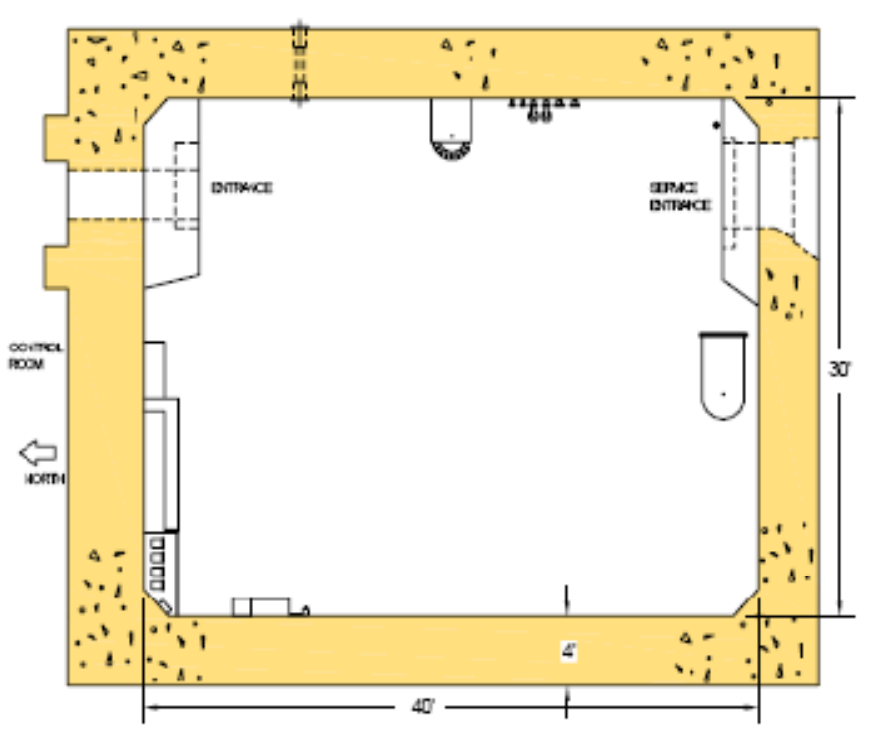

Figure 11. Cross-section view of ANL Zero Power Reactor (ZPR) Cell 5. 


\begin{tabular}{|c|lll|}
\hline NEXT GENERATION NUCLEAR PLANT & Identifier: & PLN-2498 & \\
METHODS TECHNICAL & Revision: & 3 & \\
PROGRAM PLAN & Effective Date: & $12 / 21 / 10$ & Page: 28 of 84 \\
\hline
\end{tabular}

form a long and torturous vent path. During events involving primary coolant leakage into the silo and into the building, natural processes will act to reduce the level of entrained radionuclides as the gas stream transits. Mechanistic radionuclide retention in the vented low-pressure containment is considered when showing compliance with the Protection Action Guide dose limits at the exclusion area boundary with source terms for core conduction cooldown accidents. Data are needed to develop and validate the methods describing the behavior of condensable radionuclides in the building under wet and dry conditions for these accidents. The reactor silo with the cavity and the RCCS piping forms a compartment with internals in this long vent path for the transit of gas. Once the NSTF is configured for the RCCS experiment, the structures and geometry for the condensation of the fission products will be available for an integral large-scale experimental simulation of fission product transport in this cavity and silo. A preliminary scoping evaluation will be the starting point to assess the feasibility of utilizing the NSTF to perform multifunctional integral experiments. Simulant fission product transport experiments will be the focus.

Other facilities and experiments have recently been proposed to provide data for fission product and dust migration through the reactor building. Argonne's ZPR Cell 5 shown in Figure 11 is a tightly sealed structure rated to take an explosion from $45 \mathrm{~kg}$ of TNT and 4 bar of overpressure. It has a nuclear qualified ventilation system that can be rigged to facilitate aerosol and dust dispersion experiments after a blow down. The building is currently an empty cavity (mostly), but partitions and compartments can be installed to simulate the geometry of an actual power plant.

A consortium of European organizations (AREVA, GRS, and Becker Technologies) is proposing to the Organization of Economic Cooperation and Development (OECD) the so-called THAI facility be used for investigating aerosol and dust transport in a generic HTGR building as shown in Figure 12. Like ZPR Cell 5, the experiments would support gas mixing phenomena and complex flow patterns within multiple compartments. A primary deliverable of this series of experiments would be fission product retention factors (amount released from the building/amount released from the core) which could be incorporated directly into a safety analysis or probabilistic risk assessment. The work at these large facilities would be added to the separate effects experiments taking place at some universities under the NEUP Program (Tokuhiro 2009; Loyalka 2009). 


\begin{tabular}{|c|lll|}
\hline NEXT GENERATION NUCLEAR PLANT & Identifier: & PLN-2498 & \\
METHODS TECHNICAL & Revision: & 3 & \\
PROGRAM PLAN & Effective Date: & $12 / 21 / 10$ & Page: 29 of 84 \\
\hline
\end{tabular}

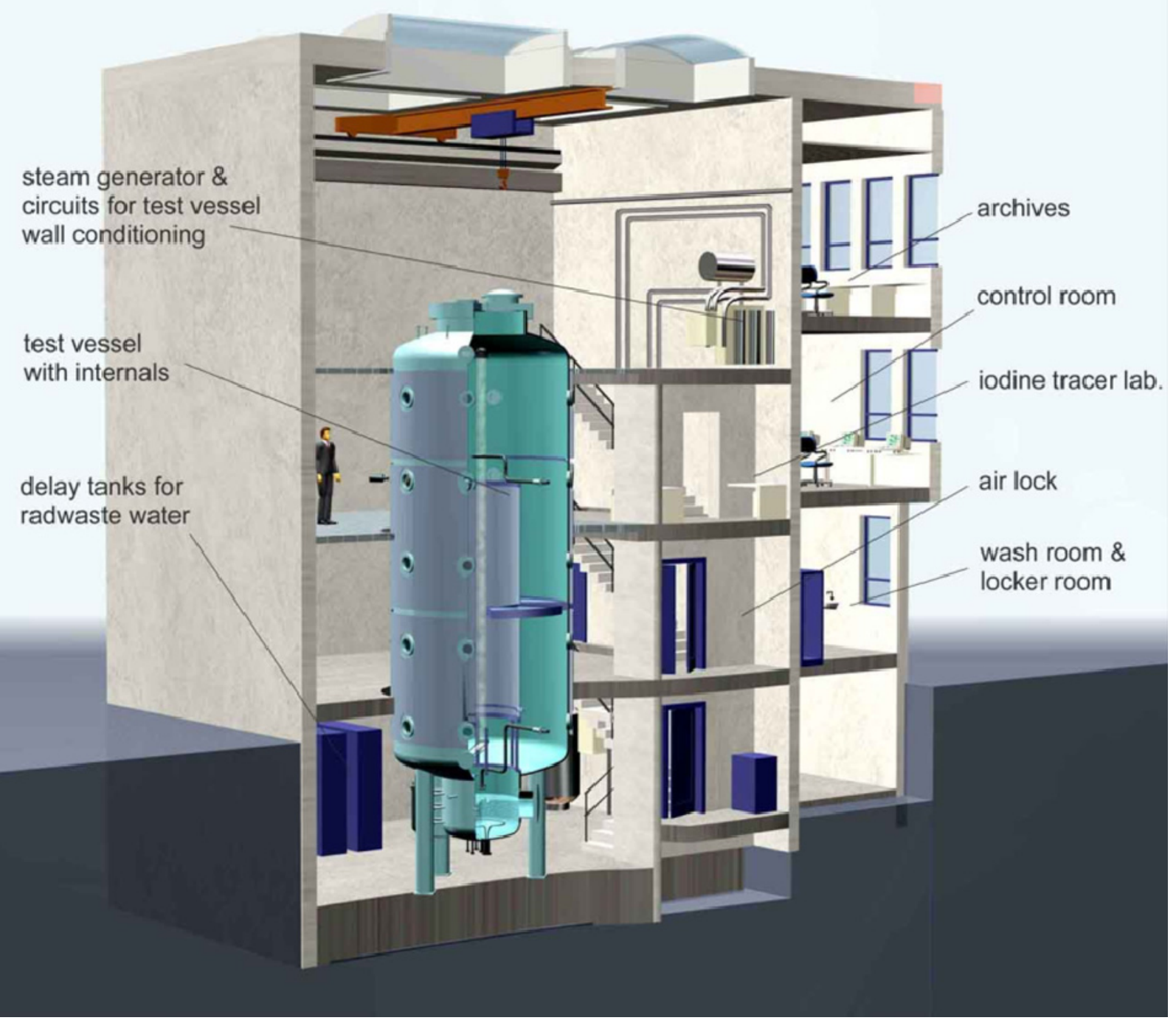

Figure 12. Rendition of the OECD-THAI Facility for investigating fission product and dust transport [Poss 2009].

The proposal is being considered by both the NGNP Project and the NRC; however, it is necessary to conduct system and sensitivity analyses on the candidate NGNP design to determine what experimental data is desired and to guide the experiment design. For example, if a prismatic core is selected by DOE, it is likely that the need for experiments targeted specifically at dust would be significantly reduced.

\subsubsection{Engineering Scale Reactors}

Two gas-cooled test reactors are presently operational for integral experiments: the HTR-10 located at the Institute of Nuclear Energy Technology (INET) in Beijing, China, and the HTTR at the Japan Atomic Energy Agency (JAEA) in Oarai, Japan. Since integral experiments are the only experimental sources that may be able to produce the complex interactions between dominant phenomena identified in the NGNP system-specific PIRT, they are essential for systems analysis code validation. Data of particular interest are: outlet temperature and pressure during transients, response of plant components to system perturbations, tritium distribution through the primary and secondary systems, and efficiency of heat 


\begin{tabular}{|c|lll|}
\hline $\begin{array}{c}\text { NEXT GENERATION NUCLEAR PLANT } \\
\text { METHODS TECHNICAL }\end{array}$ & Identifier: & PLN-2498 & \\
PROGRAM PLAN & Revision: & 3 & \\
PROctive Date: & $12 / 21 / 10$ & Page: 30 of 84 \\
\hline
\end{tabular}

removal systems. Data from both the HTTR and the HTR-10 will be important in the calculational matrix required for plant licensing by NRC.

Sketches of these two facilities are presented in Figure 13 and Figure 14. Existing data that would be useful to NGNP include steady-state temperature and power distributions in the startup core and plant flow, temperature, and power trajectories during loss of fluid and control rod withdrawal transients. Some of this data was obtained during the International Atomic Energy Agency's (IAEA's) Coordinated Research Program V and is available in the literature. Other plant data is available and being pursued. For example, tritium migration and permeation data in the HTTR has been acquired for NGNP and is being used to validate the tritium permeation analysis code (TPAC) code. In addition, a collaboration will be explored with INET to determine if further experiments can be performed that can serve NGNP design data needs and PIRT issues. A formal cooperative agreement is being pursued with JAEA to acquire HTTR test data and to collaborate on future high temperature R\&D.

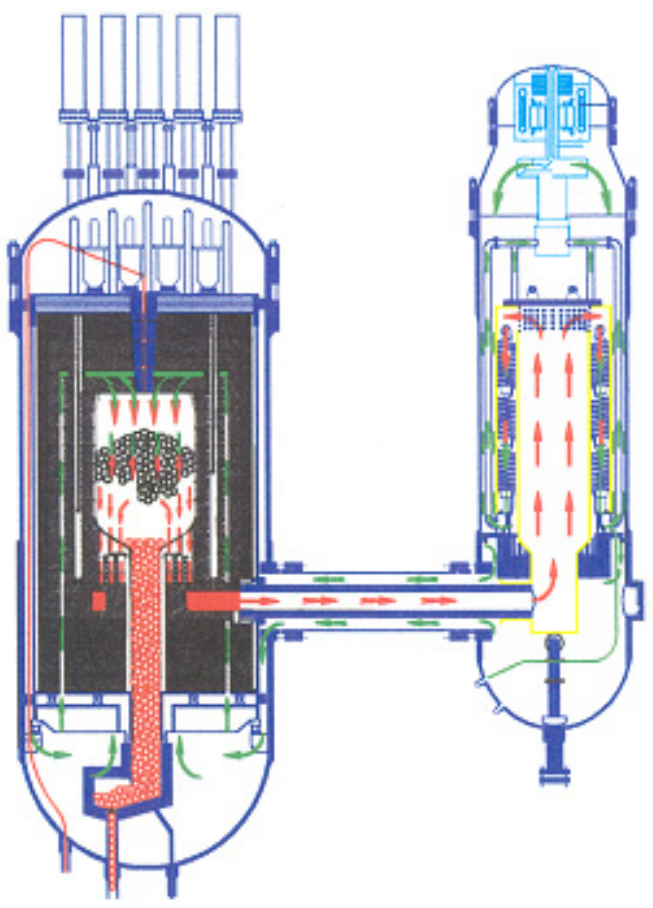

Figure 13. Schematic of HTR-10 (from HTGR Proceedings, Beijing, China, March 2001).

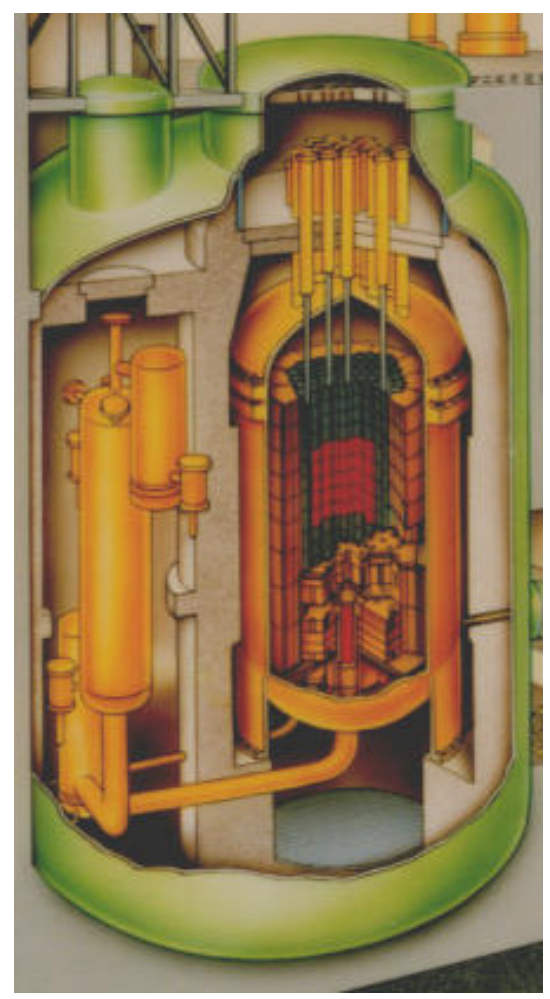

Figure 14. Schematic of HTTR.

\section{HTR-10}

HTR-10 is a $10 \mathrm{MW}$ pebble bed HTGR that became operational in 2000. INET plans to perform a spectrum of experiments that would provide further validation of NGNP system analysis codes. Among the experiments may be a loss of forced coolant (LOFC), a rod ejection experiment, and an anticipated transient without scram. Heat rejection from a PBR is of particular interest because this cannot be obtained from the HTTR.

The HTR-10 reactor vessel (see Figure 13 and Figure 14) is approximately $11.2 \mathrm{~m}$ high with a $1.8 \mathrm{~m}$ diameter core that is $1.97 \mathrm{~m}$ high with $\sim 27,000$ pebbles. The reactor is designed to operate at $10 \mathrm{MWth}$. 


\begin{tabular}{|c|lll|}
\hline NEXT GENERATION NUCLEAR PLANT & Identifier: & PLN-2498 & \\
METHODS TECHNICAL & Revision: & 3 & \\
PROGRAM PLAN & Effective Date: & $12 / 21 / 10$ & Page: 31 of 84 \\
\hline
\end{tabular}

The average power density is $2 \mathrm{MW} / \mathrm{m}^{3}$, the core inlet temperature is 250 to $300^{\circ} \mathrm{C}$, and the core outlet temperature ranges from 700 to $900^{\circ} \mathrm{C}$. Benchmark experiments performed in HTR-10 are available via the IAEA [2003].

\section{HTTR}

The HTTR Project is centered on the 30 MWth prismatic engineering test reactor shown in Figure 14. However, the HTTR Project also has a number of support projects that provide useful data (e.g., the vessel cooling system test series based on cooling panels inside a vessel containing heating elements and the heat transfer studies based on the hemispheres heated from below and cooled using natural convection). JAEA has a spectrum of HTTR experiments planned that include various reactivity transients and loss of cooling conditions. Some of these tests have been performed and still others are planned in 2010 through 2012. JAEA has proposed a collaboration on HTGR R\&D that would provide data to the NGNP Project for validating codes.

The HTTR became operational in 1998. The reactor vessel is $13.2 \mathrm{~m}$ tall (inner dimension) and has a $5.5 \mathrm{~m}$ inner diameter. The core has 30 fuel columns, seven control rod guide columns, 12 replaceable reflector columns, and nine control rod guide columns. The HTTR is fitted with an RCCS and operates at $4 \mathrm{MPa}$ with a core inlet temperature of $395^{\circ} \mathrm{C}$ and outlet temperature of $850^{\circ} \mathrm{C}$. However, it is known that the HTTR does not have a full set of instrumentation, so additional instrumentation is required to obtain the needed data.

Supporting experiments include a series of tests performed to simulate the heat transfer to the HTTR vessel cooling system (VCS) cooling panels [IAEA 2000]. The experiments are summarized in Table 2.

Table 2. VCS experiments: HTTR Project.

\begin{tabular}{lccccccc}
\hline \multicolumn{1}{c}{ Experiment } & I & II & III & IV & V & VIa & VIb \\
\hline Gas & Vacuum & Helium & Nitrogen & Helium & Helium & Helium & Helium \\
Pressure $(\mathrm{MPa})$ & $1.3 \times 10-6$ & 0.7 & 1.1 & 0.47 & 0.64 & 0.96 & 0.98 \\
Power $(\mathrm{kW})$ & 13.1 & 28.8 & 93.9 & 77.5 & 29.7 & 2.6 & 8.0 \\
Cooling panel & Water & Water & Water & Water & Air & Air & Air \\
\hline
\end{tabular}

Cooling panels were placed inside a pressure vessel and experiments were performed by varying the gas in the pressure vessel to change the natural convection characteristics. Thus, Experiment I was performed with a vacuum so that no natural convection would occur and the only heat transfer from the heaters to the cooling panels would be radiation. Experiment III was performed with nitrogen, and the remainder of the experiments were performed using helium. Also, the cooling medium in the cooling panels was run with water for four experiments and air with three experiments. The power level was changed as shown. Details of the design and construction of the HTTR Vessel Cooling System have been acquired and used for building RELAP5-3-D and CFD models of the water-cooled RCCS experiment to be conducted at ANL.

In addition to the VCS data, tritium permeation measurements were made and acquired by the Project in 2010. This data will be used to validate the TPAC code recently developed at INL to study tritium permeation in HTRs.

As shown in Figure 15, a 50-day run at full power was completed in the HTTR early in 2010. 


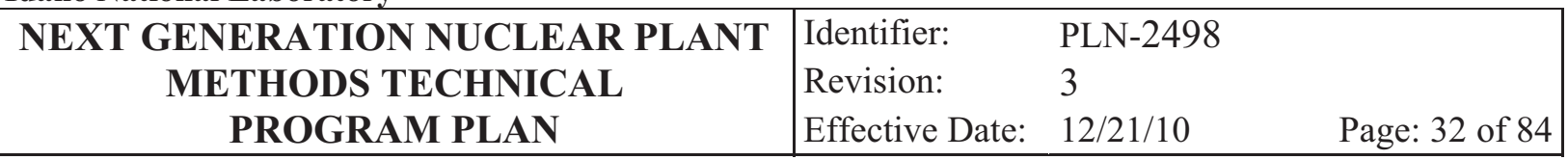

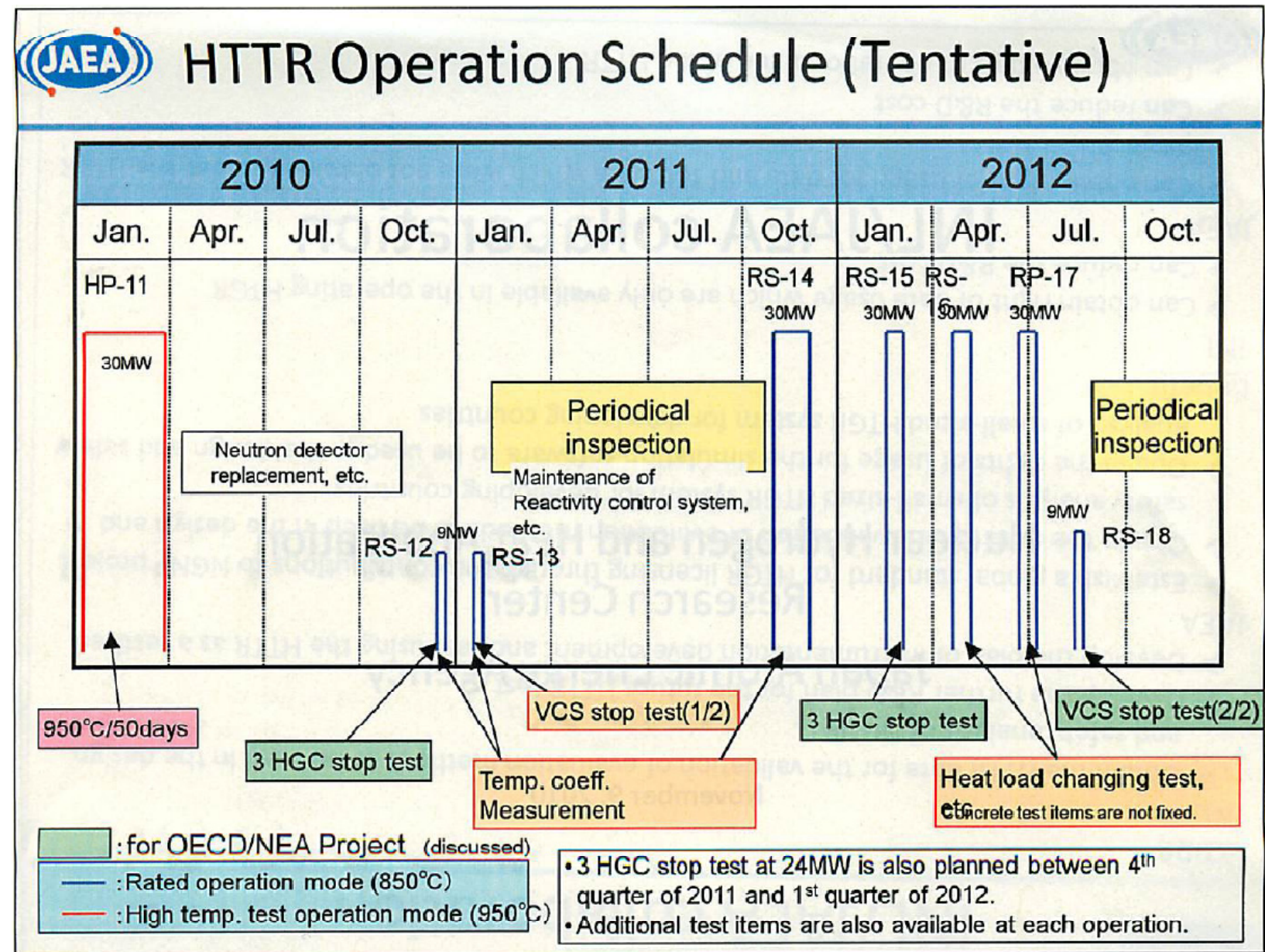

Figure 15. Planned experiment campaign in the HTTR.

Nine transient experiments are planned to study reactor response to loss of cooling under different circumstances (see Figure 15). Data from these tests will be provided to the NGNP Project under a data acquisition agreement in FY 2011. Table 3 lists the specific data to be negotiated in discussions starting in November 2011.

Data from future (>2011) experiments will be acquired as part of a collaborative research and development program, which will enable an exchange of test data (HTTR and NGNP) via the NGNP Data Management and Acquisition System. 
Idaho National Laboratory

\begin{tabular}{|c|lll|}
\hline NEXT GENERATION NUCLEAR PLANT & Identifier: & PLN-2498 & \\
METHODS TECHNICAL & Revision: & 3 & \\
PROGRAM PLAN & Effective Date: & $12 / 21 / 10$ & Page: 33 of 84 \\
\hline
\end{tabular}

Table 3.Test data to be acquired from 2010 HTTR experiments under a Proposed Data Acquisition Contract.

\begin{tabular}{|c|c|}
\hline Test No. & Description \\
\hline 1-0 & Core Physics \\
\hline $1-1$ & Burn-up characteristics (block burnup) \\
\hline $1-2$ & Temperature coefficients \\
\hline $1-3$ & Power distribution (by block) \\
\hline 2-0 & Thermal Hydraulics \\
\hline $2-1$ & Reactor system temperature distribution \\
\hline 3-0 & Fuel \\
\hline $3-1$ & Fission Product gas release measurements \\
\hline $3-2$ & Fuel temperature measurements \\
\hline $3-3 a$ & FP transport - Fuel Failure as a function of temperature \\
\hline $3-3 b$ & FP transport measurements \\
\hline $3-4$ & Dust characteristics in primary coolant (concentration/morphology) \\
\hline $3-5$ & Data from PIE of HTTR first loading fuel \\
\hline 4-0 & Graphite \\
\hline \multirow[t]{4}{*}{ 4-1 } & Thermal/irradiation stress measurements \\
\hline & Residual stress by micro-indentation technique \\
\hline & Strain measurement (destructive evaluation) \\
\hline & Data from PIE of HTTR first fuel graphite block and surveillance tests \\
\hline \multirow[t]{3}{*}{ 4-2 } & Measurements of Oxidation under normal coolant condition \\
\hline & Results from Visual inspection (TV) \\
\hline & Data from PIE of HTTR first fuel graphite block and surveillance tests \\
\hline 4-3 & B-10, C-14 concentrations \\
\hline 5-0 & Tritium code and impurity control method development \\
\hline $5-1$ & Tritium permeation behavior at normal/transient operation \\
\hline $5-2$ & Chemical impurity behavior at normal operation \\
\hline $5.2 \mathrm{a}$ & Chemical impurity control method development \\
\hline $5.2 \mathrm{~b}$ & Results of Hastelloy eddy current testing \\
\hline 6-0 & Plant Dynamics \\
\hline $6-1$ & Plant monitor data from Reactivity insertion test \\
\hline $6-2$ & Plant monitor data from Coolant flow reduction test \\
\hline $6-3$ & Plant monitor data from Loss of forced cooling test \\
\hline $6-4$ & Plant monitor data from Vessel cooling system stop test \\
\hline $7-0$ & Hydrogen System Coupling \\
\hline $7-1$ & Simulated thermal load fluctuation test \\
\hline
\end{tabular}




\begin{tabular}{|c|lll|}
\hline NEXT GENERATION NUCLEAR PLANT & Identifier: & PLN-2498 & \\
METHODS TECHNICAL & Revision: & 3 & \\
PROGRAM PLAN & Effective Date: & $12 / 21 / 10$ & Page: 34 of 84 \\
\hline
\end{tabular}

\subsubsection{Integral Thermal Hydraulic Experiments in the HTTF}

An integral facility is one that is scaled directly to the reference reactor and which can be used to study the majority of the phenomena for the scenarios of interest, including the phenomena interactions for each phase of the scenario. For example, during steady-state operations the core power distribution influences the exit helium temperature distribution entering the lower plenum and thus influences the potential for mixing in the lower plenum and the potential for having hot streaking that could translate to large temperature gradients in the gas velocity profiles leaving the reactor vessel and entering downstream heat exchangers or power conversion equipment. Phenomena in the core are thus related to the phenomena in the lower plenum and downstream equipment because they interact with one another. Similarly, for depressurized conduction cooldown and pressurized conduction cooldown, the phenomena occurring in the lower plenum affect the heat transfer and phenomena occurring in the core and reflectors.

The reference prismatic reactor proposed for the NGNP is a modular high temperature gas-cooled reactor (MHTGR). Based on the MHTGR, an HTTF is being designed and will be constructed at a facility at Oregon State University in Corvallis, Oregon. The HTTF is scaled to one quarter the size of the MHTGR and will have an electrically-heated core as shown in Figure 16. The first HTTF configuration is prismatic, but subsequent HTTF configurations may also be pebble bed, depending on the need.

The HTTF will be operational for startup testing in FY 2012 and the formal prismatic test program will begin in FY 2013. It is anticipated that the HTTF will generate data for several years and the experimental test matrix will be tailored to match the experiments scheduled for inclusion in all of the other experimental facilities, including the reactor cavity cooling system, plenum experiments, core heat transfer experiments, air ingress experiments, and bypass flow experiments. Each experiment will be accompanied by pre-test and post-test CFD or system code analyses as part of the code validation process.

\subsubsection{Accomplishments and Status of Experimental V\&V and CFD Studies}

The following list presents the accomplishments and status of experimental V\&V and CFD studies:

- The preliminary validation matrix of experiments has been defined.

- Seven experiment types have been specified to produce data for the needed validation matrix.

- Lower plenum flow experiments in the MIR Facility have been completed.

- Two experiments underway are the bypass flow experiments in the MIR facility and air ingress experiments.

- Preliminary designs of the integral experiments - reactor cavity cooling experiment (at ANL) and the integral reactor vessel experiment (HTTF at Oregon State University) - have been completed and are being refined.

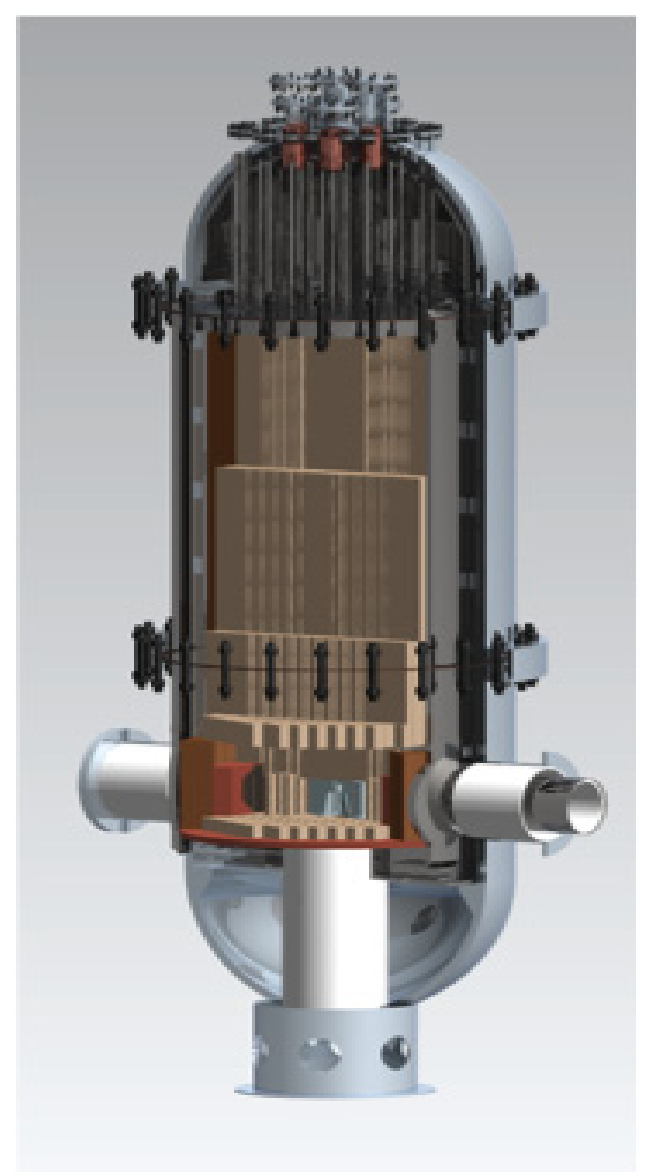

Figure 16. The HTTF integral experiment: a one-quarter-scale experiment based on the MHTGR. 


\begin{tabular}{|c|lll|}
\hline NEXT GENERATION NUCLEAR PLANT & Identifier: & PLN-2498 & \\
METHODS TECHNICAL & Revision: & 3 & \\
PROGRAM PLAN & Effective Date: & $12 / 21 / 10$ & Page: 35 of 84 \\
\hline
\end{tabular}

- $\quad$ The HTTF will initiate shakedown testing in FY 2012.

- Contract negotiations are underway to acquire HTTR test data. Informal inquiries have been made into acquiring HTR-10 data, but the approval process is expected to take some time.

- The NGNP Project is working closely with universities via NEUP to define and build experiments that complement the NGNP. Presently, at least 15 universities are cooperating with NGNP via NEUP.

- The V\&V30 standard committee has been established.

- Practices and procedures for reviewing and accepting thermal-fluids software are being formulated.

\subsection{Reactor Physics and Core Simulation}

Simulations of the reactor core and plant under steady-state and transient core conditions form the basis for licensing calculations. Confidence in the results of such analysis is required by the plant vendor, the regulator, and the plant operator. Early HTGR development and demonstration in the United States and Germany relied less on plant simulation and more on conservative analyses, post-construction testing, and improvements derived from operational experience. The NGNP will rely much more heavily upon simulations to ascertain plant behavior under all anticipated circumstances. The design and analysis codes developed under the early HTGR programs, however, have not been subjected to the continual improvement and operational validation enjoyed by LWR simulation codes. Hence, the codes used by vendors for design and licensing calculations, and the codes used by the NRC to evaluate those calculations, are characterized by numerous simplifying assumptions and large uncertainties. The main objectives of the NGNP Core Simulation task are to develop high fidelity models and benchmarks for investigating challenging HTGR phenomena and scenarios, and to increase the confidence or at least quantify the uncertainties in vendor calculations and NRC evaluation models. Although it is geared toward LWR design, Chapter 4 of Regulatory Guide 1.206, "Reactor Design," describes the neutronic and thermal fluid parameters to be included in a license application and can therefore serve as a guide for determining the requirements of NGNP Core and Plant simulations.

\subsubsection{Goals, Assumptions, and Requirements}

The overall goal of the Reactor Physics and Core Simulation task is to develop a set of tools (evaluation models) that enable the simulation of steady state and anticipated transient phenomena and events at different stages in a burnup cycle. Results of these tests will be used to confirm or verify those obtained from vendor or NRC tools and thus should capture all of the relevant physics with equivalent or greater fidelity than can be achieved with those tools.

In order to achieve this goal, the Methods program seeks to:

- Ensure that analysis tools will generate results for HTGR benchmarks and standard problems that meet all acceptance criteria for accuracy and uncertainty.

- Develop a capability to quantify key core safety parameters and their sensitivities to specified material and boundary conditions.

- Define and construct core steady-state and transient reference problems that reflect a broad range of normal and anticipated off-normal core events in two or three dimensions.

- Perform simulations that estimate the range of conditions for fuels and materials to inform fuel and material testing.

- Validate reactor physics tools against past and existing critical experiments and power reactors. Core and plant simulation assumptions are as follows: 


\begin{tabular}{|c|lll|}
\hline NEXT GENERATION NUCLEAR PLANT & Identifier: & PLN-2498 & \\
METHODS TECHNICAL & Revision: & 3 & \\
PROGRAM PLAN & Effective Date: & $12 / 21 / 10$ & Page: 36 of 84 \\
\hline
\end{tabular}

- HTGR core neutronics can be simulated accurately with known neutron transport and cross section homogenization theory, albeit with some modifications and enhancements to fit the specific HTGR geometry and materials.

- Uncertainties in key safety parameters generated by core analysis software can be quantified to the extent that they can be compared to integral facility data and results from comparable simulations.

Core and plant simulation requirements are as follows:

- The core simulation capability shall rely on a different set of tools than those being used by or developed for the NRC in order to provide independent confirmation of analysis results.

- Neutronics models of the core shall account for all significant neutron transport effects including: local absorbers (burnable poisons and control rods), all levels of heterogeneity in the fuel and core, internodal leakage (spectral interpenetration), elevated concentrations of minor actinides and fission product build-up at high burnup. The codes and models shall be valid under all anticipated prismatic and pebble fuel loading scenarios.

- Uncertainty and sensitivity analyses shall conform to industry and regulator standards where defined (e.g., Code Sensitivity and Uncertainty method).

- Core steady-state and transient reference problems shall encompass the range of normal and anticipated off-normal core events considered to be within the design basis. Beyond design basis scenarios may be investigated if the simulation of such events provides insight into the safety characteristics of the system. The current core simulation development plan will be able to model:

- Steady-state $\mathrm{k}_{\text {eff, }}$ power, temperature, burnup, and flux profiles at steady-state full power operation at beginning of cycle (BOC), end of cycle (EOC), and selected conditions in between

- load follow transients (slow rod withdrawal and primary coolant inventory changes)

- pressurized and depressurized loss-of-primary-flow conditions

- rapid rod withdrawal transients

- alternative fuel loadings

- shutdown reactivity margins and refueling criticality.

Requirements for validating simulation codes are as follows:

- Experimental data from past critical experiments and power reactors is sufficient to validate neutronic software to the NQA-1 standard required of license applications. The quality of legacy data will be evaluated on a case-by-case basis and its suitability for code validation will be weighted accordingly and annotated in the data management system. Data from existing facilities (e.g., HTR-10, HTTR, ASTRA) will be added as it becomes available.

- The NGNP calculational matrix will be updated periodically to reflect both updates in the reference reactor design and the iterations performed to ensure the PIRT and other benchmark evaluations are consistent with the updated reference reactor design.

\subsubsection{Scope}

\subsubsection{Calculational Needs}

Confirming or auditing calculations by the vendors (designer and licensee) or NRC (license evaluation) requires that comparable evaluation models be developed by the NGNP Project. This means that any code under development must generate one or more of the design and safety parameters to be generated as part of a license application. The codes and evaluation models must also supply the 


\begin{tabular}{|c|lll|}
\hline NEXT GENERATION NUCLEAR PLANT & Identifier: & PLN-2498 & \\
METHODS TECHNICAL & Revision: & 3 & \\
PROGRAM PLAN & Effective Date: & $12 / 21 / 10$ & Page: 37 of 84 \\
\hline
\end{tabular}

boundary and initial conditions of the design basis events mentioned previously, as well as provide prototypical core conditions to support the design of fuel and material qualification experiments. The needs in each of these areas are described below.

\section{PIRT and Thermal Fluid Experimental Support}

The initial and bounding neutronic conditions for the PIRT scenarios are captured mainly by the steady-state power profile and the decay heat trajectory. Both of these require the application of basic neutronic and thermal fluid core modeling capability (cross section or 'lattice' generation, whole core neutron transport and burnup, whole core thermal fluid (solid and gas) analysis). As discussed in the following sections, these calculations are interdependent and must be solved iteratively. For steady-state calculations, the coupling can be relatively loose (explicit iterations between the modules). For transient analyses, implicit coupling is required to treat the vastly different timescales of the neutronic and thermal fluid phenomena in a practical period of simulation time. Historically, computer power and coupling algorithms have limited such simulations to two dimensions but recent advances are enabling 3-D transient simulation on a developmental basis.

\section{Fuel and Material Qualification Support}

The design of fuel qualification experiments requires knowledge of the range of temperatures, power, and fluences to which the fuel elements will be exposed. Detailed temperature and fluence profiles within the coated particles is important for determining fission gas pressure buildup, fission product diffusion rates, and stresses within particle layers under both steady-state and transient conditions. Similarly, the design of suitable tests for graphite and high temperature alloy testing requires knowledge of the anticipated temperatures and fluences for these components (blocks, control rod guide tubes, pressure vessels) during operation and during loss of flow conditions. Most of these require no more than the basic 2-D core simulation capability mentioned above along with a suitable estimate of uncertainties.

\section{Confirmation or Auditing of License Analyses}

The NGNP licensee will be required to provide a wide range of steady-state and transient analysis results with associated uncertainties. For LWRs, the set of operational parameters is spelled out in some detail in Chapter 4 of Regulatory Guide 1.206. There are, therefore, many parameters that have no meaning in HTGR analysis, such as void fraction distributions, maximum clad temperatures, and critical heat flux ratios. Still, many of the listed parameters are present in HTGRs or have HTGR analogs. As the precise list of requirements for an HTGR application is still a work in progress, the following list is to be considered tentative. The items are listed according to the subsection in the Regulatory Guide in which they are found.

C.1.4.3.2.1 Fuel enrichment and burnable poison distributions and other physical features of fuel elements, delayed neutron fractions and lifetimes, core lifetime and burnup, plutonium buildup.

C.1.4.3.2.2 Normal power (axial and radial) distribution in the core and within the fuel elements, representative and limiting power distributions, transient power shapes and magnitudes accompanying normal transients (load follow, xenon buildup and decay, redistribution, and control). Uncertainties associated with these profiles are needed along with their relationships to monitoring instrumentation.

C.1.4.3.2.3 Reactivity coefficients (fuel Doppler, moderator, reflector) — normal and limiting values at $\mathrm{BOC}$ and $\mathrm{EOC}$ (or equilibrium in the case of continuously fueled PBRs)

C.1.4.3.2.4 Control requirements for cold and hot shutdown, xenon override, burnable poison concentration changes, and power shaping. 


\begin{tabular}{|c|lll|}
\hline NEXT GENERATION NUCLEAR PLANT & Identifier: & PLN-2498 & \\
METHODS TECHNICAL & Revision: & 3 & \\
PROGRAM PLAN & Effective Date: & $12 / 21 / 10$ & Page: 38 of 84 \\
\hline
\end{tabular}

C.1.4.3.2.5 Expected control rod patterns - this is a design issue but the NGNP code system must be able to model all reasonable configurations, including maximum rod worths to be removed from the core in the case of an ejection.

C.1.4.3.2.6 Reactivity during refueling (maximum $k_{\text {eff }}$ ). Not included in the regulatory guide but an anticipated question in the reactivity worth of a PBR settling event (as induced by seismic activity).

C.1.4.3.2.7 Stability (axial and otherwise) and response to xenon transients induced by power changes.

C.1.4.3.2.8 Neutron flux distribution in the core, core boundaries, and vessels (for fluence damage).

Subsection C.1.4.3.3 requires a detailed description of the analytical methods used in the nuclear design along with the estimates of the accuracy of the methods. As the methods employed by the NGNP vendors have not matured at the same pace as those used for LWRs, the uncertainties in these methods are expected to be relatively large.

Subsection C.1.4.4 specifies the thermal fluid design parameters required of the applicant. Most of these are not applicable to helium-cooled reactors yet the HTGR poses its own thermal fluid challenges, which the vendors will be required to address to various degrees for the license applications. The ability to accurately simulate thermal fluid phenomena is the focus of the experimental validation of CFD and system software program element discussed in Section 4.1. Thermal fluid code development is not planned for the Core Simulation program element, except as needed to support the objectives listed above. For example, an existing thermal fluid software package such as RELAP5 or GAMMA can be used to generate temperature profiles for a core simulation but may require modifications to be coupled to the experimental reactor physics code. Additionally, the multiphysics software being developed to investigate complex behavior does not possess an internal thermal fluids module and one must be provided. The complexity and fidelity of the thermal fluid module will depend upon the nature of the problem being solved, but the flexibility of the multiphysics development platform allows considerable latitude in this regard without requiring significant resources.

\subsubsection{Required Analyses and Capabilities}

To generate the parameters and figures-of-merit listed above will require the following capabilities and analyses. Each is followed by the parameters or profiles that the capability can provide. Together they cover the needs outlined in the previous section.

- Steady-state, high fidelity, 3-D neutron and photon transport (no burnup):

- criticality and start-up physics evaluations (including control rod worths)

- few-group cross sections for cycle and transient analysis

- isothermal temperature reactivity coefficients for low-order plant simulations

- BOC power profiles and shutdown rod reactivity worth

- verification of low-order (diffusion) core models

- reactivity of cores during refueling

- fluence and radiation damage of structural components

- nonlocal heat deposition profiles (gamma and thermal scattering in ex-core components)

- Lower fidelity, 3-D, steady-state whole core neutron transport (diffusion) coupled with whole core depletion and steady-state thermal fluid analysis: 


\begin{tabular}{|c|lll|}
\hline NEXT GENERATION NUCLEAR PLANT & Identifier: & PLN-2498 & \\
METHODS TECHNICAL & Revision: & 3 & \\
PROGRAM PLAN & Effective Date: & $12 / 21 / 10$ & Page: 39 of 84 \\
\hline
\end{tabular}

- enveloping power distributions

- EOC power and burnup profiles

- EOC reactivity coefficients and shutdown reactivity margins

- Decay heat trajectories and profiles

- Lower fidelity, 3-D, time-dependent whole core neutron transport (diffusion) coupled with timedependent thermal fluid analysis:

- core transient (safety) trajectories and load follow simulations

- xenon transients and stability analysis

- Meso/Microscale fuel temperature, energy deposition, and stress analysis coupled to core transient simulation:

- fuel performance and particle structural analysis

- high fidelity Doppler fuel reactivity calculations

- Pebble bed dynamics and pebble flow simulation:

- flow patterns to support burnup analysis

- pebble bed settling transient simulations

- dust generation rates

- Multicomponent fluid transport:

- fission product and dust transport profiles for source-term analysis

- water ingress rates between primary loop and confinement building

- Uncertainty and sensitivity analysis:

- bounding trajectories and safety-significant parameters

- sensitivity coefficients

- 95/95 confidence intervals on uncertain inputs and model assumptions.

The set of simulation tools (the Evaluation Model) used to generate these parameters is show in Figure 17. Reactor physics code modules are shown in red, thermal fluid and plant component modules are shown in blue, and mechanical modules are shown in green. 


\begin{tabular}{|c|lll|}
\hline NEXT GENERATION NUCLEAR PLANT & Identifier: & PLN-2498 & \\
METHODS TECHNICAL & Revision: & 3 & \\
PROGRAM PLAN & Effective Date: & $12 / 21 / 10$ & Page: 40 of 84 \\
\hline
\end{tabular}

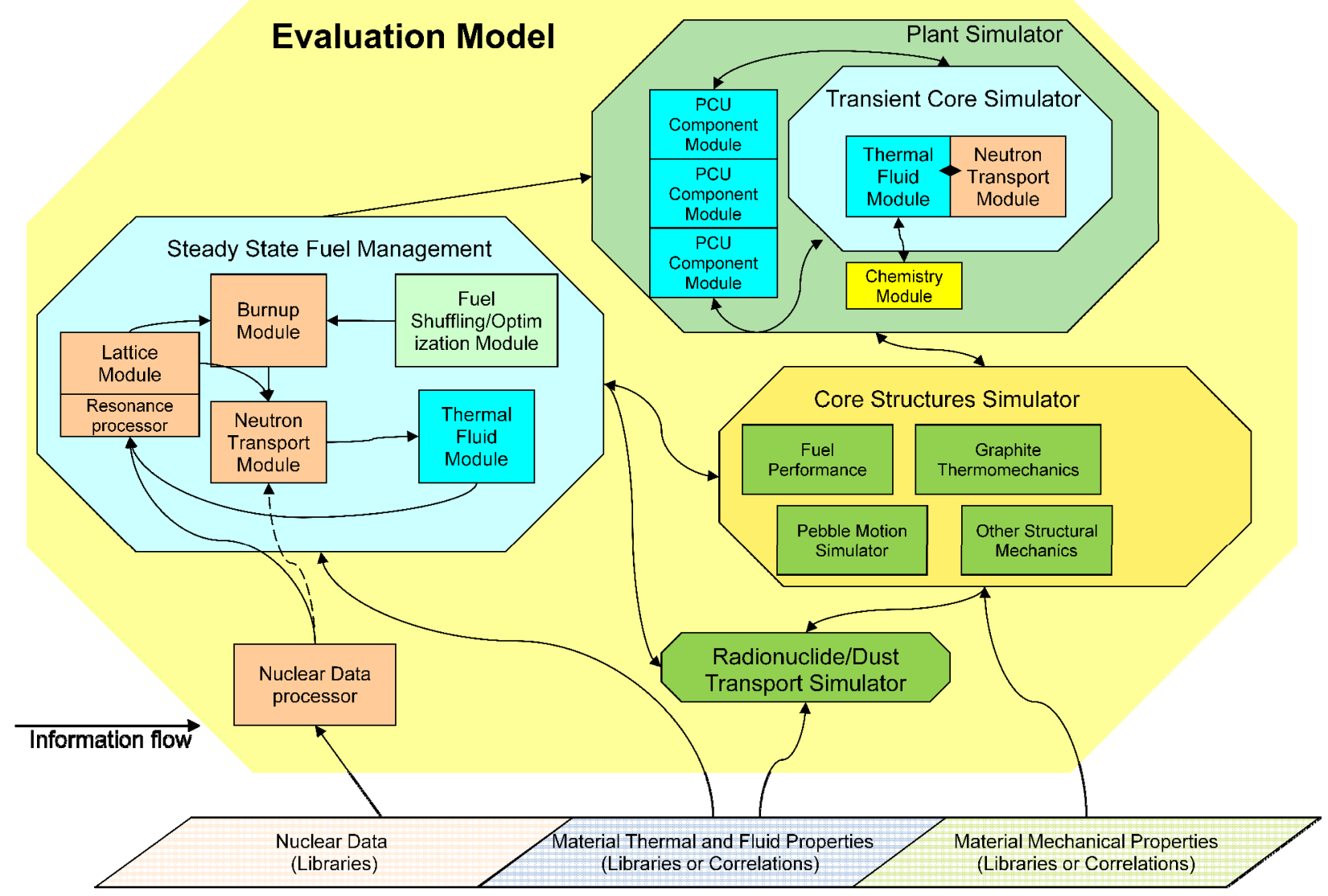

Figure 17: Code functionality and data flow used to simulate core and plant behavior

Existing tools available to the NGNP Project can generate some of these parameters with the accuracy and fidelity required to confirm vendor and regulator analyses. For items not covered, the following section summarizes the areas in which new or modified tools are required.

\subsubsection{Areas in Need of Development}

\section{Steady-State, High Fidelity, 3-D Neutron and Photon Transport (No Burnup)}

Monte Carlo neutral and charged particle transport codes such as MCNP and SERPENT are mature and powerful tools for a range of high fidelity transport simulations. They can be and have been applied to specific HTGR analyses. The computational demands of these codes limit their use in whole core analyses but they are the preferred tool for criticality and physics evaluations, reactivity coefficients, and gamma and fluence profiles. In addition to MCNP, the SERPENT code has been acquired because it possesses the additional ability to generate few-group diffusion coefficients for whole core analysis. These will be used to confirm cross section values generated by the lattice codes under development.

Deterministic transport codes (e.g., CASMO [Smith 2000], HELIOS [Studsvik 2000], DRAGON [Marleau 1996] ) are usually used for generating few-group fuel assembly cross sections for subsequent whole core analysis. These codes can handle the hexagonal geometry of prismatic fuel blocks with, in some cases, modifications. These codes and the method in which they are used are optimized for LWR fuel assembly calculations and have only recently been applied to the problem of HTGR few-group cross section generation. 


\begin{tabular}{|c|lll|}
\hline NEXT GENERATION NUCLEAR PLANT & Identifier: & PLN-2498 & \\
METHODS TECHNICAL & Revision: & 3 & \\
PROGRAM PLAN & Effective Date: & $12 / 21 / 10$ & Page: 41 of 84 \\
\hline
\end{tabular}

The dominant features of the HTGR that pose a challenge for these codes are the:

- Unique heterogeneity of the fuel (Figure 18)

- Neutron leakage between blocks (also known as interspectral penetration)

- $\quad$ Large reflector regions and placement of control absorbers in those regions (leading to difficulty in defining

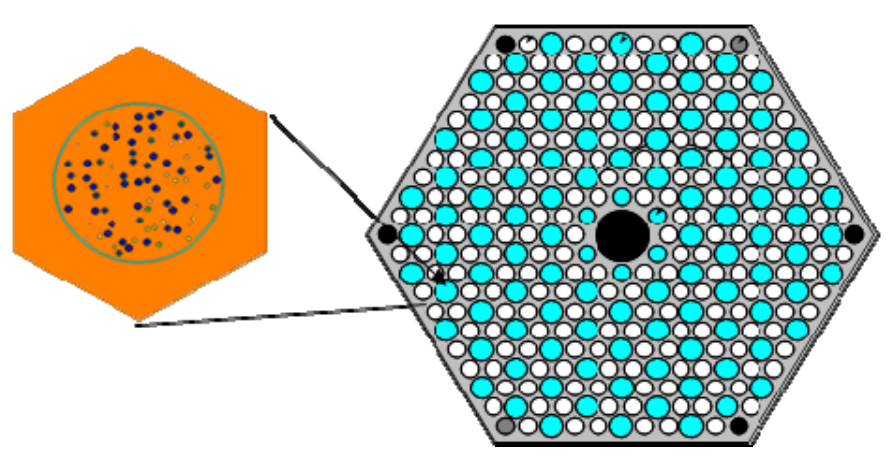

Figure 18. Heterogeneity within a single prismatic fuel block. "average" spectral zones for generating few-group cross sections).

Additionally, prismatic fuel block designs often employ asymmetrically placed burnable poisons or large voids occasionally filled by shutdown absorber elements. PBR analysis is inherently imprecise because of the continuous and stochastic loading and movement of fuel elements during operation. Legacy HTGR analysis methods use a number of approximate methods and assumptions that can now be avoided using modern computational tools and methods.

\section{Few-Group Cross Section Generation for Whole Core Analysis}

The effect of the geometry of TRISO fuel particles embedded in compacts or spheres (termed the double heterogeneity effect) is felt in fuel utilization and reactivity feedback. It must be adequately represented in the lattice physics code used for the NGNP analysis in order to obtain accurate results in the core simulations over the entire fuel cycle. This effect has been found to be about 2 to $4 \% \Delta \mathrm{k} / \mathrm{k}$ (reactivity) in NGNP assemblies/cores using enriched uranium fuels, and about 10 to $15 \% \Delta \mathrm{k} / \mathrm{k}$ for those using transuranic fuels as in the deep-burn concepts. A traditional approach to double heterogeneity employs Dancoff factors to correct the absorption cross section for the shadowing by surrounding lumps. INL assisted with development of a rigorous calculation of the Dancoff factor for TRISO-fueled systems and implemented it into the PEBDAN code [Kloosterman 2005]. This appears to yield reasonable results when used in codes that employ the Wigner Rational approximation such as SCALE and COMBINE. Lattice codes under investigation by the NGNP Project for prismatic reactor analysis are DRAGON and HELIOS. A new heterogeneity treatment (Hébert 2008) has been implemented in DRAGON. A statistical approach treating resonance interactions in heterogenous fuels developed by Sanchez and Pomraning has been implemented recently in HELIOS. DRAGON has 3-D geometry capability so it can explicitly model the axial burnable poison found in the HTTR. It cannot, however, model the partial hexagonal blocks found in the outer reflector region of the prismatic reactor. HELIOS has more flexibility in treating different geometries but is limited to two dimensions.

All existing codes (including MCNP) rely upon a simple treatment of scattering of neutrons by heavy metal atoms. In the past 10 years this treatment has been shown to lead to uncertainty $(\sim 10 \%)$ in core eigenvalue calculations because of the error induced in the resonance cross sections. A correction to MCNP exists (Becker 2009) but it has yet to be implemented. Discussions with the custodians of MCNP are being pursued to assess the effort needed to do this. Research into a more accurate treatment of heavy metal resonances in lattice codes is also underway at Penn State with the support of NGNP Methods and the Deep Burn Project. 


\begin{tabular}{|c|lll|}
\hline NEXT GENERATION NUCLEAR PLANT & Identifier: & PLN-2498 & \\
METHODS TECHNICAL & Revision: & 3 & \\
PROGRAM PLAN & Effective Date: & $12 / 21 / 10$ & Page: 42 of 84 \\
\hline
\end{tabular}

The NGNP blocks and core are also neutronically thin (as measured by the neutron mean free path) compared to LWR assemblies and core, which poses a challenge to the neutronic codes based on homogenized few-group constants. The spectra of the surrounding fuel or reflector blocks penetrate the block in question to the extent that the usual assumption of infinite medium or 'white' boundary condition is invalid. Even the 'colorset' approach cannot fully capture the leakage spectra. 'SuperCell' or partial-core calculations as shown in Figure 19, or more sophisticated treatments of block boundary conditions are needed to capture this effect.

To illustrate the problem, Figure 19 shows the results of a sensitivity study in which one-group diffusion parameters

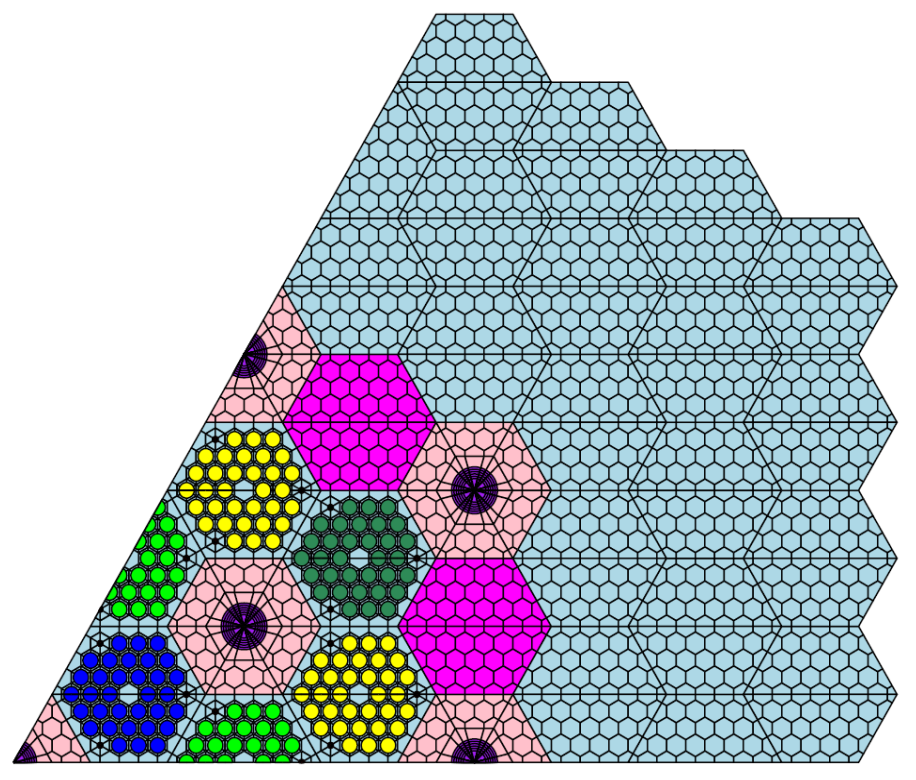

Figure 19. Partial core (SuperCell) model of a prismatic reactor used for cross section generation. were generated for a single prismatic block as a function of the extent of the surrounding core that was included in the model. The plots indicate that one must include at least $50 \mathrm{~cm}$ (almost two blocks in any direction) of the surrounding core to adequately capture leakage effects within the block. Because the core annulus for the current NGNP designs contains only three rings of blocks, a lattice core calculation must include all of the surrounding fuel blocks and at least one reflector block. This approach has the added benefit of being able to generate the cross sections for the reflector regions.

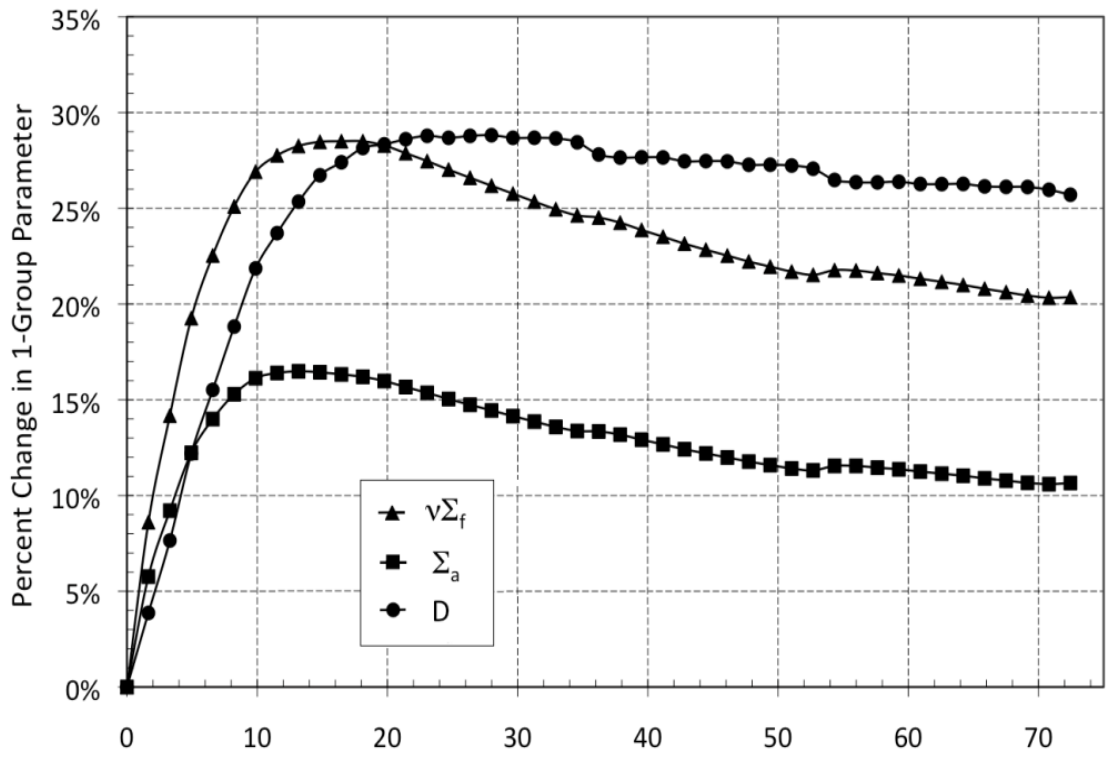

Figure 20. Extent of domain beyond a single block needed to capture leakage spectra.

Another approach is to perform a lattice calculation on single blocks, but apply group and surface dependent boundary conditions (flux or current) obtained from the core calculation. This would require a 


\begin{tabular}{|c|lll|}
\hline NEXT GENERATION NUCLEAR PLANT & Identifier: & PLN-2498 & \\
METHODS TECHNICAL & Revision: & 3 & \\
PROGRAM PLAN & Effective Date: & $12 / 21 / 10$ & Page: 43 of 84 \\
\hline
\end{tabular}

modification of the lattice code to accept such boundary conditions and the whole core diffusion code to generate them. This approach would also require iterations between the lattice and core calculations until boundary condition convergence is obtained.

Both approaches are computationally more demanding than the traditional LWR sequence and, thus, would probably require parallel processing power.

The lattice physics and whole core diffusion codes must be able to treat all of these effects in order to accurately compute the temperature coefficients, core reactivity, flux, and power distributions in the annular core. Local neutron streaming effects arising from the large control rod holes in prismatic HTGR designs must also be accurately represented. The core depletion state, including the nuclide number densities and core burnup distribution, must also be accurately predicted. These core physics parameters directly impact thermal-fluids/safety analysis, fuels and materials designs, and plant economics. The code suite must also be computationally efficient in order to perform the large number of calculations required to support core scoping analysis and detailed designs in reasonable time.

Final development and evaluation of the DRAGON and HELIOS codes is planned for FY 2010. INL is working with Ecole Polytechnique du Montreal to implement a more flexible geometry specification in DRAGON that can model partial blocks and other block structures. INL is also working with Studsvik USA to develop an optimized HTGR cross section library for HELIOS. These codes will be tested against lattice code benchmarks by comparing the values of few-group cross sections, flux profiles, and eigenvalues and with those of other lattice codes and high fidelity SERPENT models. Given the lack of experimental benchmarks for HTGR lattice calculations, such computational benchmarks and simpler unit cell models must suffice for lattice code verification. Coupled with whole core calculations, these codes will also be tested against critical experiments (HTTR, VHTR Critical [VHTRC], PROTEUS), which work has already begun. In 2010, the DRAGON code was used to generate cross sections for a whole core calculation of the HTTR. Results were comparable to MCNP evaluations [Ortensi 2010]. About one full-time equivalent (FTE) person is devoted to this activity in FY 2011. Final testing and verification of the chosen lattice code will require another FTE and is scheduled to be completed in FY 2012.

\section{Schedule for Prismatic Core Cross Section Generation}

- FY 2011:

- Complete development and evaluation of DRAGON and HELIOS (0.5 FTE)

- Complete evaluation of SERPENT for producing reference cross sections (0.25 FTE)

- Prepare cross sections for the steady-state exercises of the prismatic coupled core benchmark (0.25 FTE)

- $\quad$ FY 2012

- Complete generation of cross sections for prismatic coupled core benchmark transient exercises. (.25 FTE)

- Begin Phase 1 verification of selected lattice code (1FTE)

- $\quad$ FY 2013

- Complete Phase 1 verification of selected lattice code (1FTE).

The pebble bed neutronics problem is similar but somewhat less severe. Burnable poisons are not used in the leading pebble bed core designs and the important structures that must be treated in the cross section generation process possess considerable 1-D symmetry. Like the prismatic reactor, however, the mean free path of neutrons is relative to the size of the spectral zones - the equivalent of blocks in the prismatic core and the region for which cross sections are generated. Leakage between these spectral 


\begin{tabular}{|c|lll|}
\hline $\begin{array}{c}\text { NEXT GENERATION NUCLEAR PLANT } \\
\text { METHODS TECHNICAL }\end{array}$ & Identifier: & PLN-2498 & \\
PROGRAM PLAN & Revision: & 3 & \\
PROGtive Date: & $12 / 21 / 10$ & Page: 44 of 84 \\
\hline
\end{tabular}

zones is significant, particularly in the radial direction, and therefore partial core calculations are also required. Like the prismatic reactor, these partial core calculations are also required to obtain cross sections for the reflector regions in which there is no internal source of neutrons.

COMBINE has since been modified to support PBR core simulation. The B-3 transport equation is now solved over the entire spectrum with simultaneous upscattering and resonance treatments in 167 energy groups. User-supplied buckling terms can reflect net inward or outward leakage. COMBINE accepts Dancoff factors generated by the PEBDAN code [Kloosterman 2005] to account for shadowing. A 1-D discrete ordinates transport (ANISN) solver has been embedded in the code to capture spatial effects. With pebble bed geometry in mind, COMBINE employs a multistage homogenization process that minimizes the error inherent in the multigroup approximation. Explicit transport models of the TRISO particle, pebble, and radial core wedges are solved in 167 groups before being coalesced in energy and space to generate few-group cross sections for PEBBED (Figure 20). Axial and azimuthal leakages are still treated with transverse buckling terms. Radial leakage, which is the dominant contribution to leakage from the spectral zones, is captured explicitly in the core transport stage and in 167 groups. The source for the radial reflector regions (including control rods) is the true current emanating radially from the core region with adjustments for axial and azimuthal effects.

Implementation of the multistage approach to homogenization in COMBINE enables the explicit modeling of the different structures that are present. For the pebble bed itself, the transport equation is solved in spherical geometry first for the TRISO particles and then for the pebbles and surrounding coolant. Results from analysis of individual pebbles (in an infinite array of pebbles) in an NEA pebble benchmark indicate excellent agreement with both Monte Carlo and other deterministic lattice calculations. Explicit geometrical models are not required for the bulk of the reflector and core barrels because these regions are largely homogeneous. A 1-D cylindrical transport calculation is used, however, in the homogenization of control rod regions.

The new COMBINE code with the embedded 1-D solver has been validated against a number of spherical and cylindrical critical assemblies but these are largely water-moderated thermal systems or bare fast assemblies. Critical assemblies of simple graphite-moderated systems are rare, so validation in the HTGR spectra is not possible. The slowing down solver in COMBINE has been verified against both the MCNP and an analytic solution [Ganapol 2008] for a graphite-plutonium mixture.

\section{Schedule for Pebble Bed Cross Section Generation}

In FY 2010, final development of the COMBINE code will be completed with the

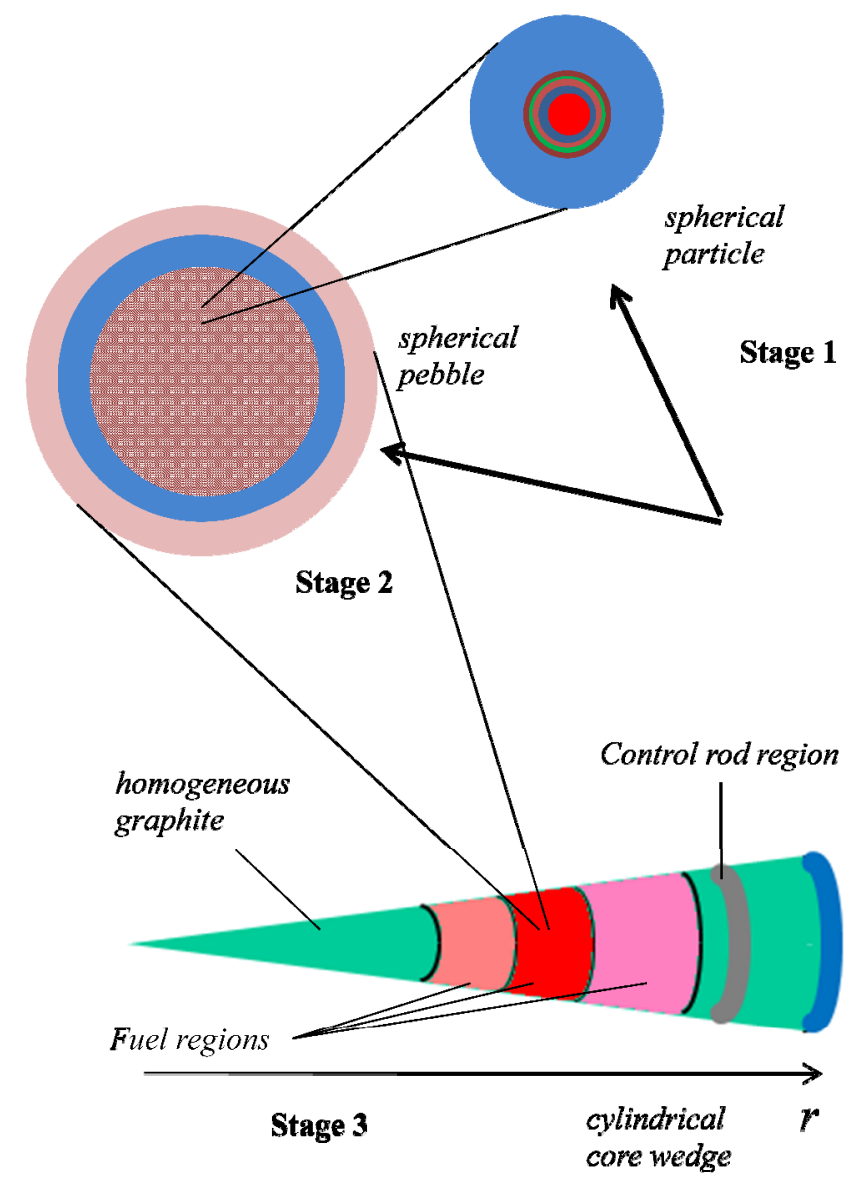

Figure 21. 3-Stage homogenization process in COMBINE. 


\begin{tabular}{|c|lll|}
\hline NEXT GENERATION NUCLEAR PLANT & Identifier: & PLN-2498 & \\
METHODS TECHNICAL & Revision: & 3 & \\
PROGRAM PLAN & Effective Date: & $12 / 21 / 10$ & Page: 45 of 84 \\
\hline
\end{tabular}

addition of an adjoint solver, editing of additional cross sections to support complex transmutation studies, and the addition of a photon transport solver to enable gamma heating calculations. The validation of the basic cross section solver is largely complete, but validation of these other modules will take an estimated two FTE and is scheduled to be completed by the end of FY 2012.

- $\quad$ FY 2011

- Complete validation of COMBINE against critical experiments (0.25 FTE)

- Complete development of adjoint solver, photon transport solver, and enhancement of output editor (0.5 FTE)

- Implement COMBINE on the multiphysics development platform (MOOSE) (0.25 FTE)

- FY 2012

- Complete testing of adjoint and photon solvers for PBR application (0.5 FTE).

Lower Fidelity, 3-D, Steady-State Whole Core Neutron Transport (Diffusion) Coupled with Whole Core Depletion and Steady-State Thermal Fluid Analysis

Like LWRs, whole core neutronic calculations for fuel cycle and safety analyses historically rely on diffusion theory with a single hexagonal block forming the node or assembly. DIF3-D [Lee 2006] has often been used because of its hexagonal geometry and burnup capability. Like most LWR diffusion codes, however, the nodal solver in DIF3-D has limited ability to capture the interspectral penetration (leakage) among blocks even with the recent addition for basic discontinuity factors. Burnable poisons and control rods pose further challenges for legacy codes. In current NGNP designs, burnable poisons are placed at some of the vertices of the hexagonal blocks (Figure 22). In the traditional LWR lattice physics approach, the effect of these poisons would be smeared across the block. Even though the effect is limited to just part of the block, it extends into the neighboring blocks, further necessitating the need for supercell lattice calculations or enhanced boundary condition specification. The optional VARIANT solver in DIF3D can treat many of these transport effects adequately and quickly enough for depletion calculations. For transient calculations, however, the computational burden of this advanced transport solver would be too high for practical simulations.

Advanced nodal diffusion methods typically employ nodal equivalence parameters (discontinuity factors) to reduce errors arising from the homogenization of such features. Surface-dependent discontinuity factors are particularly very useful to take into account geometric asymmetry in the nodal approach and, if properly formulated and computed, can also capture the leakage from adjacent blocks. Enhancement of the DIF3-D code with such factors was begun at ANL [Lee 2006] with the modification of several routines in the DIF3-D-nodal Hex-Z version of the code. It was originally thought that using surface-dependent discontinuity factors in the DIF3-D-nodal option would give good accuracy for all core configurations. This has not been the case for rodded configurations because of the relatively poor transverse leakage approximation made for the nodal option (particularly when a large hexagonal pitch is used in the code). Generally, REBUS3/DIF3-D results for the core multiplication factor and power distribution were found to be in good

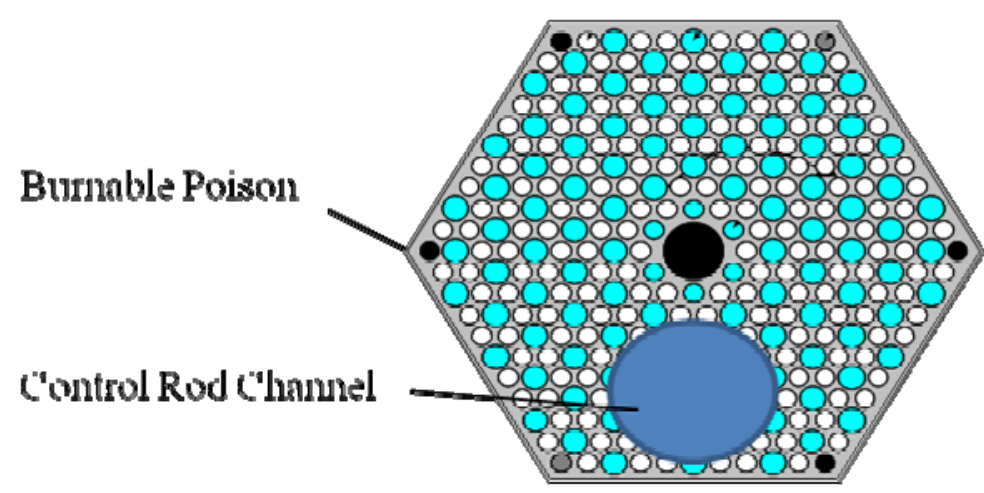

Figure 22. Absorber locations in prismatic blocks. 


\begin{tabular}{|c|c|c|}
\hline NEXT GENERATION NUCLEAR PLANT & Identifier: & PLN-2498 \\
\hline METHODS TECHNICAL & Revision: & 3 \\
\hline PROGRAM PLAN & Effective Date: & $12 / 21 / 10$ \\
\hline
\end{tabular}

agreement with MCNP results, particularly when discontinuity factors are applied. It was also shown that the DIF3-D-VARIANT option provides a better spatial solution in its diffusion approximation. It was also observed that control rod worths could be estimated within an acceptable range compared to MCNP results, but the core power tilt (particularly in the rodded zones) was not accurately modeled. It was hypothesized that this could be improved with modification to the existing methods.

Under NGNP, INL has developed a modification to the analytical Nodal Green's Function Method (NGFM) for nodal diffusion codes that explicitly treats local absorption in the nodal balance equation [Ougouag 2010]. The method requires that cross sections be generated for the absorber region in addition to the background cross sections for the block. Because the absorber is treated explicitly in the core calculation of the flux, the effect is properly represented both locally within the block and within the neighboring blocks. The new method has been implemented in the HEXPEDITE code, which employs an analytical nodal solution to the diffusion equation in hexagonal geometry. Results for a simplified HTTR benchmark [Ferrer 2010] indicate that this approach yields promising results for rodded and unrodded blocks and for burnable poisons. Comparisons to MCNP results would have to be performed to evaluate the efficacy of this approach.

\section{Burnup Analysis}

Although Monte Carlo transport codes have been coupled to burnup solvers and are used for a wide variety of depletion studies, they remain computationally too slow for whole core fuel cycle analysis if accuracy in all of the individual fuel compacts and burnable poisons is required. LWR analysis employs nodal depletion methods and uses the spatial flux profile generated from the nodal diffusion solution to simulate the depletion of fuel across the blocks. These methods are fast enough for whole core calculations with only a small loss of fidelity at the block level. A nodal depletion solver suitable for hexagonal geometry has not been developed. An accurate solver has been developed for cartesian geometry. This is available to the NGNP Project [Rajic 1987] and has been proposed as a template for a similar solver in hexagonal geometry.

Another approach is to discretize the blocks into its component regions (fuel compacts and absorbers) and solve the depletion equations for each region separately, given the local flux profile. This is computationally more intensive and would require a large parallel computer to achieve results in a practical time period. An advantage of this approach is that depletion can be performed at the n-lattice code level, provided the internodal leakages are supplied by the core calculation and properly captured in the lattice calculation.

Both approaches (nodal depletion and lattice depletion) require acceptable solutions to the spectral interpenetration (leakage) and local absorber problems to be accurate.

\section{Plan for Prismatic Whole Core Fuel Cycle Calculations}

The HEXPEDITE code with the enhanced absorber representation directly addresses the local absorber issue. The neutron leakage issue may be resolved with the development of an improved nodal boundary condition representation. HEXPEDITE has time-dependent analysis capability and is fully compatible with a nodal depletion solver such as NOMAD. HEXPEDITE, however, was not developed at INL and must be licensed. Negotiations with the code owners have begun, but so far an agreement has not materialized.

An alternate path being investigated is the use of a code recently developed at INL. INSTANT is a core analysis code that employs the $P_{n}$ approximation to the transport code with an arbitrary order $n$. Preliminary results indicate acceptable accuracy for HTGR test cases with low order scattering $\left(P_{0}\right)$ and reasonable computational times using triangles $\left(1 / 6^{\text {th }}\right.$ of a block $)$ as the basic computational element. Burnable poisons at the block vertices can be treated with minor modifications. INSTANT does not 


\begin{tabular}{|c|lll|}
\hline NEXT GENERATION NUCLEAR PLANT & Identifier: & PLN-2498 & \\
METHODS TECHNICAL & Revision: & 3 & \\
PROGRAM PLAN & Effective Date: & $12 / 21 / 10$ & Page: 47 of 84 \\
\hline
\end{tabular}

currently support transient analysis but this may be implemented in the near future. A nodal depletion solver such as NOMAD can be adapted for use with INSTANT with a proper mapping of the basic functions representing the flux. A decision will be made at the end of FY 2011 to support further development and validation of either HEXPEDITE or INSTANT for HTGR applications.

Temperature profiles of prismatic reactors can be obtained with varying degrees of fidelity with existing codes and are required for accurate core simulations. RELAP5 can provide coarse (blockaveraged) temperature profiles for kinetic core and plant simulations. The temperature reactivity feedback coefficients for RELAP5 simulations can be computed from isothermal neutronic analysis using MCNP or other available codes. Burnup analysis requires a higher level of fidelity. Local (intranodal) temperature profiles are required for accurate cross section generation for fuel compacts and burnable poisons. A higher level of fidelity can be obtained with a thermal fluid simulator such as the GAMMA (June 2008) code which models fuel blocks as a porous media and thus can generate some information about the temperature distribution within the core as well as whole core profiles. It remains to be determined if this level of fidelity is sufficient. Detailed temperature profiles can be generated with CFD calculations of blocks with explicit representation of compacts, matrix, and coolant channels. The computers and algorithms to perform such analyses are just being developed (Thomas 2010) and are not yet practical for fuel cycle calculations. They can be used, however, to verify the accuracy of profiles generated for lower order simulations and estimate bounds. Furthermore, high fidelity CFD analyses of individual blocks can generate information for coarse mesh CFD models. As with nodal methods in neutronics, high fidelity CFD models of blocks may be averaged (homogenized) to yield parameters for faster coarse mesh simulations, provided that certain global quantities are conserved. This is an area of research recently undertaken by the NGNP Project in conjunction with university partners.

For both methods, the overall accuracy of the core calculation depends upon the accuracy of the lattice calculation used to provide the cross sections. Initial testing of the HTTR startup core occurred with both HEXPEDITE and INSTANT in FY 2010. Further evaluation is planned using models of the VHTR critical experiment and, as a code comparison only, a model of the MHTGR being developed as part of a prismatic coupled core transient benchmark. This benchmark activity was initiated by INL in an effort to compare and evaluate the ability of current code packages to simulate prismatic reactor core behavior and will consist of a range of steady-state and transient exercises.

\section{Schedule for Development and Testing of Prismatic Core Fuel Cycle Analysis Capability}

- FY 2011:

- License HEXPEDITE and NOMAD codes $\left(0 \mathrm{FTE}^{\mathrm{f}}\right)$

- Develop and execute a steady-state model of the MHTGR (0.5 FTE) with HEXPEDITE and INSTANT

- Develop and execute a steady-state model of the VHTRC (0.5 FTE) with HEXPEDITE and INSTANT

- Formulate nodal depletion equations in hexagonal geometry (0.6 FTE)

- Specify the transient exercises for the prismatic core benchmark and preparation of the data sets (0.5 FTE).

- FY 2012:

- Code a nodal depletion solver and coupling to the neutronics code (1 FTE)

- Specify the transient exercises and initially testing the kinetic solver (1 FTE)

f. Negotiation between BEA and HEXPEDITE owners is not charged to NGNP. 


\begin{tabular}{|c|lll|}
\hline NEXT GENERATION NUCLEAR PLANT & Identifier: & PLN-2498 & \\
METHODS TECHNICAL & Revision: & 3 & \\
PROGRAM PLAN & Effective Date: & $12 / 21 / 10$ & Page: 48 of 84 \\
\hline
\end{tabular}

- Couple the core neutronics code with the thermal fluid code and constructing the prismatic benchmark steady-state test cases (1 FTE).

- Generate temperature reactivity feedback coefficients for BOC and EOC core conditions to support RELAP analyses (0.4 FTE)

- FY 2013:

- Simulate a prismatic core cycle with a coupled burnup/neutronics/thermal fluids calculation (1FTE)

- Verify prismatic core fuel cycle calculations against computational benchmarks and validating them against HTTR first cycle physics parameters (1 FTE).

For PBR steady-state and depletion problems (core design and fuel management), INL has developed the PEBBED code [Gougar 2010-1]. PEBBED solves the multigroup diffusion and burnup equations for recirculating pebble bed cores in which the fuel is continuously loaded and moving downward through the core during operation. Under NGNP, the COMBINE code has been modified [Gougar 2010-2] to generate accurate cross sections for PBR analysis and has been incorporated into the PEBBED code.

Figure 23 is a simplified, 6-group model of the original PBMR-268 core in which axial variations and leakage have been neglected to facilitate a direct comparison to the radial transport solution. The PBMR268 featured an inner reflector composed of flowing graphite pebbles surrounded by a fuel pebble annulus. A $30 \mathrm{~cm}$ 'mixing zone', centered at $87 \mathrm{~cm}$ from the core centerline, is predicted to be formed by the inter-mingling of graphite and fuel pebbles. The solid lines are the transport (ANISN) flux profiles and the points are generated by the PEBBED diffusion solver. The agreement is good even through the control rod region (green).

Currently, PEBBED converges directly upon the equilibrium core burnup state, i.e., the asymptotic flux and burnup profile that a PBR achieves with continuous loading and discharge of fuel. This state is achieved only after the reactor has been operating at steady-state for a considerable period of time (6 months to a few years). Because the preasymptotic operation phase will contain a significant amount of fresh fuel, there may be periods during this interim state in which the reactor attains a reactivity in excess of the equilibrium core. A regulator will likely require that this peak reactivity state be determined and used as a starting point for transient analyses. The PEBBED burnup solver therefore must be modified to treat the transition period leading up to this asymptotic state in order to provide the initial conditions for safety simulations.

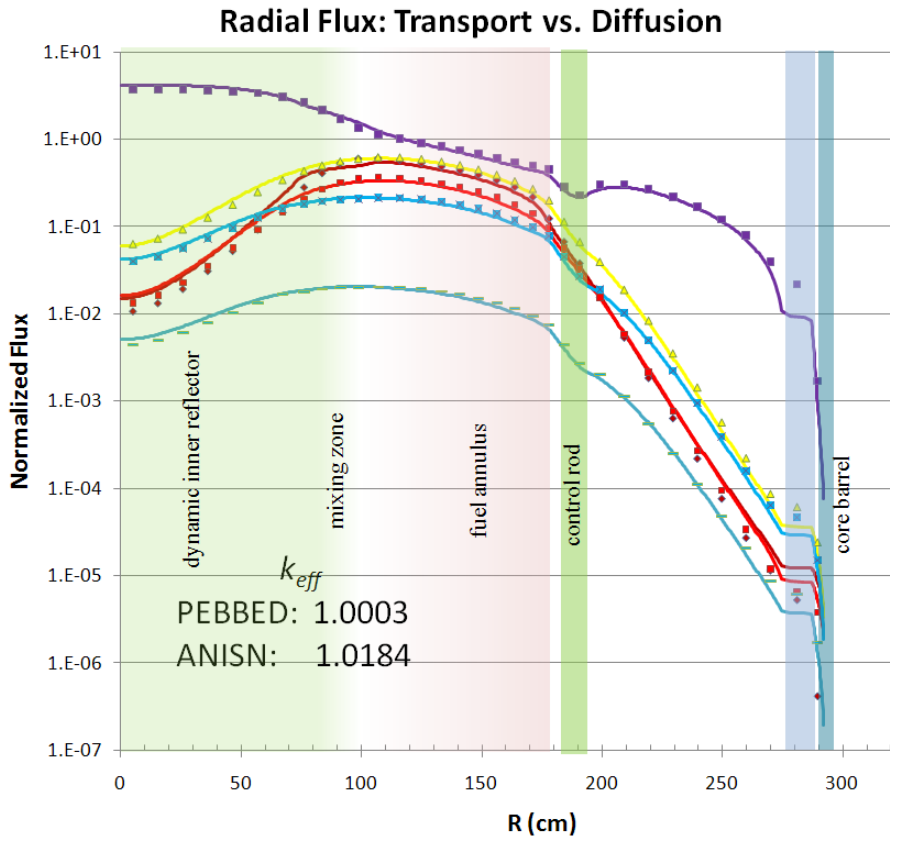

Figure 23. Radial flux profiles in the simplified PBMR-268. PEBBED's pebble flow model also assumes that the flow is strictly axial. This is adequate for benchmark evaluations and scoping studies, but actual core designs require that the pebbles move in the radial, and in some cases, the azimuthal 


\begin{tabular}{|c|lll|}
\hline NEXT GENERATION NUCLEAR PLANT & Identifier: & PLN-2498 & \\
METHODS TECHNICAL & Revision: & 3 & \\
PROGRAM PLAN & Effective Date: & $12 / 21 / 10$ & Page: 49 of 84 \\
\hline
\end{tabular}

direction toward the discharge chutes at the bottom of the vessel. Non-axial flow can be implemented along with the preasymptotic flow capability.

The PEBBED neutronics solver has been compared successfully to the results of a number of simple analytic models (verification). Results for the steady-state PBMR400 exercises of OECD Coupled Core Benchmark [Reitsma 2008] and the equilibrium cycle (E-2) problem of the IAEA CRP-5 project compare favorably to other codes [Gougar 2010-2]. The depletion solver was separately tested against (Gougar 2009) the VSOP code and compared favorably for general fuel management analysis. An improved solver would have to be implemented if detailed analysis of higher actinide buildup is desired. None of these tests can be considered a validation of the code as no experimental data was used. PEBBED was used to model Core 4.2 of the Proteus pebble bed critical facility [Gougar 2010-3]. The eigenvalue was in error by about $1.5 \% \delta \mathrm{k} / \mathrm{k}$. Most of the error has been traced to the method in which the diffusion coefficients are calculated in COMBINE and the development of a more accurate method is a task in FY 2011.

The PEBBED solver currently employs a finite difference solution to the diffusion equation which is adequate for 2-D (R-Z) core analysis but is too slow for 3-D core models. Improved accuracy and speed may be achieved with a nodal diffusion solver which would allow a much coarser mesh to be used with no loss of fidelity. An analytical nodal solver in cylindrical geometry was formulated by Ougouag [Ougouag 2001] and partially implemented in PEBBED. To complete implementation, the terms of the radial source expansion must be derived from complex transcendental basis functions and be cast in a computationally tractable form. This work consists of a tedious process that was started in FY 2010 and are continuing in FY 2011. The same problems used for V\&V of the finite difference solver can be used to test the nodal solution.

PEBBED is also coupled to the THERMIX-KONVEK thermal fluid analysis code developed for the German HTR program [Reitsma 2005]. THERMIX-KONVEK solves the solid heat conduction and steady-state gas dynamics equations in 2-D (R-Z) and possesses correlations and other capabilities specifically suited for PBR analysis. Detailed PBR analysis in which control rods are modeled explicitly will require a 3-D solver. The task of upgrading THERMIX-KONVEK to 3-D and modern FORTRAN 90 code standards was begun in FY 2011.

A complete validation of the PEBBED fuel management capability is not possible because no experimental data exist against which the combined diffusion, burnup, and pebble mixing scheme can be compared. The individual modules within PEBBED, however, can be verified analytically and against simple experimental and computational benchmarks.

\section{Schedule for Development and Testing of Pebble Bed Fuel Cycle Calculations}

- FY 2011:

- Begin upgrade of THERMIX-KONVEK to support 3-D PBR fuel cycle analysis (0.3 FTE)

- Final validation of the PEBBED diffusion solver against the Proteus critical experiment using an improved COMBINE treatment of diffusion coefficients and transverse buckling (0.5 FTE)

- Complete the radial source term expansion for the cylindrical nodal diffusion solver (0.5 FTE)

- FY 2012:

- Complete upgrade of THERMIX-KONVEK to support 3-D PBR fuel cycle analysis (.5 FTE)

- Begin modifications of PEBBED to treat preasymptotic (nonequilibrium) core burnup states and radial pebble flow (0.5 FTE)

- FY 2013: 


\begin{tabular}{|c|lll|}
\hline NEXT GENERATION NUCLEAR PLANT & Identifier: & PLN-2498 & \\
METHODS TECHNICAL & Revision: & 3 & \\
PROGRAM PLAN & Effective Date: & $12 / 21 / 10$ & Page: 50 of 84 \\
\hline
\end{tabular}

- Complete and test modifications of PEBBED to treat pre-asymptotic (non-equilibrium) core burnup states (1.0 FTE)

- Verify PEBBED fuel cycle calculations against computational benchmarks (1 FTE).

Lower Fidelity, 3-D, Time-dependent Whole Core Neutron Transport (Diffusion) Coupled with Time-Dependent Thermal Fluid Analysis

For transient calculations, one also requires an accurate yet fast neutronic solver. As mentioned above, the DIF3-D-nodal solver, which uses the nodal expansion method to treat transverse leakage terms, is not sufficiently accurate, but it does run fast enough to be included in a transient core simulator. The more accurate DIF3-D-VARIANT nodal transport solver, on the other hand, is too slow to be practical for many HTGR transients. The NGFM solver in HEXPEDITE retains the accuracy of DIF3-DVARIANT and the speed of DIF3-D-nodal. Table 4 shows the results of a comparison between HEXPEDITE and the different solvers available in DIF3-D (nodal diffusion, fine mesh finite difference diffusion, and nodal transport) for a simplified HTTR benchmark with all control rods inserted.

Table 4. Comparison of $\boldsymbol{k}_{\text {eff }}$ and runtimes for HEXPEDITE and various DIF3-D solvers.

\begin{tabular}{llccc}
\hline \multicolumn{1}{c}{ Code } & \multicolumn{1}{c}{ Method } & \multicolumn{1}{c}{$\begin{array}{c}\text { Deviation from } \\
\text { Reference } \\
\mathbf{( \% )}[\mathbf{k} / \mathbf{k})\end{array}$} & Runtime [sec] \\
\hline HEXPEDITE & NGFM & 0.87130 & 0.11 & 0.8 \\
DIF3-D & NEM & 0.86384 & -0.63 & 1.8 \\
DIF3-D & Fine Mesh FD & 0.87139 & 0.12 & 1,250 \\
DIF3-D & Nodal Transport & 0.87017 & - & 380 \\
\hline
\end{tabular}

HEXPEDITE yielded a core eigenvalue similar to the fine mesh diffusion and nodal transport solutions of DIF3-D but with runtime comparable to DIF3-D-nodal. For this reason, the time-dependent HEXPEDITE solver is undergoing testing for use in transient analysis. A matching depletion solver is being developed that would use the hexagonal nodal flux solution generated by HEXPEDITE to accurately predict compact powers during burnup analyses.

Both normal (load follow) and off-normal transients such as recuperator bypass (cold He injection) or inadvertent rod withdrawal can place considerable stresses on fuel and structural materials. More importantly, these reactors rely on Doppler feedback rather than control rods to shut down the fission reaction in the event of a significant reactivity insertion. An accident analysis must involve coupled, timedependent diffusion and thermal fluid analysis in order to capture and bound all anticipated transient phenomena. For rod adjustments and some thermal initiators, simple temperature feedback coefficients can be estimated from stand-alone neutronics analyses and used in system codes with simple point kinetics solvers. These are relatively fast and reasonably accurate if the reactivity insertion is small.

For the larger reactivity events listed above, spatial effects can be considerable and result in unacceptable local fuel stresses or xenon oscillations. In these cases, fully coupled 3-D neutronics/thermal fluid analysis is required. These are computationally intensive and can take days to complete, even for a simple reactivity simulation. Coarse mesh nodal solvers, such as HEXPEDITE, relieve the computational burden by solving the diffusion equation in a higher fidelity form but over a much coarser mesh. Nonetheless, the solver must be very efficient as the system of equations must be solved at each time step. Time steps may be a short, at milliseconds, earlier in the transient but lengthen to minutes later on.

Likewise the thermal fluid solver must be similarly efficient and detailed in order to capture the thermal feedback effects that dominate these transients. The GAMMA thermal fluid solver may be 


\begin{tabular}{|c|lll|}
\hline NEXT GENERATION NUCLEAR PLANT & Identifier: & PLN-2498 & \\
METHODS TECHNICAL & Revision: & 3 & \\
PROGRAM PLAN & Effective Date: & $12 / 21 / 10$ & Page: 51 of 84 \\
\hline
\end{tabular}

adequate for this task but that remains to be determined. GAMMA was developed in a joint INERI effort by the INL and the Korean Advanced Institute for Science and Technology (KAIST). It is a systems analysis code with specific abilities to model air ingress and graphite oxidation. If GAMMA is deemed to be inadequate, a porous medium thermal fluid solver will be developed on the MOOSE platform (to be discussed in the next section) and coupled to the neutronic solver, The solver in RELAP5 is adequate for plant simulations in which detailed fuel and coolant behavior is not required. The time-dependent version of the HEXPEDITE or INSTANT solvers must be incorporated into the RELAP5 code package to achieve this capability.

\section{Schedule for Prismatic Core Transient Calculations}

- FY 2011:

- Complete preliminary testing of the HEXPEDITE time-dependent solver (0.3 FTE)

- Complete development and preliminary testing of the INSTANT kinetic solver (0 FTE $\left.{ }^{\mathrm{g}}\right)$

- Assess the GAMMA code for transient thermal fluid analysis (0.3 FTE)

- FY 2012:

- Couple the GAMMA (or equivalent) solver with the neutronic solver (1 FTE)

- FY 2013:

- Execute the transient exercises in the Prismatic Coupled Code Transient Benchmark (0.5 FTE).

- Perform V\&V of the prismatic core transient calculations against computational benchmarks and the HTTR safety tests (2 FTE).

Concurrently with PEBBED development, the CYNOD kinetic solver was developed to support PBR transient analysis. Using the same partially developed cylindrical nodal diffusion solver implemented in PEBBED, CYNOD has been recently upgraded to support 3-D analyses [NGNP 2010-2]. The treatment of control rods in transient simulations is more complicated because the simple treatment of the control absorber in a computational node leads to nonphysical cusping of power ramps. For this reason, a more sophisticated approach that uses 3-D response functions is being developed in conjunction with Georgia Tech. These response functions are computed using high fidelity transport codes but are integrated seamlessly in the nodal diffusion core simulator for fast yet accurate reactivity simulation [NGNP 2010-1]. The modifications were completed in FY 2010 and testing is to be completed in FY 2011.

Temperature feedback in these calculations requires coupling of the CYNOD solver with an efficient thermal fluid solver such as RELAP5 or THERMIX-KONVEK. RELAP5 has the advantage of being a world standard for system analyses codes. The coupling of CYNOD to RELAP5 was completed in early FY 2010 and demonstrated on a PBMR400 Transient Benchmark problem. The coupling was observed to be quite inefficient, and more optimization is required to make it suitable for NGNP analyses. The THERMIX-KONVEK code is a legacy PBR thermal fluid solver developed in Germany. For higher fidelity xenon feedback transients, a porous medium thermal fluid solver such as THERMIX-KONVEK is required. Detailed CFD calculations of pebble beds are both too computationally intensive for practical analysis and unnecessary for describing whole core PBR gas dynamics and heat transfer.

\section{Schedule for Pebble Bed Core Transient Calculations}

- FY 2011:

- Complete 3-D testing of the response function treatment for control rods $(0.3 \mathrm{FTE})$

- FY 2012:

g. Being conducted under LDRD funding. 


\begin{tabular}{|c|lll|}
\hline NEXT GENERATION NUCLEAR PLANT & Identifier: & PLN-2498 & \\
METHODS TECHNICAL & Revision: & 3 & \\
PROGRAM PLAN & Effective Date: & $12 / 21 / 10$ & Page: 52 of 84 \\
\hline
\end{tabular}

- Upgrade the 3-D THERMIX-KONVEK solver to solve time-dependent gas dynamics problems (1 FTE).

- FY 2013:

- Execute of the transient exercises in the Pebble Bed Couple Code Transient Benchmark (1 FTE)

- Perform V\&V of the pebble bed core transient calculations against computational benchmarks and the HTR-10 safety tests (2 FTE).

\section{Meso/Microscale Fuel Temperature, Energy Deposition, and Stress Analysis Coupled to Core Transient Simulation}

The ability of the HTGR to shut itself down after a reactivity event is a consequence of Doppler broadening of neutron capture resonances in U-238 and is strongly dependent upon the geometry and temperature of the fuel. Low-order thermal fluid analyses contain pebble models in which the heavy metal is homogeneously mixed with the graphite rather than lumped into kernels. The temperature of the mixture near the center of the pebble is taken as the temperature of the fuel. This is a reasonable assumption for steady-state analysis but leads to considerable error in transient calculations. In FY 2009 and FY 2010, the fuel temperature model in the THERMIX code was modified to compute the kernel temperature during a reactivity transient [Ortensi 2009]. The new fuel temperature model was verified against an analytical solution and yielded better agreement than a comparable computational model using the HEATING code (Childs 2007).

The new model was incorporated into the THERMIX code for core transient analysis. The effect on the predicted trajectory of a rod ejection event is shown in Figure 24. Three fuel temperature models were tested with the time-dependent heterogeneous (TDHe) fuel model yielding a better prediction of the physical behavior of the core as compared to quasistatic homogeneous (QSHo) and heterogeneous fuel (QWHe) models. This model will be incorporated into the time-dependent thermal fluid solver to be used for both PBR and prismatic reactor core analysis. Results will be compared to transient data in the HTTR and HTR-10 when this data becomes available.

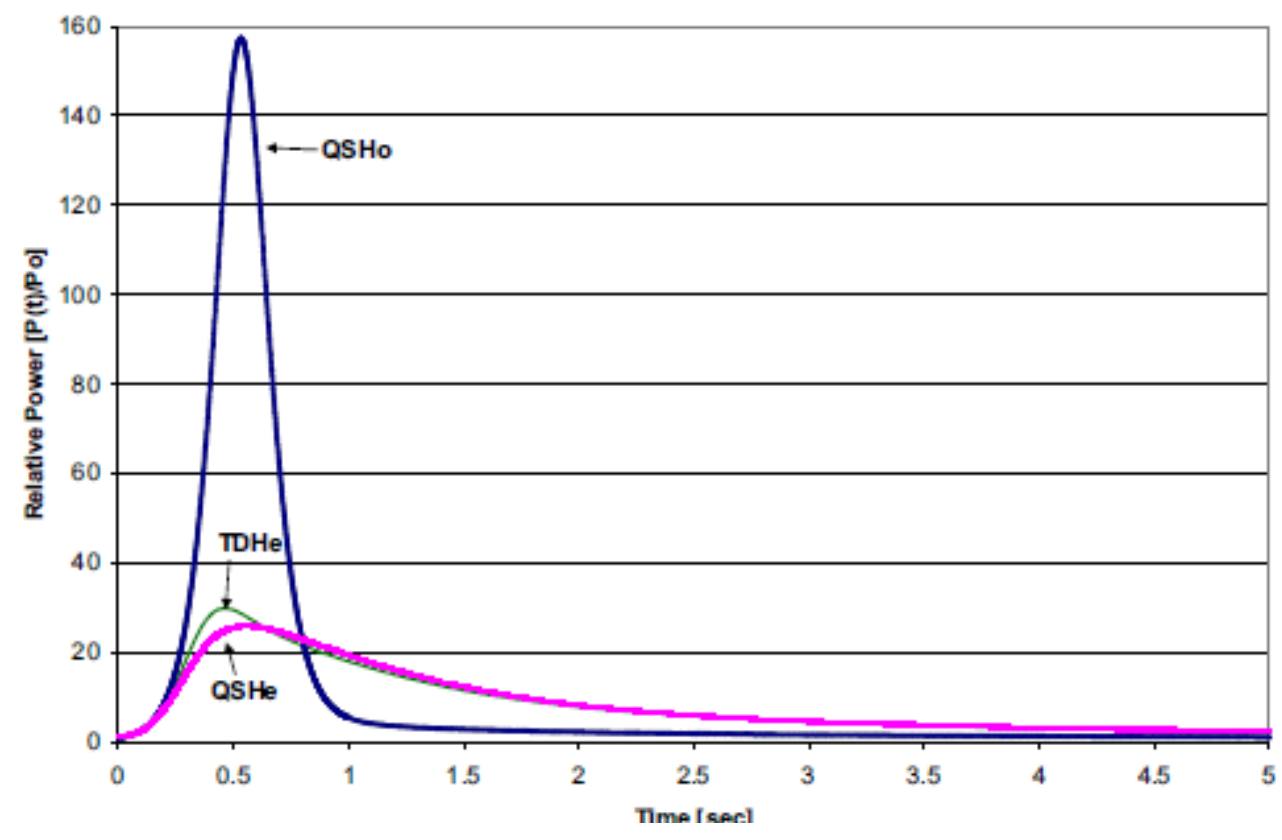

Figure 24. Comparison of core power (normalized to steady state) assuming three different fuel temeprature models in CYNOD-THERMIX. 


\begin{tabular}{|c|lll|}
\hline NEXT GENERATION NUCLEAR PLANT & Identifier: & PLN-2498 & \\
METHODS TECHNICAL & Revision: & 3 & \\
PROGRAM PLAN & Effective Date: & $12 / 21 / 10$ & Page: 53 of 84 \\
\hline
\end{tabular}

The integrity of the TRISO pressure boundary is assaulted during the reactivity and thermal transients of normal power ramps and accident trajectories. INL has developed the PArticle STress Analysis (PASTA) code for computing the mechanical stress on the TRISO boundaries as a function of temperature, gas pressure, and other factors [Boer 2010]. Under the Deep Burn Project, PASTA was coupled to PEBBED to compute the fuel durability of particles in a typical PBMR400 pebble during its life in the core and in transmutation particles in a deep burn pebble. Figure 25 shows the history of temperature and layer stresses in normal $\mathrm{UO}_{2}$ and Deep Burn $(\mathrm{Pu})$ fuel as the respective pebbles circulate through the core. Although development of PASTA is no longer supported by Deep Burn, under the NGNP Methods plan it will be coupled to the CYNOD-THERMIX core simulation code to simulate the stresses on pebble bed fuel during various power ramps under normal and accident conditions. PASTA will also be coupled to the time-dependent prismatic core simulator (HEXPEDITE or INSTANT).

As with PARFUME, PASTA solves the stress equations for the particle layers. PARFUME solves the equations in three dimensions and implements sophisticated statistical treatments to account for the uncertainty in fuel performance parameters. This makes PARFUME to cumbersome to be coupled to core physics codes. PASTA runs much faster and thus can be used with first order accuracy to investigate the effects of different core power and temperature histories on HTGR fuel. In this manner, PASTA complements, rather than duplicates, the higher fidelity PARFUME code being developed under the fuel qualification program.
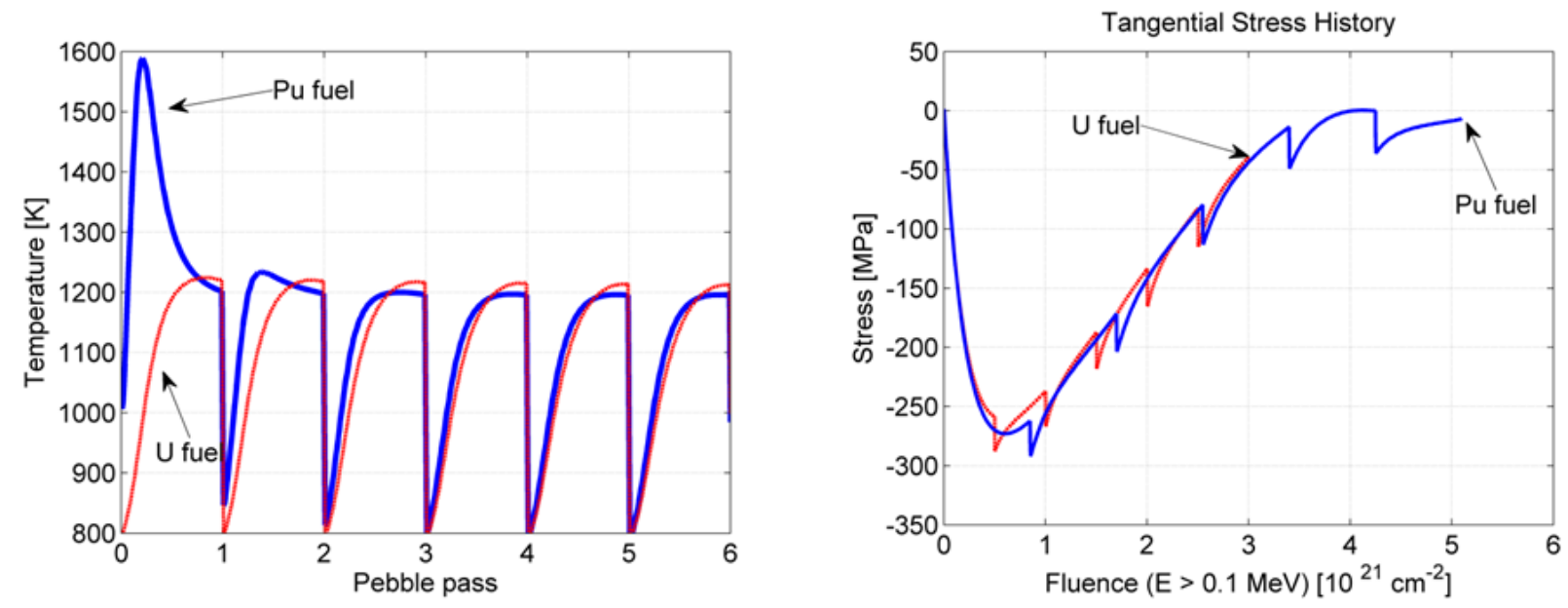

Figure 25. Comparison of the temperature and stress histories of $\mathrm{UO}_{2}$ and deep burn pebbles.

\section{Schedule for Coupling Fuel Performance and Core Simulations}

- FY 2011:

- Complete evaluation of particle stress in pebble Bed Deep Burn core (0 FTE $)$

- FY 2012:

- Incorporate fuel particle temperature model in PBR and prismatic thermal fluid solver (1.5 FTE)

- FY 2013:

- Evaluate particle fuel performance during PBR reactivity insertions (1 FTE).

Pebble Bed Dynamics and Pebble Flow Simulation

h. Supported by the Deep Burn Project. 


\begin{tabular}{|c|lll|}
\hline NEXT GENERATION NUCLEAR PLANT & Identifier: & PLN-2498 & \\
METHODS TECHNICAL & Revision: & 3 & \\
PROGRAM PLAN & Effective Date: & $12 / 21 / 10$ & Page: 54 of 84 \\
\hline
\end{tabular}

The accurate computation of burnup in the pebble bed requires knowledge of the direction and speed of the pebble flow. INL has developed the PEBBLES code [Cogliati 2010], which simulates the mechanics of flowing pebbles. PEBBLES has been used to simulate the loading and pebble flow in the PBMR400, but the simulation takes too long to support practical core design calculations. Progress in parallelizing the code was made in FY 2010 to support future burnup analyses using PEBBED. PEBBED currently assumes pebble flow profiles obtained empirically from literature sources.

The PEBBLES code also has other uses; it was used to simulate the densification of the pebble bed during an earthquake [Ougouag 2007]. The result was fed into a CYNOD-THERMIX simulation to estimate the reactivity effect of shaking the vessel. The effect was shown to be measurable but not significant in terms of core safety [Ougouag 2008]. Figure 26 shows the settling of the top loading cones (the conical stacks of pebbles that form under the loading tubes) in the PBMR400 during an earthquake, while the plot in Figure 27 shows the power response of the core.

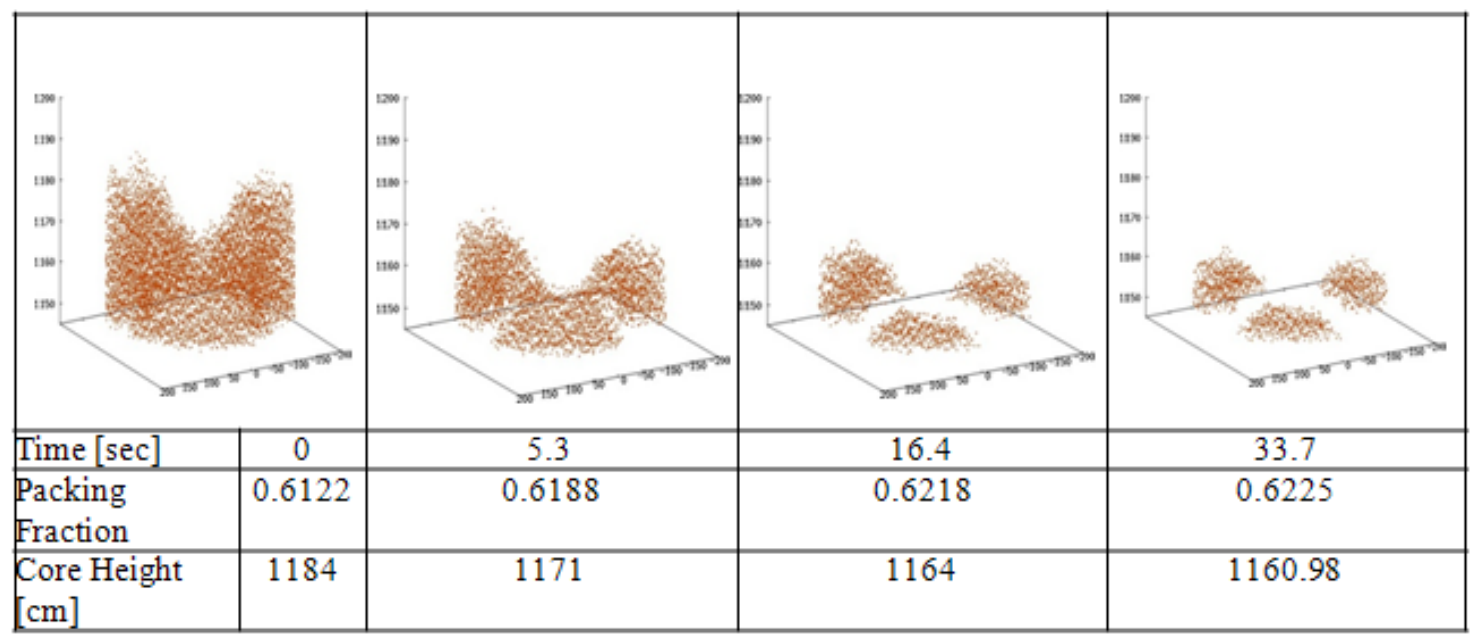

Figure 26. Snapshots of PBR loading cones during an earthquake as simulated using PEBBLES. 


\begin{tabular}{|c|lll|}
\hline NEXT GENERATION NUCLEAR PLANT & Identifier: & PLN-2498 & \\
METHODS TECHNICAL & Revision: & 3 & \\
PROGRAM PLAN & Effective Date: & $12 / 21 / 10$ & Page: 55 of 84 \\
\hline
\end{tabular}

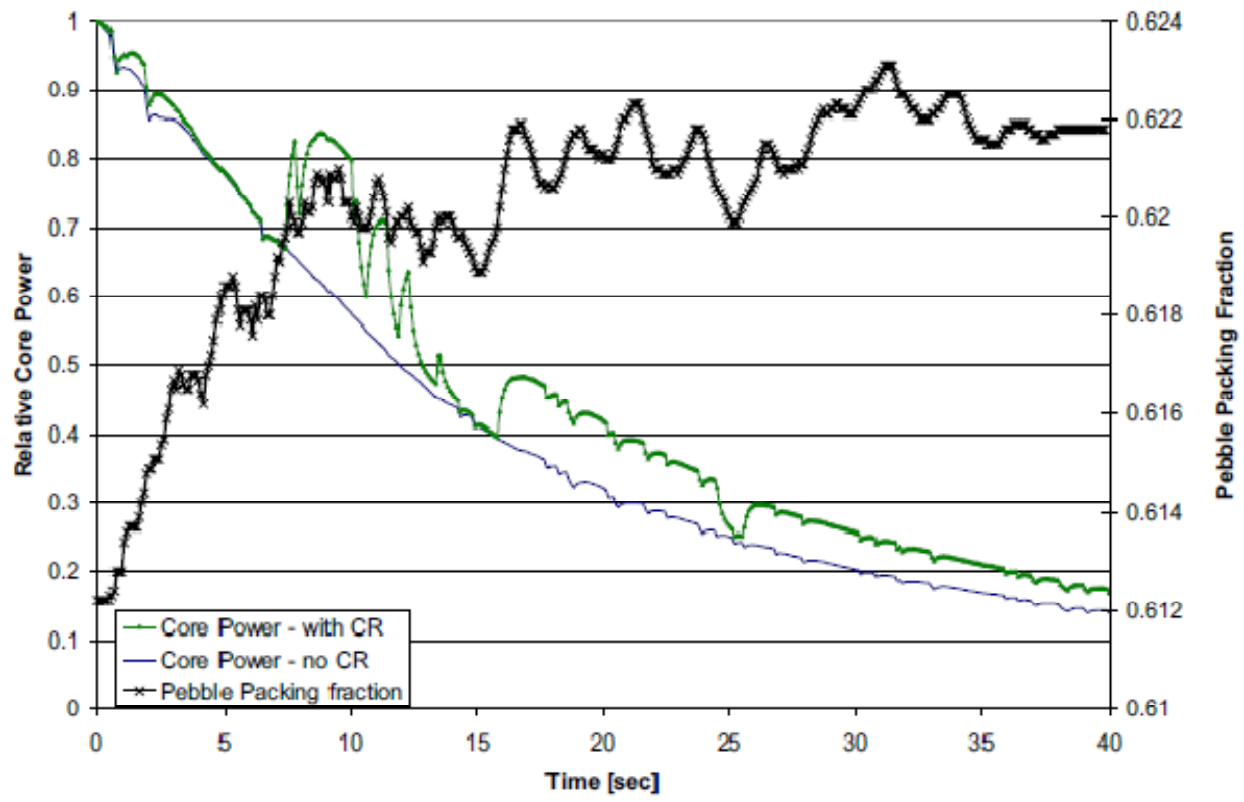

Figure 27. Core power trajectory and pebble packing fraction during an earthquake.

Modifications to the PEBBLES code commenced in FY 2010 to support analysis of dust generation [Cogliati 2008]. Friction and wear correlations were being added to the governing equations to predict the creation of dust in the primary. Limited data exist for validating pebble flow models but measured residence times for pebbles flowing through the AVR will be examined. Data on pebble graphite wear coefficients and friction factors will be generated as part of graphite research sponsored by DOE's NEUP program at the Universities of Missouri and Idaho.

\section{Schedule for Modeling Pebble Mechanics and Dust Production}

- FY 2011:

- Complete modifications to the PEBBLES code to model AVR pebble flow (0.25 FTE)

- The Department of Energy is scheduled to choose an NGNP preliminary design in 2011. If the design is chosen to be a PBR, or if a decision is not made, but the work can be carried out at a university under NEUP the following tasks will be performed.

- FY 2012:

- Validate friction factors and other pebble mechanical properties with experimental data. (0.5 FTE)

- Construct a pebble flow model in AVR (1FTE)

- FY 2013:

- Construct and execute a PEBBED neutronic/thermal fluid model of AVR using pebble flow profiles generated with PEBBLES (1 FTE). 


\begin{tabular}{|c|lll|}
\hline NEXT GENERATION NUCLEAR PLANT & Identifier: & PLN-2498 & \\
METHODS TECHNICAL & Revision: & 3 & \\
PROGRAM PLAN & Effective Date: & $12 / 21 / 10$ & Page: 56 of 84 \\
\hline
\end{tabular}

\section{Multicomponent Fluid Transport}

\section{Dust generation, Transport, and Fission Product Interaction}

Dust is of interest to HTGR regulators because it is a unique vector for fission product transport in and out of the system. Certain fission product species react with, or agglomerate on, dust particles that can accumulate in various regions of the primary loop. During a break in the primary, the contaminated dust can undergo 'liftoff' and be transported into the reactor building, posing an exposure and cleanup risk. In a vented confinement system, the performance of HEPA filters in capturing the dust during the postprimary break venting event becomes particularly important. Water ingress accidents are also compounded by dust as the water tends to wash out dust deposits and transport them to other exposed regions.

Dust appears to be an issue primarily in the PBR concept. The semi-continuous movement of pebbles against each other and the reflector walls results in a continuous buildup of dust in the primary loop. About $4 \mathrm{~kg}$ of dust per year were estimated to have been generated in the AVR during operation [Fachinger 2008]. In contrast, very little dust has been detected in the 10 years of prismatic HTTR operation. The little dust that was detected appears to have originated from the graphite seals used in the primary circulators.

The MELCOR code [Gauntt 2000] has been used by the NRC to model fission product transport in LWRs. With some modifications already underway at Sandia, MELCOR can also be used for fission product and dust transport in HTGRs. The exact nature of dust and fission product interactions is only partially understood, and there is limited data with which to validate interactions and transport models. Complimentary simulations of fission product transport through and out of the primary system, including the interactions with dust, will be conducted using a system code such as MELCOR. As such codes were not originally designed to model dust, some modifications and experimental validation will have to be performed. A plan is being developed in FY 2010 and FY 2011 to identify gaps in the ability to model HTGR fission product and dust transport and will address such issues as liftoff and deposition, dust and fission product chemistry, and multicomponent fission product transport within the reactor buildings. There are large uncertainties attached to these processes so initial efforts will focus on sensitivity studies that will highlight areas where limited resources should be focused. INL has developed a version of MELCOR that specifically addresses dust behavior in fusion reactors. Recently INL and Sandia MELCOR teams met to share the features of their versions and work on a joint development effort.

The Dutch firm NRG has developed a similar dust and modeling capability in their SPECTRA code as part of a broader HTGR modeling effort (Kuijper 2002). Discussions with NRG personnel have been initiated.

Upon completion of the Dust Issues Resolution Plan in FY 2011 and the selection of an NGNP reference design, this TPP will be updated with an outline of the needed research. If the prismatic core concept is chosen for NGNP, dust research and modeling will be given a much lower priority.

\section{Water Ingress}

Water ingress is the subject of a preliminary PIRT exercise to be conducted in FY 2011 in conjunction with NGNP Engineering. The purpose of that activity is to identify the systems, processes, and physics of water ingress which have a significant impact on safety or for which there are considerable uncertainties. CFD analyses may be prescribed as a result of that effort. Water ingress is also addressed here because of its impact on core reactivity. Water is both a moderator and a poison whose addition into the primary coolant will result in either positive or negativity reactivity insertion depending upon the carbon: heavy metal ratio in the fuel and the concentration of the water. Figure 28 shows the reactivity of 


\begin{tabular}{|c|lll|}
\hline NEXT GENERATION NUCLEAR PLANT & Identifier: & PLN-2498 & \\
METHODS TECHNICAL & Revision: & 3 & \\
PROGRAM PLAN & Effective Date: & $12 / 21 / 10$ & Page: 57 of 84 \\
\hline
\end{tabular}

a PBR core at burnup equilibrium as a function of the density of water in the coolant, as computed using PEBBED.

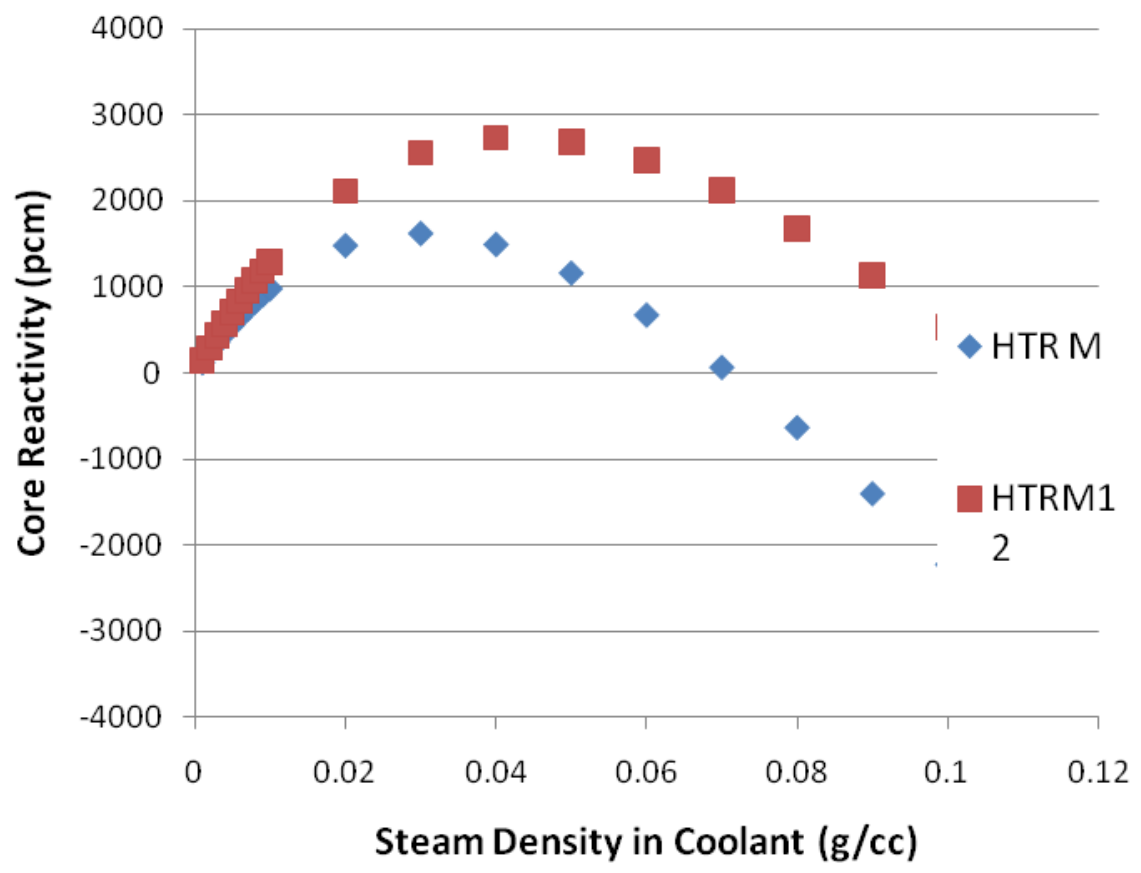

Figure 28. Core reactivity as a function of steam density.

The lower curve is for the 200 MW HTR Modul PBR designed in Germany, now being considered for the NGNP. The fuel is $7.8 \%$ enriched uranium with 7 grams of heavy metal in each fresh pebble. The upper curve is the same core configuration and heavy metal loading, but the fuel is the $14 \%$ enriched UCO being qualified under the AGR fuel program. The heavy metal content of the HTR Module fuel was deliberately limited by the ability of the control rods to counteract the reactivity worth of the steam. In the prismatic core, this reactivity can be limited by burnable poisons and the other measures proposed for holding down excess reactivity. If the AGR fuel is used in a pebble bed concept, the heavy metal loading would need to be reduced to limit the reactivity consequences of water ingress.

The actual response of an HTGR to a water ingress event is a complex function of water inventory and transport from the steam generator and plant response to the system pressure increase. A transient core simulation would have to include additional components of the primary loop to capture these effects and characterize the event.

\section{Schedule for Multicomponent Fluid Modeling}

- FY 2011:

- Complete modifications to the MELCOR code to treat dust liftoff and suspension and compare to SPECTRA results (0.5 FTE)

- Complete the Dust Issues Resolution Plan (0.5 FTE)

- Complete a preliminary PIRT exercise to identify issues and actions for further water ingress research (0.5 FTE)

- DOE: choose an NGNP preliminary design in 2011. If the design is a PBR, the following tasks will be performed. 


\begin{tabular}{|c|lll|}
\hline NEXT GENERATION NUCLEAR PLANT & Identifier: & PLN-2498 & \\
METHODS TECHNICAL & Revision: & 3 & \\
PROGRAM PLAN & Effective Date: & $12 / 21 / 10$ & Page: 58 of 84 \\
\hline
\end{tabular}

- FY 2012:

- Perform sensitivity studies on MELCOR to identify areas of research focus and experimental support (0.5 FTE)

- FY 2013:

- Apply MELCOR to a PBR primary break event with confinement venting (1.0 FTE).

\section{Uncertainty and Sensitivity Analysis}

Quantification of the uncertainties in computed core physics parameters that result from propagation of uncertainties in the underlying nuclear data and other input parameters used in the various modeling codes is a key component of the QA process for reactor physics modeling and simulation. It is also an important mechanism for quantifying the need for additional nuclear cross-section measurements and/or integral evaluations for HTGRs and as a guide in planning of future integral measurements and evaluations. Mathematically rigorous sensitivity and uncertainty analysis based on perturbation theory can, for example, be used to identify nuclides that contribute to calculational uncertainties and to quantify the propagated uncertainties in the context of the currently anticipated NGNP core designs. Sensitivity coefficients are calculated by generalized perturbation theory codes and folded with multigroup covariance data (where available) to derive propagated uncertainties in computed integral reactor parameters arising from the nuclear data. Integral parameters to evaluate include reactivity, peak power, reaction rate ratios, nuclide inventory, and safety coefficients. The impact of cross-section data uncertainty on the accuracy of each parameter is evaluated, along with the identification of nuclides, cross-section types, and energy ranges that have the greatest impacts on the accuracy of integral parameters. The process can also be used to rigorously quantify whether a given existing integral benchmark experiment is sufficiently similar to a contemplated NGNP system design to be of significant utility for validation of computations for the system being designed.

These rigorous perturbation techniques can be applied to neutronics calculations because the adjoint of the governing transport equation is available and can be manipulated numerically on a computer. The corresponding adjoint for the thermal fluid system of equations is a subject of research. Variational theory therefore cannot yet be applied to the coupled core simulation problem, causing reliance on forward sensitivity techniques. In this approach, input parameters are manipulated in a stochastic manner over their known and estimated range of variability. The effect on output parameters is computed and statistically correlated to the inputs to obtain sensitivity coefficients. Uncertainty bounds and confidence intervals can be obtained for key safety and performance parameters. The NRC has recognized a process of obtaining such parameters (the Code Scaling, Applicability, and Uncertainty method) and has accepted uncertainty analyses for both boiling water reactor and pressurized water reactor large break LOCAs. Although considerable R\&D is being expended in this area, the methods are still considered developmental. A very limited number of computer codes are available for performing such analyses, one of which is the Software for Sensitivity and Uncertainty Analysis (SUSA) code developed by the GRS (Gesellschaft für Anlagen und Reaktorsicherheit) company of Germany. SUSA envelopes the user's analysis code, manipulates the user-supplied input parameters over the specified ranges, executes the minimum number of runs to generate a certain confidence value in the output uncertainty, and computes and ranks the output sensitivities. This software has been acquired by the NGNP Project and is being evaluated.

To date, the SUSA software has been applied mainly to core thermal fluid simulations such as boiling water reactor large break LOCA analysis and, in a preliminary investigation, to the calculation of uncertainty in peak fuel temperature in the PBMR400 after a large pipe break [Strydom 2010]. Figure 29 shows the assumed distribution in the core thermal power and the inlet temperature (top) and the effects of these on the peak fuel temperature attained while the core cools off. The reactor power was assumed to 


\begin{tabular}{|c|lll|}
\hline NEXT GENERATION NUCLEAR PLANT & Identifier: & PLN-2498 & \\
METHODS TECHNICAL & Revision: & 3 & \\
PROGRAM PLAN & Effective Date: & $12 / 21 / 10$ & Page: 59 of 84 \\
\hline
\end{tabular}

vary with a Gaussian distribution between 360 and $440 \mathrm{MWt}$, while the inlet temperature was varied similarly between 480 and $520^{\circ} \mathrm{C}$. Figure 29 shows the trajectory of the peak fuel temperature after shutdown for a selection of the 93 cases sampled.
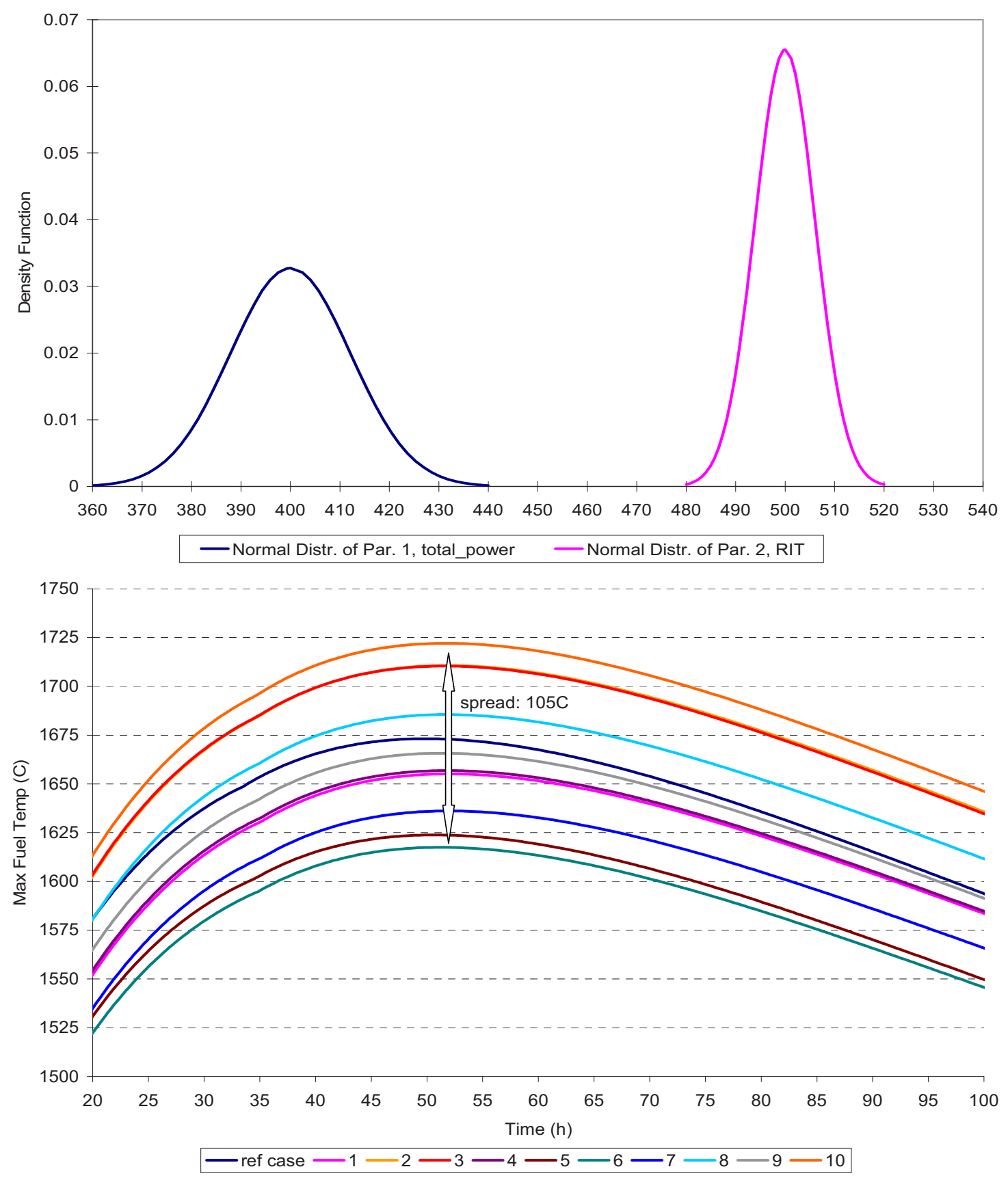

Figure 29. Input and results from a PEBBED analysis of Peak temperature during a PBMR400 depressurized conduction cooldown: distributions of core power and inlet temperature (top); distribution in peak fuel temperature (bottom). 


\begin{tabular}{|c|c|c|}
\hline NEXT GENERATION NUCLEAR PLANT & Identifier: & PLN-2498 \\
\hline METHODS TECHNICAL & Revision: & 3 \\
\hline PROGRAM PLAN & Effective Date: & $12 / 21 / 10$ \\
\hline
\end{tabular}

The nature of the tool, however, allows it to be applied to the analysis of any parameters for which a computational model can be constructed. SUSA can be applied to fission product transport models (e.g., MELCOR), fuel performance models (e.g., PARFUME), tritium migration (TPAC), etc.

The ultimate value of the uncertainty analysis capability may be in influencing design decisions early in the process. There are numerous flow and heat transfer unknowns, material properties, behavior under irradiation, manufacturing tolerances, and stochastic phenomena that feed into the overall uncertainty in various safety and performance parameters. A comprehensive effort to reduce all possible uncertainties in an effort to minimize margins would consume more resources than are available to the project. Instead, the SUSA tool can be applied to the evaluation model to compute and rank the sensitivity of a plant safety or performance parameter to any of a number of design and material inputs as shown in Figure 30. Those parameters found to have a significant impact on margin could become the focus of further experimental investigation, or provoke design changes by the vendor in the preliminary design phase. The remaining inputs could be neglected and their uncertainties safely subsumed into to overall safety margin.

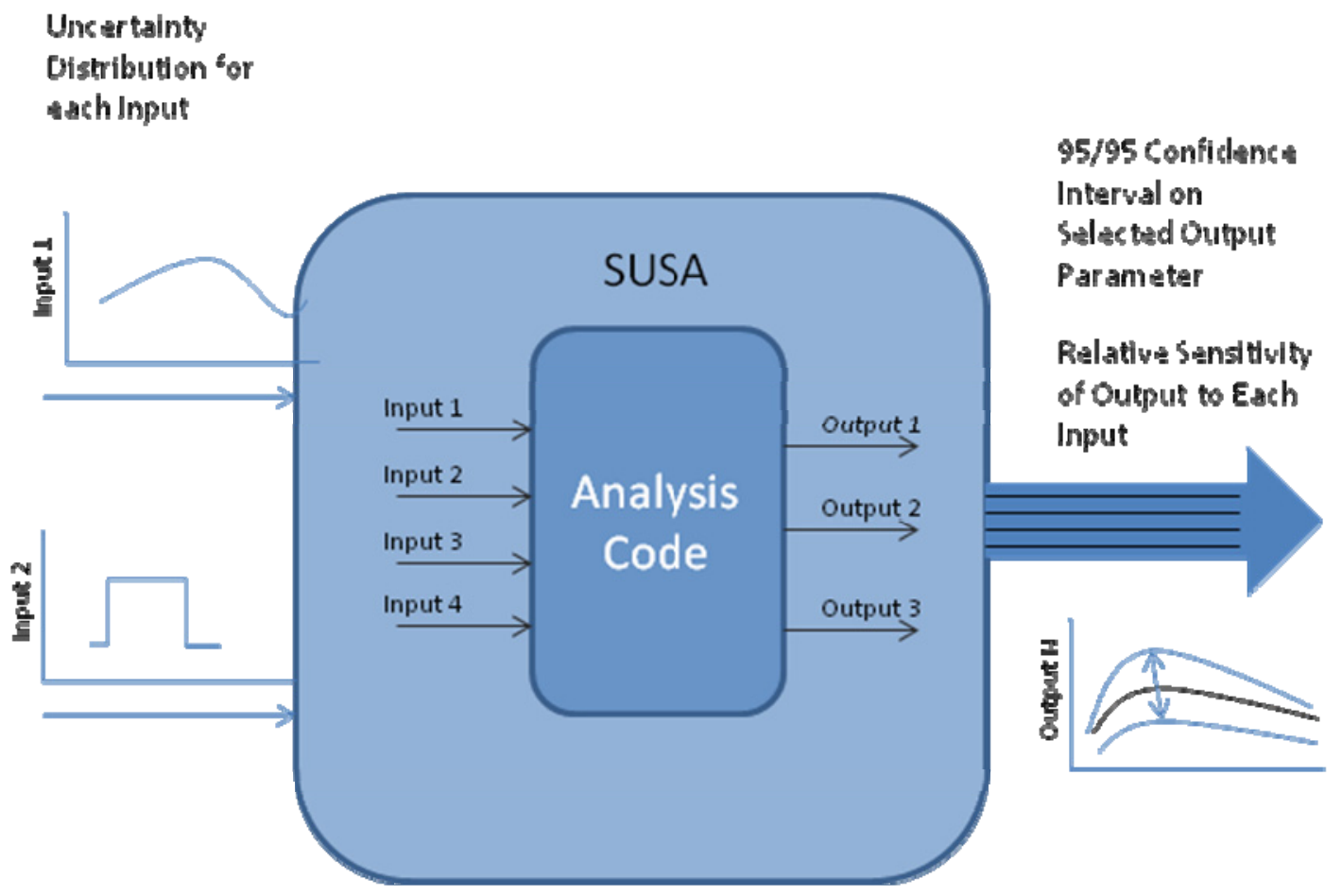

Figure 30. Information flow in a SUSA analysis.

\section{Schedule for Developing and Applying Sensitivity and Uncertainty Analysis}

- FY 2011:

- Complete analysis of PBR peak fuel temperature uncertainty (0.5 FTE)

- FY 2012:

- Initiate implementation of the prismatic coupled core analysis code within the SUSA framework (0.5 FTE) 


\begin{tabular}{|c|lll|}
\hline NEXT GENERATION NUCLEAR PLANT & Identifier: & PLN-2498 & \\
METHODS TECHNICAL & Revision: & 3 & \\
PROGRAM PLAN & Effective Date: & $12 / 21 / 10$ & Page: 61 of 84 \\
\hline
\end{tabular}

- FY 2013:

- Perform uncertainty analysis of prismatic core peak steady-state and DLOFC temperatures with SUSA (1 FTE)

- Using SUSA, analyze prismatic core peak temperatures during a rod withdrawal event (1 FTE).

\subsubsection{Reactor Physics and Core Simulation Code V\&V}

The level of V\&V of the codes under development in the NGNP Project will be determined by the nature of their use as specified in INL PLN-2247, "General Software Management Plan for the VHTR TDO." Vendor codes are planned to be used to design the plant and prepare the license application. The NRC is developing evaluation models and codes to evaluate the license. The role of the NGNP Project is closer to that of an owner/engineer in which calculations are performed to confirm or audit those of the vendor as a matter of investment protection. This is important as the operating experience and validation data with HTGRs is quite limited. A greater emphasis is placed upon verification and code-to-code comparisons. Validation of reactor physics codes is particularly hampered by the lack of a dedicated critical facility. Past critical experiments and current operating reactors will have to suffice for the validation of these tools.

Currently, no codes being developed under NGNP are being used for design or license evaluation. In this regard, they can all be considered predecisional, and thus are subjected to a minimal quality assurance standard under INL's Software Quality Assurance Program. The intent of the reactor physics and core simulation codes will be to confirm the results generated by other stakeholders. Full NQA-1 V\&V is not required under these circumstances.

The resource estimate given in the previous section assume that NGNP tools will be used only for confirmation purposes. If these tools are to be used for auditing vendor analyses, however, a full program of code V\&V must be pursued with the concomitant dedication of resources. NQA-1 level V\&V of the chosen lattice code will entail line-by-line verification of the code and the model of the NGNP selected by the NGNP Project. This cannot happen until a vendor submits a license application with details of a preliminary design, which will happen no earlier than the fourth quarter of 2013. If the NGNP Project and INL, acting in the capacity of owner/engineer, is required to fully certify the NGNP Evaluation models to NQA-1 standards, a detailed code and model quality assurance effort will need to be devised and executed.

For the basic purpose of confirming vendor calculations, verification of NGNP reactor physics and core simulation codes and models (see Appendix A-2) entails:

- Spatial convergence testing

- Temporal convergence testing for transient analysis

- Numerical stability

- Documentation (theory, code, and user manual)

- Detailed description of assumptions, method details, model details (including boundary and initial conditions), and constraints.

In the case of general purpose physics codes, only those modules within the code that are required for the analysis need to be exercised in this manner. The correlations, closure relations, subgrid models, and field equations must be shown to be valid over the range of operation.

For auditing calculations, verification requires examination of the code details (subroutines, functions, and data libraries) to confirm that the field equations, subgrid models, correlations, and data 


\begin{tabular}{|c|lll|}
\hline NEXT GENERATION NUCLEAR PLANT & Identifier: & PLN-2498 & \\
METHODS TECHNICAL & Revision: & 3 & \\
PROGRAM PLAN & Effective Date: & $12 / 21 / 10$ & Page: 62 of 84 \\
\hline
\end{tabular}

structures are properly implemented and executed. For reactor physics codes, the bottom-up approach focuses on the closure relations and ensuring that the field equations are correct for the application and are properly implemented. This is particularly challenging for the codes that were not developed under NGNP because the programming must be reverse engineered by analysts who probably had no role in the development. For coupled core analysis codes, a top-down approach is used whereby the code predictions must fall within the range of uncertainty in the data obtained from integral experiments. A code is considered adequate in applicability when it shows either excellent or reasonable agreement with the highly ranked phenomena (sometimes identified as the dominant phenomena) for a transient of interest.

Finally, benchmarking studies may either supplement the validation effort or make up the validation effort if appropriate standards are available; for example, if a code calculation can be compared with a closed form solution.

\subsubsection{Benchmarks, Data, and Computational Activities used for Reactor Physics and Core Simulator Code V\&V}

The set of tools available for V\&V of the NGNP codes and models consists of a small number of critical experiments, engineering test reactors, separate effects tests, analytical models, computational references (high fidelity, multiscale and multiphysics simulations), and code comparison. Only the first three of these are suitable for validation. The next two are suitable for verification. The last one is generally the least useful but is often used to provide insight into the physics of HTGRs and demonstrate the range of uncertainties in different modeling approaches and codes.

\subsubsection{Physics Experiments (Cross Section Measurements, Critical Experiments, and Engineering Test Reactors)}

Integral benchmark experiment data for existing critical configurations that are neutronically similar to contemplated NGNP designs are required for physics code validation and QA, both as part of the reactor design process and as for licensing applications. Modern computational simulation techniques for reactor physics are capable of very high accuracy, and can in some cases replace significantly more costly mockups and critical experiments, but only if the accuracy of the simulation is carefully established by rigorous validation of physics codes against appropriate integral experiment physics data. In addition, mathematically rigorous sensitivity studies for representative HTGR core designs are required as an aid in guiding the design of any needed critical experiments that cannot be replaced by simulations (because experiments with sufficient similarity are determined to be unavailable), and perhaps most importantly, for quantification of the propagation of uncertainties in computational simulations because of uncertainties in the underlying nuclear data and other parameters that make up the input to the simulation models.

Finally, high-accuracy differential nuclear data (nuclear cross section) libraries are required as input for all computational reactor physics tasks associated with NGNP design, licensing, and subsequent operation. Any simulation is only as accurate as the input data, and in the reactor physics field, the differential nuclear cross sections for the various materials used in the reactor constitute the most fundamental and crucial input information needed for the computational simulation process. For example, computational studies performed at INL show that for a reference prismatic HTGR fuel design, an uncertainty of as little as $10 \%$ in the $\mathrm{Pu}-240$ capture cross section can lead to uncertainties in system reactivity of as much as $500 \mathrm{pcm}$ absolute reactivity because of the propagated uncertainty in $\mathrm{Pu}-241$ buildup. This is an indication of high sensitivity to this particular cross section. Furthermore, earlier integral experiment-based code validation studies performed and published by INL [Sterbentz 2002; Sterbentz and Wemple 1996] for low-enriched fuel with thermal or slightly hyperthermal neutron spectra representative of typical HTGR designs, show that computations of the inventories of the plutonium isotopes of interest here can vary by as much as 30\% from corresponding measurements at burnups of 


\begin{tabular}{|c|lll|}
\hline NEXT GENERATION NUCLEAR PLANT & Identifier: & PLN-2498 & \\
METHODS TECHNICAL & Revision: & 3 & \\
PROGRAM PLAN & Effective Date: & $12 / 21 / 10$ & Page: 63 of 84 \\
\hline
\end{tabular}

less than one-third of what is contemplated in a baseline HTGR scenario. Such discrepancies can propagate in a manner that can have major effects on the uncertainty of computed safety-related reactor parameters such as reactivity, Doppler feedback, etc.

In FY 2004, ANL and INL examined information on several past and present experimental and prototypical facilities based on HTGR concepts that could potentially be used for the V\&V basis of codes employed in the design and analysis of HTGR cores. A preliminary assessment of the applicability of the existing test data for benchmarking the pebble-bed and prismatic-type cores was performed as part of that effort [Terry et al., 2004]. The experiments assessed included:

- Pebble-Bed Type Cores: ASTRA, AVR, CESAR II, GROG, HTR-10, HTR-PROTEUS, KAHTER, SAR, and THTR.

- Prismatic Type Cores: CNPS, DRAGON, Fort St. Vrain, GGA HTGR Criticals, HITREX-1, HTLTR, HTTR, MARIUS-IV, Peach Bottom HTGR, Peach Bottom Criticals, SHE, NESTOR/HECTOR, and VHTRC.

Trends were observed in the experiments performed in the various facilities investigated. It was found that most of the experiments for prismatic cores were performed in the United States, while those on pebble-bed cores were done predominantly in Europe. Most of the early U.S. experiments used highly enriched uranium. This was not typically the case for the European experiments. Additionally, experiments are currently being performed for both pebble-bed and prismatic cores in Asia (Japan and China) as well as in Russia. Under this NGNP program element, there will be an opportunity to influence the direction of these experiments in a way that benefits the NGNP effort.

The 2004 assessment revealed that the HTGR systems under development in the GEN IV program differ in significant ways from previous high-temperature reactors (e.g., thorium utilization, highly enriched fuel, bi-structural isotropic (BISO) versus TRISO fuel, thermal efficiency, operating temperatures, etc). These differences limit the applicability and direct usefulness of some of the existing experimental data for NGNP core designs. Furthermore, it was acknowledged that for data produced on commercial basis or by foreign governments, availability of the data might be quite limited. An effort was made to identify experimental tests of the highest priority, recover the data for those cases, and then develop standard problems (benchmarks) that are of sufficient quality for use in the licensing of the HTGR analysis codes. A set of criteria employed to judge the relevance of the different tests included: purpose of the previous experiment, geometry of core, fuel forms, core materials, physics parameters measured, measurement state, availability of design and uncertainty data, and applicability of data to $\mathrm{V} \& \mathrm{~V}$. Based on these criteria, the experiments judged to be of the highest priorities for the pebble-bed cores are ASTRA, AVR, HTR-10, and HTR-PROTEUS, and for the prismatic cores are HTTR, VHTRC, and CNPS.

Integral evaluations of HTTR and HTR-PROTEUS were performed from 2006 through 2010, and the results have been submitted for inclusion in the International Reactor Physics Benchmark Evaluation Handbook. Evaluations of the other facilities will be conducted from FY 2011 through FY 2013. In FY11, the final PROTEUS report will be edited and reviewed for acceptance into the Handbook. Data on the Japanese VHTRC and SHE (Simple Homogeneous Experiment) critical experiments is being pursued under the Agreement with JAEA. Once this data is obtained, models of those experiments will be constructed as validation tools.

\subsubsection{High Fidelity Multiphysics Confirmation of Lower Order Simulations}

The core simulators described in the previous section adhere to the traditional reactor analysis approach whereby high order transport codes are used on subsets of the core (blocks or pebbles) to obtain average diffusion theory parameters for use in fast, lower order whole core simulations. These methods 


\begin{tabular}{|c|lll|}
\hline NEXT GENERATION NUCLEAR PLANT & Identifier: & PLN-2498 & \\
METHODS TECHNICAL & Revision: & 3 & \\
PROGRAM PLAN & Effective Date: & $12 / 21 / 10$ & Page: 64 of 84 \\
\hline
\end{tabular}

have been deployed very successfully in LWR design and accident analysis but, as described in the previous section, significant enhancements and modifications must be made in order to perform HTGR analysis with the same level of accuracy. The resulting codes will be used for plant simulation for design and safety analysis where time-dependent, whole core or plant behavior is desired.

Modern computational algorithms and massively parallel computing platforms are now beginning to enable high-fidelity transport simulations, not just on subdomains but on substantial sections of the reactor. While these models and codes are still too slow and unnecessarily detailed for many basic design and safety applications, they can be useful for investigating particularly complex scenarios and phenomena. They can also be used to verify the lower order coupled simulations used for most applications. The following paragraphs describe the efforts (underway or planned) to apply so-called multiphysics/multiscale codes and techniques to the HTGR.

\section{High Fidelity Coupled Neutron and Thermal Fluid Transport for Verification of HTGR Codes}

A heterogeneous whole-core transport capability using a stochastic or deterministic transport theory solution method would be desirable for benchmarking lower order (but faster) core modeling techniques and codes. Such approaches reduce or eliminate the need for cumbersome and complex tasks of lattice cross section generation, condensation, functionalization, local information recovery, etc. On the other hand, such codes require tremendous computing power only available at a few national laboratories. ANL is developing the SHARP computational framework for implicit coupling of high resolution transport codes. Recently, ANL successfully simulated a one-twelfth core of a fresh prismatic HTGR core at steady-state using a coupled neutron transport (DECART) and CFD code (STAR-CCM). While not yet practical for core design, fuel management, and transient analyses, this effort demonstrates that high fidelity coupled transport analysis is possible [Pointer 2010].

An alternative approach being pursued under NGNP is to build a core simulator with MOOSE. MOOSE is a computational platform specifically designed for solving arbitrary and complex systems of partial differential equations. It exploits the computationally efficient Jacobian Free Newton Krylov method for implicitly coupling the physics coded by the user. Because the basic meshing and solver tools are embedded within MOOSE, the code developer need only provide the governing equations that describe the physics of the system [Gaston 2009].

In 2009, work began on the development of a transient multiphysics simulation capability built upon the MOOSE platform. Dubbed PRONGHORN, the initial code was constructed and tested in less than 6 months. It featured the multigroup diffusion and THERMIX-KONVEK thermal fluid equation sets solved on a finite element mesh. In FY 2010, the code was applied to the SANA experiment and PBMR400 Coupled Code Transient Benchmark problems to test its ability to simulate 3D pebble bed reactor transients. The new code was able to complete most of the benchmark exercises but displayed some numerical oscillations at location of the inlet plenum. This was found to be a limitation in the numerical scheme used to solve the thermal fluid equations in three dimensions (THERMIX-KONVEK assumes 1-D flow and thus does not exhibit this behavior). In FY11, a new numerical scheme (discontinuous Galerkin) will be implemented in MOOSE to address this issue. A similar code, BIGHORN, is being developed for multiphysics prismatic core simulation.

\section{Investigation of Wall Heat Transfer in PBRs}

As mentioned in the previous section, the THERMIX-KONVEK or THERMIX-DIREKT codes (or its governing equations) are used in many PBR core simulators, including VSOP, PEBBED, and PANTHERMIX. Convective heat transfer and pressure drop correlations for pebble beds of uniform packing fraction have been validated in experiments such as SANA [IAEA 2001]. Data from the SANA 


\begin{tabular}{|c|lll|}
\hline NEXT GENERATION NUCLEAR PLANT & Identifier: & PLN-2498 & \\
METHODS TECHNICAL & Revision: & 3 & \\
PROGRAM PLAN & Effective Date: & $12 / 21 / 10$ & Page: 65 of 84 \\
\hline
\end{tabular}

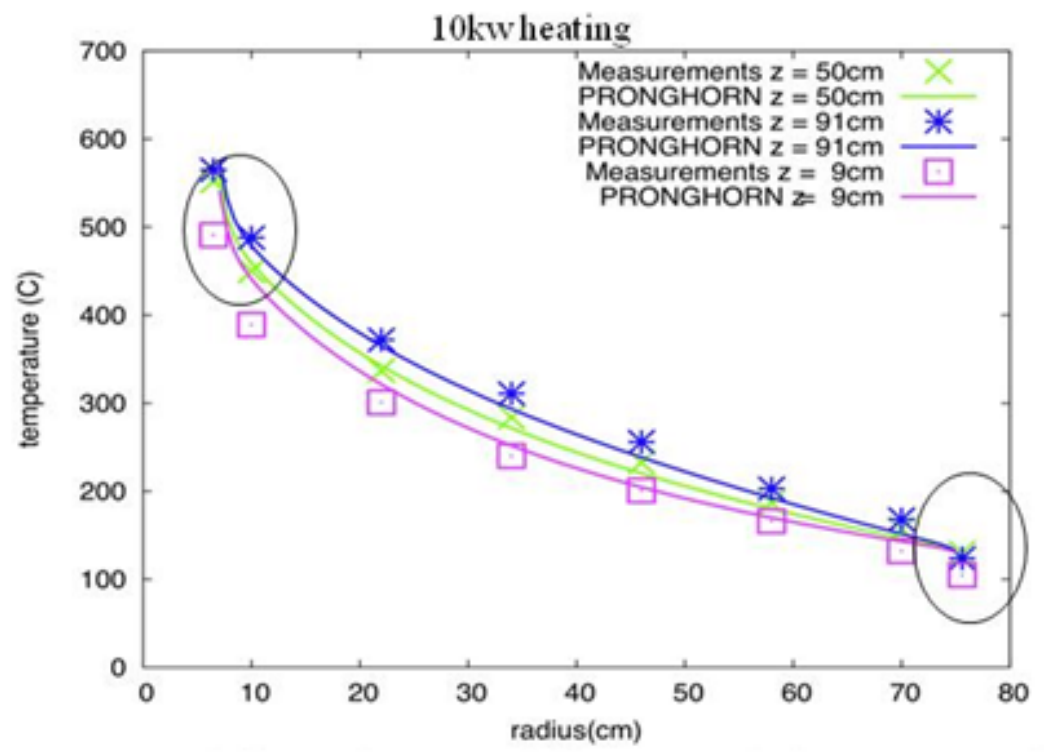

Figure 31. Measured temperature profile in the SANA experiment vs. profile predicted by PRONGHORN. experiment is often used to validate the basic thermal fluid solvers for new pebble bed simulators such as the PRONGHORN code [Park 2009] under development at INL (see Figure 30).

Codes based on the THERMIX equation set yield good agreement with data in the middle of the pebble bed, but the correlation fails somewhat near the walls where the bed porosity approaches unity. For system analysis, this error is assumed to be negligible or empirical corrections to the heat transfer correlations are applied. CFD analyses in which pebbles are modeled explicitly are computationally expensive and thus are limited to small $(<50)$ numbers of pebbles. These may be useful for detailed investigation of turbulence around a pebble, but cannot yet be used for core-wide analyses.

Under low flow conditions, radiation and conduction dominate heat transfer within pebble beds with good agreement with experiments given by the correlations of Zehner and Schlünder [1972] and Robold [1982]. Such correlations are widely used for PBR accident analysis but are still valid only in the middle of the pebble bed. Under NGNP, heat transfer across the core/reflector boundary will be developed for both steady state and low flow conditions.

\section{Modeling of Graphite Dimensional Changes}

Graphite shrinks and swells as a complex function of irradiation and temperature. These dimensional changes cause the bypass flow profile to change over time and with the attendant effects on core temperature. The bypasss flow studies being performed under the Experimental Validation program elements necessarily focus on the modeling of bypass flow under very controlled circumstances (fixed gap width, fixed power profile, etc.) In fact, the various temperature and fluence profiles across the core and individual blocks will cause nonuniform and time-dependent changes in gap size that will in turn change the temperature and coolant flow profiles. Coupling neutronics, thermal fluids, and mechanics poses a particularly demanding computational problem and is one of the grand challenges of HTGR core simulation.

\section{Schedule for Developing and Applying Multiphysics/Multiscale Modeling Capability}

- FY 2011:

- Continue development of the SHARP-VHTR platform with testing of a steady-state VHTR core model and investigation of SHARP-PRONGHORN interoperability $\left(0.5 \mathrm{FTE}^{\mathrm{i}}\right)$

i. This is INL support. SHARP-VHTR is funded independently of NGNP by DOE. 


\begin{tabular}{|c|lll|}
\hline NEXT GENERATION NUCLEAR PLANT & Identifier: & PLN-2498 & \\
METHODS TECHNICAL & Revision: & 3 & \\
PROGRAM PLAN & Effective Date: & $12 / 21 / 10$ & Page: 66 of 84 \\
\hline
\end{tabular}

- Upgrade of the porous medium CFD solver in PRONGHORN (0.5 FTE)

- Implement COMBINE-based cross section generation in PRONGHORN (0.25 FTE)

- Develop BIGHORN - a neutronic solver for prismatic geometry on the MOOSE platform (0.5 FTE)

- Execute the PBMR400 Benchmark Control Rod Withdrawal exercise (0.35 FTE)

- FY 2012:

- Implement cross section generation in BIGHORN (0.5 FTE)

- Investigate wall heat transfer in PBRs using PRONGHORN (0.5 FTE)

- Initiate development of a coarse mesh CFD solver in PRONGHORN (.5 FTE)

- Implement particle fuel temperature and stress model in PRONGHORN (0.5 FTE)

- $\quad$ FY 2013

- Complete development of a coarse mesh CFD solver for in PRONGHORN (.5 FTE)

- Implement the coarse mesh CFD solver in BIGHORN (0.5 FTE)

- Execute the Prismatic Coupled Code Transient Benchmark exercises with BIGHORN (1 FTE)

- Implement the particle fuel temperature and stress model in BIGHORN (0.5 FTE)

- Implement the graphite deformation model (2 FTE).

\subsubsection{Accomplishments and Status}

The following tasks were accomplished in FY 2010:

- Upgraded the COMBINE code to perform multiscale homogenization and generation of cross sections for pebble bed core simulation and integrated the code into the PEBBED-THERMIX PBR fuel cycle analysis code.

- Developed and code a 3-D transport treatment of control rods in the PBR to support CYNOD simulations of PBR transients.

- Completed and test a pebble dynamics simulation tool to support PBR burnup analysis, earthquake simulation, and dust production studies.

- Completed and test the integration of the CYNOD PBR nodal kinetics solver into the RELAP system analysis code.

- Performed simulations of earthquake-induced PBR transients using a high-fidelity time-dependent fuel temperature model and a discrete element pebble dynamics.

- Completed the CRP-5 Benchmark Evaluation of the PBMR400 Equilibrium Cycle using the PEBBED-COMBINE-THERMIX code package.

- Completed evaluations of the HTTR and Proteus Reactor Physics Benchmarks using MCNP.

- Completed development of an analytical treatment of burnable poisons in prismatic fuel blocks and integrated the treatment into a nodal diffusion solver.

- Completed the 3-D analysis of the HTTR critical core using deterministic core analysis tools as a $\mathrm{V} \& \mathrm{~V}$ of methods and a step toward full core burnup and transient analysis.

- Completed most of the PBMR400 Transient Benchmarks using the PRONGHORN multiphysics core simulator developed on the MOOSE platform. 


\begin{tabular}{|c|lll|}
\hline NEXT GENERATION NUCLEAR PLANT & Identifier: & PLN-2498 & \\
METHODS TECHNICAL & Revision: & 3 & \\
PROGRAM PLAN & Effective Date: & $12 / 21 / 10$ & Page: 67 of 84 \\
\hline
\end{tabular}

- Acquired and test the SUSA software for uncertainty and sensitivity analyses.

The following tasks are planned for FY 2011 through FY 2013:

- Steady State Prismatic Core Simulation: Develop, code, and verify a depletion algorithm to support prismatic core burnup and fuel management analyses using either HEXPEDITE or INSTANT.

- Time-dependent prismatic and pebble bed simulation: Develop a fast an accurate online cross section generation capability to support space-dependent HTGR transient simulations.

- Time-dependent prismatic and pebble bed simulation: Integrate the nodal diffusion solvers (CYNOD and HEXPEDITE) with a 3-D thermal fluid core and plant simulators to support 3-D transient analysis of PBRs and prismatic reactors.

- Time-dependent prismatic and pebble bed simulation: Conduct investigations of PBR wall heat transfer and other complex neutronic/thermal-fluid phenomena using the multiscale, multiphysics capabilities of PRONGHORN.

- Pebble bed dynamics and flow simulation: Verify the pebble motion and dust generation simulation capabilities of PEBBLES and validate against AVR or other experimental data.

- Validation of reactor physics codes: Finalize the HTTR and Proteus reactor physics benchmark evaluations.

- Meso/Microscale fuel temperature, energy deposition, and stress analysis: Analyze fuel behavior during HTGR transients using a coupled fuel performance code (PASTA) and core simulator (CYNOD and HEXPEDITE).

- Validation of reactor physics codes Lead the specification for a prismatic core transient benchmark and complete the evaluation.

- Multicomponent fluid transport: Complete and test upgrades to the MELCOR code in support of dust and fission product transport studies.

- Uncertainty and sensitivity analysis: Compute the uncertainties in peak fuel temperatures and shutdown margin because of uncertainties in core parameters.

- Other Program Support: Support experimental campaigns in thermal V\&V and fuel and graphite $\mathrm{V} \& \mathrm{~V}$. 


\begin{tabular}{|c|lll|}
\hline NEXT GENERATION NUCLEAR PLANT & Identifier: & PLN-2498 & \\
METHODS TECHNICAL & Revision: & 3 & \\
PROGRAM PLAN & Effective Date: & $12 / 21 / 10$ & Page: 68 of 84 \\
\hline
\end{tabular}

\section{PROGRAM SCHEDULE AND COST}

A detailed, resource-loaded, activity-based schedule for the activities presented in the TPP for experimental V\&V and core simulation activities has been developed and is used to guide and prioritize activities year by year. A higher-level summary of that schedule is shown in Figure 31 and Figure 32. The critical path for experimental validation of system and CFD codes is through the construction and operation of the HTTF and Natural Convection Shutdown Heat Removal Test Facility (NSTF), with simultaneous experiments in air ingress and bypass flow. Activity then shifts to core heat transfer, plenum-to-plenum, and the other experiments defined in the plan. HTTF and NSTF are the more complex integral facilities that will require considerable construction and shakedown testing before data is generated. Activities in Core Simulation initially focus on basic neutronics modeling (development of acceptable cross section generation and neutron transport techniques) along with the establishment of a bounding range of core transient exercises to be used in benchmark studies. Based on the schedule, the high priority experiments for the prismatic reactor will be completed by 2013 , with the remainder to be completed by 2016.

An itemized cost breakdown by task is shown in Table 5; the experimental V\&V tasks are followed by the core simulation tasks. The total program cost is estimated to be $\sim \$ 71$ million.

Table 5. Itemized cost breakdown by task.

\begin{tabular}{|lc|}
\hline \multicolumn{1}{|c|}{ Item } & $\begin{array}{c}\text { Estimated Cost } \\
\text { (\$ Million) }\end{array}$ \\
\hline Integral tests in HTTF & $\mathbf{1 5}$ \\
$\quad$ NRC Prismatic $(\$ 8 \mathrm{M})^{*}$ & \\
DOE Prismatic $(\$ 2 \mathrm{M})$ & \\
$\quad$ DOE Pebble Bed $(\$ 5 \mathrm{M})$ & $\mathbf{4 . 6}$ \\
Ex-Core Heat Transfer in NSTF & $\mathbf{5}$ \\
Air Ingress & $\mathbf{5}$ \\
Fission Product Transport (outside the core) & $\mathbf{1 0}$ \\
Water Ingress & $\mathbf{4 . 5}$ \\
Bypass in MIR & $\mathbf{2}$ \\
Core Heat Transfer & $\mathbf{2}$ \\
Plenum-to-Plenum & $\mathbf{1 0}$ \\
Lower Plenum & $\mathbf{3}$ \\
HTTR/HTR-10 Data Acquisition & $\mathbf{1 5}$ \\
Supporting Analyses & \\
\hline & \\
\hline
\end{tabular}

* Cost born by NRC, not NGNP Methods, and not included in the total

The schedule of high-level experimental thermal fluid V\&V tasks is presented in Figure 31. It should be noted that, to accommodate possible budget limitations in the future, Methods V\&V activities will be undertaken using a triage approach based on (a) utilizing university expertise combined with experimental design simplification to reduce the experimental scope to fit future budget constraints, and (b) reducing the data and validation matrix based on the scenario classification, e.g. performing validation 


\begin{tabular}{|c|lll|}
\hline NEXT GENERATION NUCLEAR PLANT & Identifier: & PLN-2498 & \\
METHODS TECHNICAL & Revision: & 3 & \\
PROGRAM PLAN & Effective Date: & $12 / 21 / 10$ & Page: 69 of 84 \\
\hline
\end{tabular}

functions only for design basis accidents (DBAs), i.e. not including beyond design basis accident scenarios (BDBAs).

\begin{tabular}{|c|c|c|c|}
\hline Activity & Start & Finish & 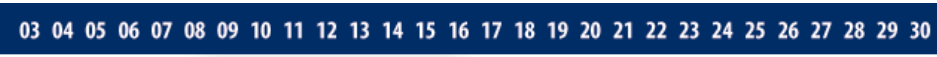 \\
\hline EXPERIMENTAL THERMAL FLUID V\&V & $9 / 1 / 08$ & $4 / 30 / 16$ & 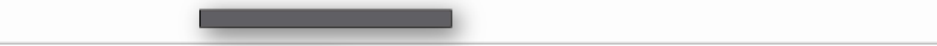 \\
\hline HTTF - NRC Prismatic & $8 / 15 / 09$ & $8 / 30 / 12$ & $\square$ HTTF - NRC Prismatic \\
\hline HTTF - DOE Prismatic & $8 / 30 / 12$ & $9 / 1 / 13$ & $\square$ HTTF-DOE Prismatic \\
\hline HTTF - DOE Pebble & $9 / 1 / 13$ & $8 / 30 / 14$ & $\square \quad$ HTTF-DOE Pebble \\
\hline NSTF - Ex-Core Heat Transfer & $9 / 1 / 08$ & $9 / 1 / 13$ & Irradiate AGC-2 (South Flux Trap) \\
\hline Air Ingress (INL) & $9 / 1 / 09$ & $8 / 30 / 12$ & $\square$ Air Ingress (INL) \\
\hline Fission Product Transport (THAl or ANL) & $4 / 30 / 11$ & $4 / 30 / 14$ & Fission Product Transport (THAl or ANL) \\
\hline Water Ingress & $8 / 30 / 12$ & $8 / 30 / 14$ & $\square$ Water Ingress \\
\hline MIR - Bypass Flow Prismatic & $9 / 1 / 09$ & $8 / 30 / 12$ & $\square$ MIR-Bypass \\
\hline MIR - Bypass Flow Pebble Bed & $8 / 30 / 12$ & $9 / 1 / 13$ & $\square$ MIR - Bypass Flow Pebble Bed \\
\hline Core Heat Transfer & 9/1/11 & $8 / 30 / 14$ & $\square$ Core Heat Transfer \\
\hline Plenum - to - Plenum & $9 / 1 / 11$ & $9 / 1 / 13$ & $\square$ Plenum - to - Plenum \\
\hline Lower Plenum & $9 / 1 / 11$ & $8 / 30 / 14$ & $\square$ Lower Plenum \\
\hline Fundamental Experiments \& Separate Ef & ts $9 / 1 / 08$ & $4 / 30 / 16$ & $\square$ Fundamental Experiments \& Separate Effects \\
\hline HTTR/HTR10 & $1 / 1 / 10$ & $4 / 30 / 13$ & $\square$ HTTR/HTR10 \\
\hline
\end{tabular}

\section{Figure 32. High level schedule of experimental thermal fluid V\&V tasks.}

The critical path for core simulation and reactor physics codes is the development of a whole prismatic core coupled diffusion/thermal fluid/depletion simulation capability with testing against critical facility benchmarks and comparisons to other results for the prismatic coupled core benchmark exercises. This basic capability already exists for the pebble bed reactor, so activity in this area will take a lower priority over the next couple of years unless the pebble bed reactor is chosen by NGNP as the preferred design. Activities in Core Simulation initially focus on basic neutronics modeling (development of acceptable cross section generation and neutron transport techniques) along with the establishment of a bounding range of core transient exercises to be used in benchmark studies. Based on the schedule, the high priority experiments for the prismatic reactor will be completed by 2013 , with the remainder to be completed by 2016. Estimates of cost and schedule for the core simulation (coupled thermal fluid and reactor physics) development and $\mathrm{V} \& \mathrm{~V}$ are listed in Table 6.

Table 6. Itemized cost for core simulation development and V\&V.

\begin{tabular}{|lc|}
\hline \multicolumn{1}{|c|}{ Item } & $\begin{array}{c}\text { Estimated Cost } \\
\text { (\$ Million) }\end{array}$ \\
\hline High Fidelity Steady-state Neutron Transport & $\mathbf{1 . 5}$ \\
Steady-state Fuel Cycle Simulation & $\mathbf{4}$ \\
3-D Core Transient Simulation & $\mathbf{2 . 5}$ \\
Meso/microscale fuel modeling coupled to core & $\mathbf{0 . 7 5}$ \\
simulation & \\
Pebble bed Dynamics and pebble flow & $\mathbf{0 . 7 5}$ \\
Multicomponent fluid transport & $\mathbf{1 . 0}$ \\
Uncertainty and Sensitivity Analysis & $\mathbf{1 . 0}$ \\
Multiscale/Multiphysics Development and & $\mathbf{2}$ \\
Application & $\mathbf{3 0}$ \\
Phase 2 Verification and Validation & $\mathbf{4 3 . 5}$ \\
\hline \multicolumn{2}{c}{ TOTAL } \\
\hline
\end{tabular}




\begin{tabular}{|c|lll|}
\hline NEXT GENERATION NUCLEAR PLANT & Identifier: & PLN-2498 & \\
METHODS TECHNICAL & Revision: & 3 & \\
PROGRAM PLAN & Effective Date: & $12 / 21 / 10$ & Page: 70 of 84 \\
\hline
\end{tabular}

The schedule of Reactor Physics and Core Simulation is presented in Figure 33.

\begin{tabular}{|c|c|c|c|}
\hline Activity & Start & Finish & 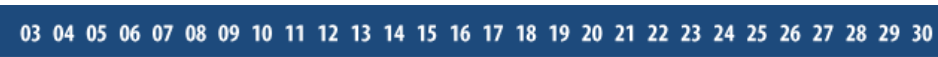 \\
\hline EXPERIMENTAL THERMAL FLUID V\&V & $9 / 1 / 08$ & $4 / 30 / 16$ & 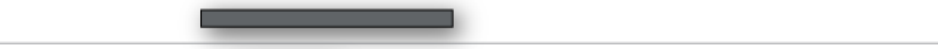 \\
\hline HTTF - NRC Prismatic & $8 / 15 / 09$ & $8 / 30 / 12$ & $\square$ HTTF - NRC Prismatic \\
\hline HTTF - DOE Prismatic & $8 / 30 / 12$ & $9 / 1 / 13$ & $\square$ HTTF-DOE Prismatic \\
\hline HTTF - DOE Pebble & $9 / 1 / 13$ & $8 / 30 / 14$ & $\square$ HTTF-DOE Pebble \\
\hline RCCS & 9/1/08 & $9 / 1 / 13$ & $\square$ RCCS \\
\hline Air Ingress (INL) & $9 / 1 / 09$ & $8 / 30 / 12$ & $\square$ Air lngress (INL) \\
\hline Fission Product Transport (THAl or ANL) & $4 / 30 / 11$ & $4 / 30 / 14$ & Fission Product Transport (THAl or ANL) \\
\hline Water Ingress & $8 / 30 / 12$ & $8 / 30 / 14$ & $\square$ Water Ingress \\
\hline MIR - Bypass Flow Prismatic & $9 / 1 / 09$ & $8 / 30 / 12$ & $\square$ MIR-Bypass \\
\hline MIR - Bypass Flow Pebble Bed & $8 / 30 / 12$ & $9 / 1 / 13$ & $\square$ MIR - Bypass Flow Pebble Bed \\
\hline Core Heat Transfer & $9 / 1 / 11$ & $8 / 30 / 14$ & $\square$ Core Heat Transfer \\
\hline Plenum - to - Plenum & $9 / 1 / 11$ & $9 / 1 / 13$ & $\square$ Plenum - to - Plenum \\
\hline Lower Plenum & $9 / 1 / 11$ & $8 / 30 / 14$ & $\square$ Lower Plenum \\
\hline Fundamental Experiments \& Separate Ef & ts $9 / 1 / 08$ & $4 / 30 / 16$ & $\square$ Fundamental Experiments \& Separate Effects \\
\hline HTTR/HTR10 & $1 / 1 / 10$ & $4 / 30 / 13$ & $\square$ HTTR/HTR10 \\
\hline
\end{tabular}

\section{Figure 33. High level schedule of core simulation activities .}

If the NGNP Evaluation Model is needed for the auditing of NRC or vendor calculations, a higher level of validation and verification will be required of the core simulation evaluation model. Based upon past experience with codes such as RELAP, this effort would be expected to take three to five years and many full time equivalents (FTEs) to complete. A detailed resource estimate has not been performed for such an effort but $\$ 30 \mathrm{M}$ is an educated guess for the total cost. 


\begin{tabular}{|c|lll|}
\hline NEXT GENERATION NUCLEAR PLANT & Identifier: & PLN-2498 & \\
METHODS TECHNICAL & Revision: & 3 & \\
PROGRAM PLAN & Effective Date: & $12 / 21 / 10$ & Page: 71 of 84 \\
\hline
\end{tabular}

\section{REFERENCES}

Ball, S. J., 2003, "MHTGR Accident Analysis," American Nuclear Society MHTGR Technology Course, June 2003.

Ball, S, et al., 2008, "Next Generation Nuclear Plant Phenomena Identification and Ranking Tables (PIRTs),” NUREG/CR-6944.

Bayless, P. et al., 2009, Developmental Assessment of RELAP5-3-D Version 2.9.2, INL/EXT-09-15969, September 2009.

Boer, B. and A. M. Ougouag, 2010, Stress Analysis of Coated Particle Fuel in the Deep-Burn Pebble Bed Reactor Design, INL/CON-09-17162, October 2010.

Briesmeister, J. D., 2003, MCNP - A General Monte Carlo N-Particle Transport Code_Version 5.

Childs, K. W.,2007, PSR-0199/05, HEATING 7.3.

Cogliati, J., 2010, “PEBBLES Operation and Theory Manual,” INL/EXT-10-19305, September 2010.

Cogliati, J. and A. M. Ougouag, 2008, Pebble Bed Reactor Dust Production Model, INL/CON-08-14226, September 2008.

Becker, B. at al, 2009, "Improvement of the resonance scattering treatment in MCNP in view of HTR calculations," Annals of Nuclear Energy, Vol. 36, Issue 3, pp. 281-285, April 2009.Fachinger, J., et al., 2008, "Examination of Dust in AVR pipe components," HTR2008 58033, Proceedings of the 4th International Topical Meeting on High Temperature Reactor Technology, HTR2008, September 28October 1, 2008, Washington, DC USA.

Ferrer, R. M., A. M. Ougouag, and F. Rahnema, 2010, “A Simplified HTTR Diffusion Theory Benchmark," Proceedings of the $5^{\text {th }}$ International Topical Meeting on High Temperature Reactor Technology, HTR 2010, Prague, Czech Republic, October 18-20, 2010.

Ganapol, B. D., W. Y. Yoon, and D. W. Nigg, 2007, Verification of the INL/COMBINE7 Neutron Energy Spectrum Code, INL/CON-07-13263.

Gaston, D., G. Hansen, and C. Newman, 2009, MOOSE: A Parallel Computational Framework for Coupled Systems of Nonlinear Equations, INL/CON-08-15008, May 2009.

Gauntt, R. O., R. K. Cole, C. M. Erickson, R. G. Gido, R. D. Gasser, S. B. Rodriguez, M. F. Young, 2000, MELCOR Computer Code Manuals, Vol. 1: "Primer and Users' Guide," Version 1.8.5, May 2000, NUREG/CR-6119, Vol. 1, Rev. 2, SAND2000-2417/1, October.

General Atomics, MHTGR Nuclear Physics Benchmarks, DOE-HTGR-90406, San Diego, February 1994.

Generation IV International Forum, 2002, A Technology Roadmap for Generation IV Nuclear Power Systems, GIF-002-00, December 2002.

Gougar, H. D., F. Reitsma, and W. Joubert, 2009, “A Comparison of pebble mixing and depletion algorithms used in pebble-bed reactor equilibrium cycle simulation," Proceedings of the 2009 International Conference on Mathematics, Computational Methods, and Reactor Physics, Saratoga Springs, May 2009.

Gougar, H. D., A. M. Ougouag, W. K. Terry, and K. I. Ivanov, 2010, “Automated Design and Optimization of Pebble Bed Reactor Cores," Nuclear Science and Engineering, Vol. 165, pp. 245-269, July. 


\begin{tabular}{|c|lll|}
\hline NEXT GENERATION NUCLEAR PLANT & Identifier: & PLN-2498 & \\
METHODS TECHNICAL & Revision: & 3 & \\
PROGRAM PLAN & Effective Date: & $12 / 21 / 10$ & Page: 72 of 84 \\
\hline
\end{tabular}

Gougar, H. D., W. Y. Yoon, and A. M. Ougouag, 2010, "Multiscale Analysis of Pebble Bed Reactors," Proceedings of the 5th International Topical Meeting on High Temperature Reactor Technology, Prague, Czech Republic, October 17-20, 2010.

Gougar, H. D., 2010, Results of the simulation of HTR_Proteus Core 4.2 using PEBBED-COMBINE: FY10 Report, INL/EXT-10-19208, July.

Hébert, A., 2008, "Scattering reduction of the double heterogeneity treatment in DRAGON," Nuclear Science and Engineering, Vol. 160, No. 2, October 2008.

IAEA, 2000, Heat Transport and Afterheat Removal for Gas Cooled Reactors Under Accident Conditions, IAEA-TECDOC-1163.

IAEA, 2001, Heat Transport and Afterheat Removal for Gas Cooled Reactors Under Accident Conditions,. International Atomic Energy Agency, IAEA-TECDOC-1163.

IAEA, 2003, "Evaluation of high temperature gas cooled reactor performance: Benchmark analysis related to initial testing of the HTTR and HTR-10," International Atomic Energy Agency, IAEATECDOC-1382.

Jun, J. S., H. S. Lim, and W. J. Lee, 2009, "Benchmark Calculations of the GAMMA+ Code with the HTR10 Safety Demonstration Experiments," Nuclear Engineering and Technology, Vol. 41, No. 3, April 2009.

Kloosterman, J. L. and A. M. Ougouag, 2005, "Spatial Effects in Dancoff Factor Calculations for PebbleBed HTRs," Proceedings of the American Nuclear Society Topical Meeting on Mathematics and Computation, Supercomputing, Reactor Physics and Nuclear and Biological Applications, Palais des Papes, Avignon, France, September 12-15, 2005.

Krüger, K., A. Bergerfurth, S. Burger, P. Pohl, M. Wimmers, and J. C. Cleveland, 1991, "Preparation, Conduct, and Experimental Results of the AVR Loss-of-Coolant Accident Simulation Test," Nuclear Science and Engineering, Vol. 107, pp. 99-113.

Kuijper, J. C., J. B. M. de Haas, and J. Oppe, 2002, "HTR Core Physics Analysis at NRG," Proceedings of the $1^{\text {st }}$ International Topical Meeting on High Temperature Reactor Technology, HTR 2002, Petten, the Netherlands, April 22-24, 2002.

Lee, C. H., Z. Zhong, T. Taiwo, W. Yang, and M. Smith, 2006, Enhancement of REBUS-3/DIF3-D for Whole-Core Neutronics Analysis of Prismatic Very High Temperature Reactor (VHTR), ANLGenIV076, September.

Lee, W. J., T. Y. C. Wei, and R. R. Schultz, 2005, Generation of a Preliminary PIRT (Phenomena Identification and Ranking Table) for Very High Temperature Gas-Cooled Reactors, KAERI/TR-3050/2005, INL/EXT-05-00829, ANL-GenIV-066, September 2005.

Loyalka, S. 2009, "Some Dust Transport Issues in VHTRs and Some Recent Work at the University of Missouri," HTGR Graphite Dust Meeting, Omni Shoreham Hotel, Washington, DC, November 16, 2009.

Marleau, G.,A. Hébert and R. Roy, 1996, “A User’s Guide for DRAGON,” Report IGE-174, Rev. 1, Ecole Polytechnique de Montréal, March.

McCreery, G. and K. Condie, 2006, Experimental Modeling of VHTR Plenum Flows During Normal Operation and Pressurized Conduction Cooldown, INL/EXT-06-11760, September. 


\begin{tabular}{|c|lll|}
\hline NEXT GENERATION NUCLEAR PLANT & Identifier: & PLN-2498 & \\
METHODS TECHNICAL & Revision: & 3 & \\
PROGRAM PLAN & Effective Date: & $12 / 21 / 10$ & Page: 73 of 84 \\
\hline
\end{tabular}

McEligot, D. M., et al, 2002. Fundamental thermal fluid physics of high temperature flows in advanced reactor systems. Final. rpt., INEEL/EXT-2002-1613, INEEL.

McEligot, D. M., and G. E. McCreery, 2004, Scaling Studies and Conceptual Experiment Designs for NGNP CFD Assessment, INEEL/EXT-04-02502, 30 November.

Miller, G. K., D. A. Petti, J. T. Maki, and D. L. Knudson, 2004, "Current Capabilities of the Fuel Performance Modeling Code PARFUME," Proceedings of the High Temperature Reactor Conference HTR-2004, Beijing, China, September 2004.

Murphy, H. D., F. W. Chambers, and D. M. McEligot, 1983, "Laterally converging flow. I. Mean flow," J. Fluid Mech., Vol. 127, pp. 379-401.

NGNP, 2010-1, 2010, "Next Generation Nuclear Plant Steam Generator and Intermediate Heat Exchanger Materials Research and Development Plan," PLN-2804, September 2010.

NGNP, 2010-2, 2010, Next Generation Nuclear Plant Project Monthly Report, INL/LTD-09-17300, August 2010.

OECD, 2005, “OECD/NEA/NSC PBMR Coupled Neutronic/Thermal Hydraulics Transient Benchmark The PBMR-400 Core Design," Draft V03, September 2005.

Ortensi, J. and A. M. Ougouag, 2009, Improved Prediction of Temperature Feedback in TRISO-Fueled Reactors, INL/EXT-09-16494, 2009.

Ortensi, J. and M. A. Pope, 2010, "Deterministic Modeling of the High Temperature Test Reactor with DRAGON-HEXPEDITE,” INL/CON-10-18012, 2010.

Ougouag, A. M. and W. K. Terry, 2001, Development of a Nodal Method for the Solution of the Neutron Diffusion Equation in General Cylindrical Geometry, INEEL/EXT-2002-489, Idaho National Laboratory External Report, April 2001.

Ougouag, A. M., and J. Ortensi, 2009, “Analysis of an Earthquake-Initiated Transient in a PBR,” INL/CON-08-14876, May 2009.

Ougouag, A. M., and Cogliati, J., 2007, "Earthquakes and Pebble Bed Reactors; Time-Dependent Densification," INL/CON-08-12288, April 2007.

Ougouag, A. M. and R. M. Ferrer, 2010, "Nodal Diffusion Burnable Poison Treatment for Prismatic Reactor Cores," Proceedings of the 2010 International Meeting on High temperature Reactor Technology, Prague, Czech Republic, October 2010.

Park, H., Knoll, D., and Sato, H, 2009, Progress on PRONGHORN Application to NGNP Related Problems, INL/EXT-09-16659, August 2009.

Petti, D., 2010, “Technical Program Plan for the Next Generation Nuclear Plant/Advanced Gas Reactor Fuel Development and Qualification Program," PLN-3636, September 2010.

Pointer, W. D., 2010, "Steady-State, Whole-core VHTR Simulation with Consistent Coupling of Neutronics and Thermo-fluid Analysis," Proceedings of the International Congress on Advances in nuclear Power Plants, San Diego, June 13-17, 2010.

Poss, G. 2009, "THAI Experiments to Investigate Gas Distribution and Graphite Dust Transport in a Generic HTGR Confinement," DOE Dust Workshop, Washington, D.C., November 2009.

Rajic, H. L and A. M. Ougouag, 1987, "NOMAD: a Nodal Macroscopic Analysis Method for Nuclear Fuel Depletion," Transactions of the American Nuclear Society Annual Meeting, Los Angeles, CA, November 1987. 


\begin{tabular}{|c|lll|}
\hline NEXT GENERATION NUCLEAR PLANT & Identifier: & PLN-2498 & \\
METHODS TECHNICAL & Revision: & 3 & \\
PROGRAM PLAN & Effective Date: & $12 / 21 / 10$ & Page: 74 of 84 \\
\hline
\end{tabular}

Reitsma, F., H. J. Rütten, and W. Scherer, 2005, “An Overview of the FZJ Tools for HTR Core Design and Reactor Dynamics, The Past, Present, and Future," Proceedings of the American Nuclear Society Topical Meeting on Mathematics and Computation, Supercomputing, Reactor Physics and Nuclear and Biological Applications, Palais des Papes, Avignon, France, September 12-15, 2005.

F. Reitsma, J. Han, K. Ivanov, E. Sartori, “The OECD/NEA/NSC PBMR400 MW Coupled Neutronics Thermal-hydraulics Transient Benchmark - Status and Comparative Analysis," PHYSOR-2008 International Conference, Interlaken, Switzerland, (Contributing author), (Peer Reviewed), September 14-19, 2008.

Reshotko, E., 1967,"An analysis of the laminar-instability problem in gas-cooled nuclear reactor passages," AIAA J., Vol. 5, No. 9.

Robold, K., 1982, "Wärmetransport im Inneren und in der Randzone von Kugelschütten,” Kernforschungen Jülich GmbH, JÜL-1796, August 1982.

Sanchez, R. and C. Pomraning, 1991, "A statistical analysis of the double heterogeneity proplem, “" Annals of Nuclear Energy, Vol. 18, Issue 7, Pages 371-395.

Satake, S.-I., T. Kunugi, A. M. Shehata, and D. M. McEligot, 2000, "Direct numerical simulation on laminarization of turbulent forced gas flows in circular tubes with strong heating." Int. J. Heat Fluid Flow, Vol. 21, pp. 526-534.

Sato, H., R. W. Johnson, and R. R. Schultz, 2010, "Computational Fluid Dynamic Analysis of Core By-pass Flow Phenomena in a Prismatic VHTR," Annals of Nuclear Energy, Vol. 37, pp. 1172-1185.

Schlichting, H., 1979, Boundary Layer Theory, McGraw-Hill.

Schultz, R. R., et al., 2007, Next Generation Nuclear Plant Methods Technical Program Plan, INL/EXT-06-11804, April 2007.

Schultz, R. R., 1993, International Code Assessment and Applications Program: Summary of Code Assessment Studies Concerning RELAP5/MOD2, RELAP5/MOD3, and TRAC-B, NUREG/IA-0128, December.

Smith, K., and Rhodes, J., 2000, "CASMO-4 Characteristics Methods for Two-Dimensional PWR and BWR Core Calculations,: Trans, Am. Nucl. Soc., 83,322, Washington, D.C., November.

Sterbentz, J. W., 2002, Uranium and Plutonium Isotopic Validation Study for the Hanford Reactor, INEEL/EXT-02-01567.

Sterbentz, J. W., C.A. Wemple, 1996, Calculation of a Burnup Methodology and Validation for the Idaho National Engineering Laboratory Spent Nuclear Fuels, INEL-96/0304.

Strydom, G., 2010, Use of Uncertainty and Sensitivity Analysis for INL VHTR Coupled Codes, INL/EXT-10-19023, June.

Studsvik Scandpower, "HELIOS User Manual,” April 2000.

Tak, N., M. Kim, and W. J. Lee, 2008, "Numerical investigation of a heat transfer within the prismatic fuel assembly of a very high temperature reactor," Annals of Nuclear Energy, Vol. 35.

Terry, W. K., J. K. Jewell, J. Blair Briggs, T. A. Taiwo, W. S. Park, and H. S. Khalil, 2004, "Preliminary Assessment of Existing Experimental Data for Validation of Reactor Physics Codes and Data for NGNP Design and Analysis," September 2004. 


\begin{tabular}{|c|lll|}
\hline NEXT GENERATION NUCLEAR PLANT & Identifier: & PLN-2498 & \\
METHODS TECHNICAL & Revision: & 3 & \\
PROGRAM PLAN & Effective Date: & $12 / 21 / 10$ & Page: 75 of 84 \\
\hline
\end{tabular}

Thomas, J., C. H. Lee, W. D. Pointer, and W. S. Yang, "Steady-State, Whole-Core VHTR Simulation with Consistent Coupling of Neutronics and Thermo-fluid Analysis," Proceedings of ICAPP 2010 the International Congress on Advances in Nuclear Power Plants, San Diego, CA, June 13-15, 2010.

Tokuhiro, A. 2009, "Experimental Study and Computational Simulations of Key Pebble Bed Thermal-Mechanics Issues for Design and Safety," HTGR Graphite Dust Meeting, Omni Shoreham Hotel, Washington, D.C., November 16, 2009.

U.S. Nuclear Regulatory Commission, 2005, Regulatory Guide 1.203, December.

Vukoslavcevic, P. V. and Wallace, J. M., 2002, "The Simultaneous Measurement of Velocity and Temperature in Heated Turbulent Air Flow using Thermal Anemometry," Measurement Science and Technology, Vol. 13, pp. 1615-1624.

Yoon, S. J., J. Cho, K. Y. Kim, M. H. Kim, W. J. Lee, and G. C. Park, 2007, "Experimental Evaluation of the Bypass Flow in the VHTR Core," SMiRT-19, Toronto, August 12-17.

Zehner, P., and E. U. Schlünder, 1972,"'Einfluss der Waermestrahlung und des Druckes auf den Waermetransport in nichtdurchstroemten Schuettungen," Chem.-Ing. Techn., Vol. 23.

Zuber, N., 1991, "Appendix D: Hierarchical, Two-Tiered Scaling Analysis, An Integrated Structure and Scaling Methodology for Severe Accident Technical Issue Resolution,” NUREG/CR-5809. 


\begin{tabular}{|c|lll|}
\hline NEXT GENERATION NUCLEAR PLANT & Identifier: & PLN-2498 & \\
METHODS TECHNICAL & Revision: & 3 & \\
PROGRAM PLAN & Effective Date: & $12 / 21 / 10$ & Page: 76 of 84 \\
\hline
\end{tabular}

\section{Appendix A}

\section{Qualification, Selection, Validation, and Verification of Thermal Fluid Codes and Models}

Practices and procedures are divided into several categories to indicate the goal and intent of each. These categories include Scenario Identification, Code Verification, Code and Calculation Documentation, Reduction of Numerical Error, Quantification of Numerical Uncertainty, and Calculation Validation. Quantification of numerical uncertainty is discussed in some detail in Johnson et al 2006. A more detailed explanation of each of these concepts is provided in this Appendix.

\section{A-1. CODE VERIFICATION}

Code Verification involves the determination of coding correctness [Roache 1998], a process separate from Calculation Verification (the Quantification of Numerical Uncertainty). Idaho National Laboratory (INL) recognizes that the analysis software that will be applied to reactor safety analysis will already have been subjected to a variety of code verification tests. Documentation of these tests will be required.

Only those tests that exercise the options used in the particular computations need to be documented. The tests as a suite must be designed to exercise all the terms in the governing partial differential equations. For example, it is not adequate to only test the code on linearly varying solutions such as planar Couette flow, since this solution does not exercise vertical convection terms and others. The most complete and convincing type of Code Verification test uses the Method of Manufactured Solutions [Roache 1998], but this will not be required. If Method of Manufactured Solutions not used, it will probably be necessary to use a suite of test problems to demonstrate code correctness. For all of these problems, the observed rate of discretization error convergence should be documented and compared to a theoretical value for the discretization algorithms employed. If it is not, then more stringent requirements will be enforced during Calculation Verification (Johnson et al. 2006). The code verification must also include some data on the effect of iterative convergence criteria on numerical results. (See "Reduction of Numerical Error" below for details.)

\section{A-1.1 Code and Calculation Documentation}

Software that is used for nuclear reactor safety analysis must be described in detail in code documentation. Such documentation should include describing equations used and their discretization as well as the basic methods used to obtain a solution. The truncation error and its formal order or accuracy should be given. The code documentation must include all details of implementation of the turbulence models used in calculations, e.g., turbulence models for computational fluid dynamics (CFD) software. The code documentation should be available for reference to reviewers who must review the associated calculational results.

For each calculation performed and submitted as a safety analysis, assumptions must be listed along with the details of the methods and models used. Other details including, but not limited to boundary and initial conditions, model constants (parameters), and other relevant information must also be provided. Options not used in the calculation need not be documented. 


\begin{tabular}{|c|lll|}
\hline NEXT GENERATION NUCLEAR PLANT & Identifier: & PLN-2498 & \\
METHODS TECHNICAL & Revision: & 3 & \\
PROGRAM PLAN & Effective Date: & $12 / 21 / 10$ & Page: 77 of 84 \\
\hline
\end{tabular}

\section{A-1.2 Reduction of Numerical Error}

The reduction of numerical error is clearly a desirable objective for numerical calculations. Lessons have clearly been learned about what not to do when using computational techniques for numerical analysis. These have been canonized in the requirements for manuscripts submitted to well-known journals, such as the American Society of Mechanical Engineers (ASME) Journal of Fluids Engineering. It therefore seems prudent to apply them to the application of relevant software to reactor safety analysis. Examples of such requirements are those given in the ASME Journal of Fluids Engineering "Statement on Numerical Accuracy." Details regarding the philosophy and meaning of the various key points are discussed in Johnson et al 2006. Examples of the content include requirements that (a) methods must be at least second order accurate in space, (b) grid independence or convergence must be established, and (c) in-transient calculations phase error must be assessed and minimized.

Grid independence is the process of refining the grid from some starting point until numerical results stop changing or change by negligible amounts. Theoretically, the results will continue to change until the grid spacing approaches zero. The precision of the machine, however, will halt this process at a finite grid spacing, sometimes referred to as achieving machine zero (of the residuals). Not only is the process of obtaining grid independence important to reducing numerical errors, it is also a good way to obtain estimated numerical uncertainty (see "Quantification of Numerical Uncertainty" in Johnson et al. 2006).

Iterative convergence relates to the number of iterations required to obtain residuals that are sufficiently close to zero either for a steady-state problem, or for each time step in an unsteady problem. This error is in addition to the numerical error associated with the truncation error terms. Because of the well-known and unacceptable sensitivity of some commercial codes to the iteration tolerance, and the too lax default tolerance, the final calculations must determine this effect. At least two levels of iteration tolerance must be shown and the sensitivity presented. For example, if results for a solution functional $f$ are presented using a default iteration tolerance of (say) $10^{-3}$ reduction in residual from the initial condition, as required in Freitas et al [2003], then another calculation with $10^{-4}$ will be required, and the sensitivity f' 10 will be stated as the normalized \% change in $f$ per decade of change in iteration tolerance.

$f_{10}^{\prime}=\Delta f=\left[f\left(10^{-4}\right)-f\left(10^{-3}\right)\right] / f_{\text {norm }} \times 100 \%$

The normalization can be based on $f$ norm $=f\left(10^{-3}\right)$ when divides by near zero are not a problem, otherwise by another appropriate normalization. The final test of sufficient tightness of the iterative tolerance will be the acceptability of the final results based on estimation of numerical uncertainty and validation metrics.

For transient calculations, the same convergence criterion should apply as for spatial convergence (grid independence). The time step should be refined until negligible change is obtained. Also, though not required by the Journal of Fluids Engineering, it is recommended that the time-wise discretization scheme should be second-order accurate or better. While there are other practices to reduce numerical error, the above will constitute the required practices for rector safety analysis at the present time. Certainly, other practices that reduce numerical error are allowed and even encouraged.

\section{A-2. VALIDATION}

Whether or not software is adequate for performing best-estimate very high temperature reactor (VHTR) analyses is determined using both "top-down" and "bottom-up" evaluations, as summarized in Figure A-1 and described in the following sections. 


\begin{tabular}{|c|lll|}
\hline NEXT GENERATION NUCLEAR PLANT & Identifier: & PLN-2498 & \\
METHODS TECHNICAL & Revision: & 3 & \\
PROGRAM PLAN & Effective Date: & $12 / 21 / 10$ & Page: 78 of 84 \\
\hline
\end{tabular}

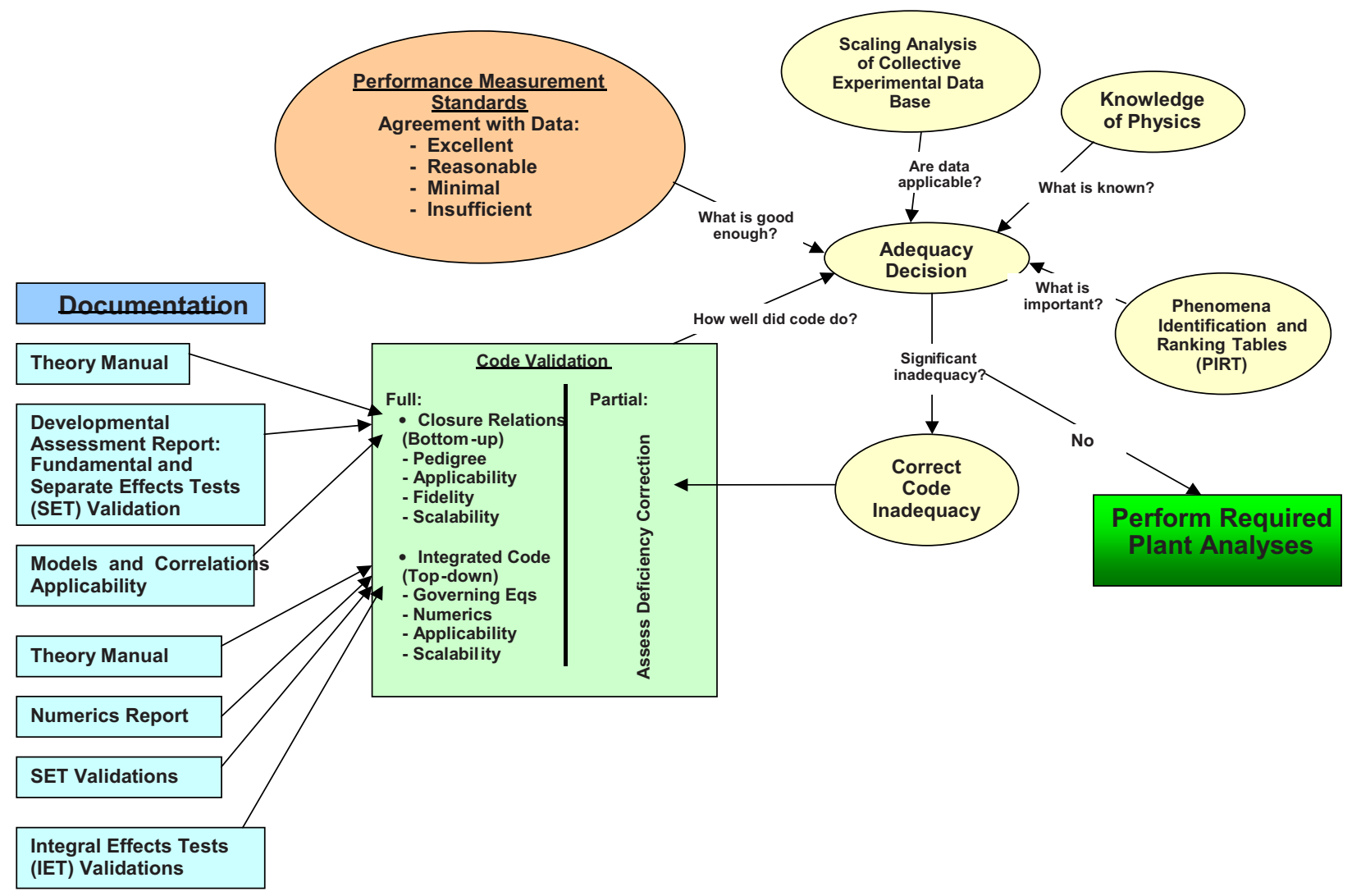

Figure A-1. VHTR system design software: elements of adequacy evaluation and acceptance testing practices.

\section{A-2.1 "Bottom-Up" Code Adequacy}

Bottom-up evaluation of code adequacy entails examination of four features: the pedigree, applicability, fidelity, and scalability of the code under consideration.

The pedigree of a systems code consists of its history, its development procedures, and the basis for each correlation that is used in the code. Any correlations, data sources, and approximations used in the code must be documented in textbooks, laboratory reports, papers, etc. The uncertainty data (instrumentation uncertainty, data system uncertainties, etc.) used to bound the correlation(s), data, and approximations must be included in the documentation. The basis for the uncertainties should be traceable and reproducible. The assumptions and limitations of the models must be known and documented.

The applicability of a systems code depends on the range of use of each of its correlations, data, and approximations. Those ranges must be documented and referenced. Finally, the range of applicability claimed in the code manual should be consistent with the pedigree - or if a greater range is claimed then the justification for the increase in range must be reported.

The fidelity of a systems code means the degree to which the code's predictions agree with physical reality. High fidelity requires that the mathematical models and correlations used in the code are not altered in an ad hoc manner from their documented formulation. A code is validated when it is shown that the code's predictions of key parameters agree, within allowable tolerances, with experimental data. The validation effort should be complete for all the key phenomena in the events of interest. Finally, 


\begin{tabular}{|c|lll|}
\hline NEXT GENERATION NUCLEAR PLANT & Identifier: & PLN-2498 & \\
METHODS TECHNICAL & Revision: & 3 & \\
PROGRAM PLAN & Effective Date: & $12 / 21 / 10$ & Page: 79 of 84 \\
\hline
\end{tabular}

benchmarking studies may either supplement the validation effort or make up the validation effort if appropriate standards are available, e.g., comparison of code calculation with a closed form solution.

"Bottom-up" scaling stems from the need to:

- Build experimental facilities that model the desired full-scale system

- Closely match the expected behavior of the most important transient phenomena in the scenarios of interest

- Demonstrate the applicability of data from a scaled facility to a full-scale system and to defend the use of data from a scaled facility in a code used to calculate the behavior of a full-scale system

- Relate a calculation of a scaled facility to a calculation of a full-scale system.

Usually, scalability studies are performed to scale key parameters for a portion of the system behavior - not to correlate the global system behavior. Scalability analyses consist of four steps:

1. Isolate the "first-order" phenomena.

2. Characterize the "first-order" phenomena.

3. Convert the defining equations into nondimensional form.

4. Adjust the experimental facility conditions to give equivalent behavior with the full-scale system within the limitation of the facility (or nearly equivalent, i.e., based on nondimensional numbers that follow from Step 3.

As implied in the above discussion, "bottom-up" code adequacy techniques focus principally on closure relationships. Thus, the field equations used in the code must be correctly formulated and programmed. In addition, the field equations must be reviewed by the scientific community, and its agreement on the correct formulation and insertion of the governing equations in the code must be obtained.

\section{A-2.2 “Top-Down” Code Adequacy}

The "top-down" approach for ensuring code adequacy focuses on the capabilities and performance of the integrated code. The top-down approach consists of four parts: numerics, fidelity, applicability, and scalability.

- Numerics. Evaluation of the numerical solution considers (i) convergence, (ii) stability, and (iii) property conservation. ${ }^{j}$ Again, agreement by the scientific community on acceptable convergence, stability, and property conservation must be obtained.

- Fidelity. The fidelity of the code is demonstrated by performing thorough code assessments based on applicable integral-effects and separate-effects data. The data are part of an agreed-upon code assessment matrix constructed based on the transients of importance and the key phenomena for each phase of the transients.

- Applicability. The code must be shown capable of modeling the key phenomena in the system components and subsystems by conducting thorough validation studies. The key phenomena are identified in the Phenomena Identification and Ranking Table (PIRT).

j. Property conservation issues arise when two calculations of the same property are performed by a systems code using two different algorithms or methods. This practice may follow in an effort to enhance the accuracy of the code result. Because the two methods are likely to calculate slightly different values of the same property (e.g., pressure and property) conservation must be considered. 


\begin{tabular}{|c|lll|}
\hline NEXT GENERATION NUCLEAR PLANT & Identifier: & PLN-2498 & \\
METHODS TECHNICAL & Revision: & 3 & \\
PROGRAM PLAN & Effective Date: & $12 / 21 / 10$ & Page: 80 of 84 \\
\hline
\end{tabular}

The method to determine whether the code is capable of modeling key phenomena is to compare the calculation produced by the code to data that have known uncertainties. For example, "excellent" agreement between the code calculation and data is achieved if the calculated value is at all times within the data uncertainty band.

The degree of agreement between the code calculation and the data is generally divided into four categories as given in Table A-1. A more rigorous definition is given in Schultz 1993. A code is considered adequate in applicability when it shows either excellent or reasonable agreement with the highly ranked phenomena (sometimes identified as the dominant phenomena) for a transient of interest. If the code gives minimal or unacceptable agreement, additional work must be performed; the work may range from additional code development to additional analysis to understand the phenomena.

Table A-1. Code adequacy identifiers.

\begin{tabular}{|ll|}
\hline \multicolumn{1}{|c|}{ Classifier } & \multicolumn{1}{c|}{ Description } \\
\hline Excellent & $\begin{array}{l}\text { The calculation lies within or near the data uncertainty band at all times during } \\
\text { phase of interest. }\end{array}$ \\
Minimal & $\begin{array}{l}\text { The calculation sometimes lies within the data uncertainty band and shows the same } \\
\text { trends as the data. Code deficiencies are minor. } \\
\text { Significant code deficiencies exist. Some major trends and phenomena are not } \\
\text { predicted. Incorrect conclusions may be drawn based on the calculation without } \\
\text { benefit of data. }\end{array}$ \\
Unacceptable & $\begin{array}{l}\text { A significant difference between the calculation and the data is present and the } \\
\text { difference is not understood. Such a difference could follow from errors in either } \\
\text { the calculation or the portrayal of the data or an inadequate code model of the } \\
\text { phenomenon. }\end{array}$ \\
\hline
\end{tabular}

- Scalability. Experimental scaling distortions are identified and isolated, e.g., inappropriate environmental heat losses that stem from the larger surface-to-volume ratios that are inherent to scaled facilities. Finally, an effort to isolate all code scaling distortions is performed through the code assessment calculations. Scaling distortions may arise from an inappropriate use of a correlation developed in a small-scale system when applied to a full-scaled system.

\section{A-2.3 Validation Process}

Validation of the analysis tools, for example the systems analysis and CFD software, will proceed using a process designed to include the expertise in not only the nuclear industry but the expertise external to the nuclear industry when required. Participation by experts at the national laboratories together with university experts and industry experts will ensure the software tools achieve the defined objectives.

The process is centered on defining a validation matrix, which serves as the foundation for a set of standard problems for both systems analysis and CFD software. The validation matrix is assembled by correlating the key phenomena identified in the PIRT for the most challenging scenarios with the available data sets. If data sets are needed, but not available, then experiments will be designed and performed to provide the needed data. The experiments will be specified to meet the standard required for software validation, that is, with a reasonable uncertainty band and with a data range that either includes the required validation range or can be scaled to include the required validation range. Subsequently, the data sets become the basis for standard problems that will be used by the VHTR validation community. The VHTR validation community consists of national laboratory users, the university community, the 


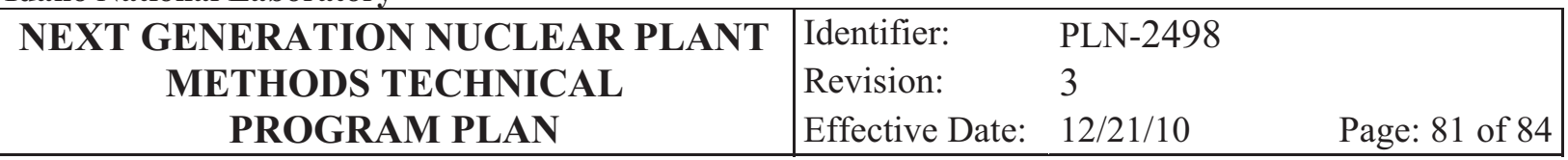

Generation IV International Forum (GIF) community (including the vendor community), and the community of users (who may be outside the nuclear community) for the software being validated. This process is shown in Figure A-2.

The process for specifying standard problems begins with the formation of a "Standard Problem Committee" (presently being formed through the auspices of the GIF Methods Project Management Board). The Standards Problem Committee will consist of members from selected universities, the VHTR Program Group, GIF organizations, and the vendors. The standard problems will be defined to meet a prescribed standard.

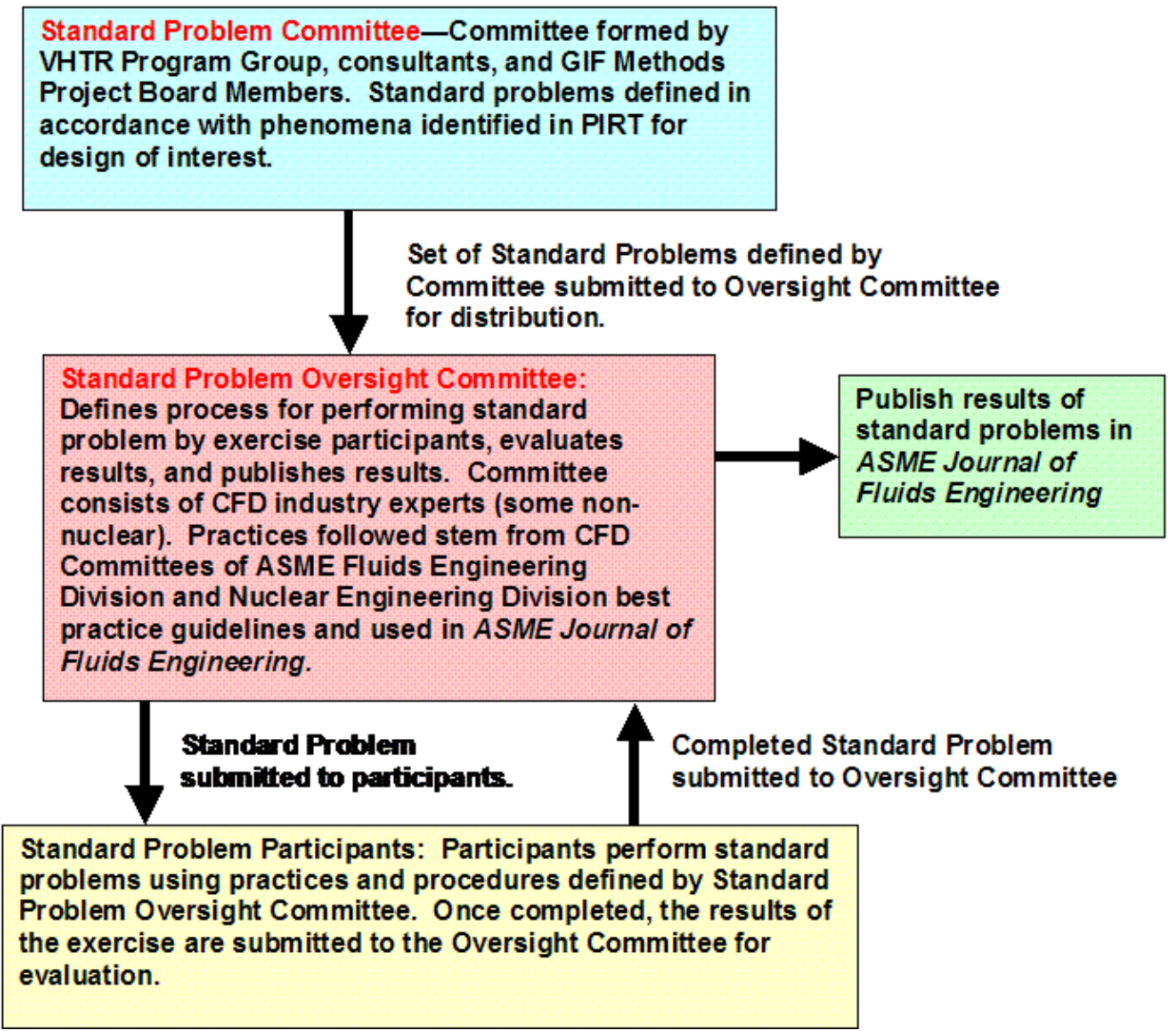

Figure A-2. Validation process-including participation by experts from the national laboratories, universities, vendors, and the community specific to software undergoing validation.

The validations performed using standard problems will be assigned to those who will perform validation exercises by the Standard Problem Oversight Committee, who will also formulate the practices and procedures that will be used for performing the validation calculations. This committee will be composed of experts in the use and validation of the software. For example, one of the committee members for the CFD Standard Problem Oversight Committee will be an expert selected by the ASME CFD Technical Committee, which was previously responsible for the well-known CFD Triathlon in the 1990s, who will not necessarily be a member of the nuclear community. Other members will be from the VHTR Program Group, universities, and perhaps the vendors. Following assignment of the standard problems to the participants, the committee will also oversee the final review and publication of the validation studies in the literature as shown in Figure A-2. 


\begin{tabular}{|c|lll|}
\hline NEXT GENERATION NUCLEAR PLANT & Identifier: & PLN-2498 & \\
METHODS TECHNICAL & Revision: & 3 & \\
PROGRAM PLAN & Effective Date: & $12 / 21 / 10$ & Page: 82 of 84 \\
\hline
\end{tabular}

\section{A-3. SOFTWARE TOOL SELECTION AND SOFTWARE DEVELOPMENT}

\section{A-3.1 Software tool selection}

When confronted with the need to calculate some of the phenomena that will be encountered in the VHTR scenarios, it is inevitable that analysts will be required to choose one software tool over another. This will be particularly true of systems analysis software (for example, GRSAC, MELCOR, and RELAP5). To assist the analyst in formally choosing software, a methodology is given in Figure A-3, where a flow chart summarizes key factors and questions such as:

1. Has the software ever been used to analyze the phenomena or scenario that requires analysis, as identified in the PIRT? By answering this question the analyst may be introduced to references and other experts who have applied the software to similar phenomena or scenarios. Hence a body of useful information may be available.

5. Are the phenomena modeled properly, and does the model region of applicability correspond to the system phenomena or scenario envelope? These questions may be most easily answered by using the manuals and documentation required to describe the models and correlations, theory, scaling relationships and applications, developmental assessment reports, validations, etc. (See Figure A-1)

6. Have validation studies been completed for the phenomena or scenario? Were the validation results reasonable or excellent (as defined in Table A-1), or were the results minimal or unacceptable? If a body of validation results are not available, or if the validation results were not reasonable, as a minimum, then either the software should not be used or it should be validated to ensure that the calculated results are reliable rather than misleading.

Only when acceptable answers are obtained for the questions listed above, can the software under consideration be used with confidence for the required analysis.

\section{A-3.2 Software Development}

The Methods Research and Development Program is geared to principally make use of existing software unless it can be shown that the present capability is inadequate for designing and licensing the VHTR. Presently, for the thermal-fluids analysis needs, it is projected that only a few additional CFD and systems analysis code development efforts will be required. For reactor physics, some developmental efforts are required to accommodate the specific fuel and material types. However, every effort is being made to complete the required reactor physics software development as early as possible in the program. 


\begin{tabular}{|c|lll|}
\hline NEXT GENERATION NUCLEAR PLANT & Identifier: & PLN-2498 & \\
METHODS TECHNICAL & Revision: & 3 & \\
PROGRAM PLAN & Effective Date: & $12 / 21 / 10$ & Page: 83 of 84 \\
\hline
\end{tabular}

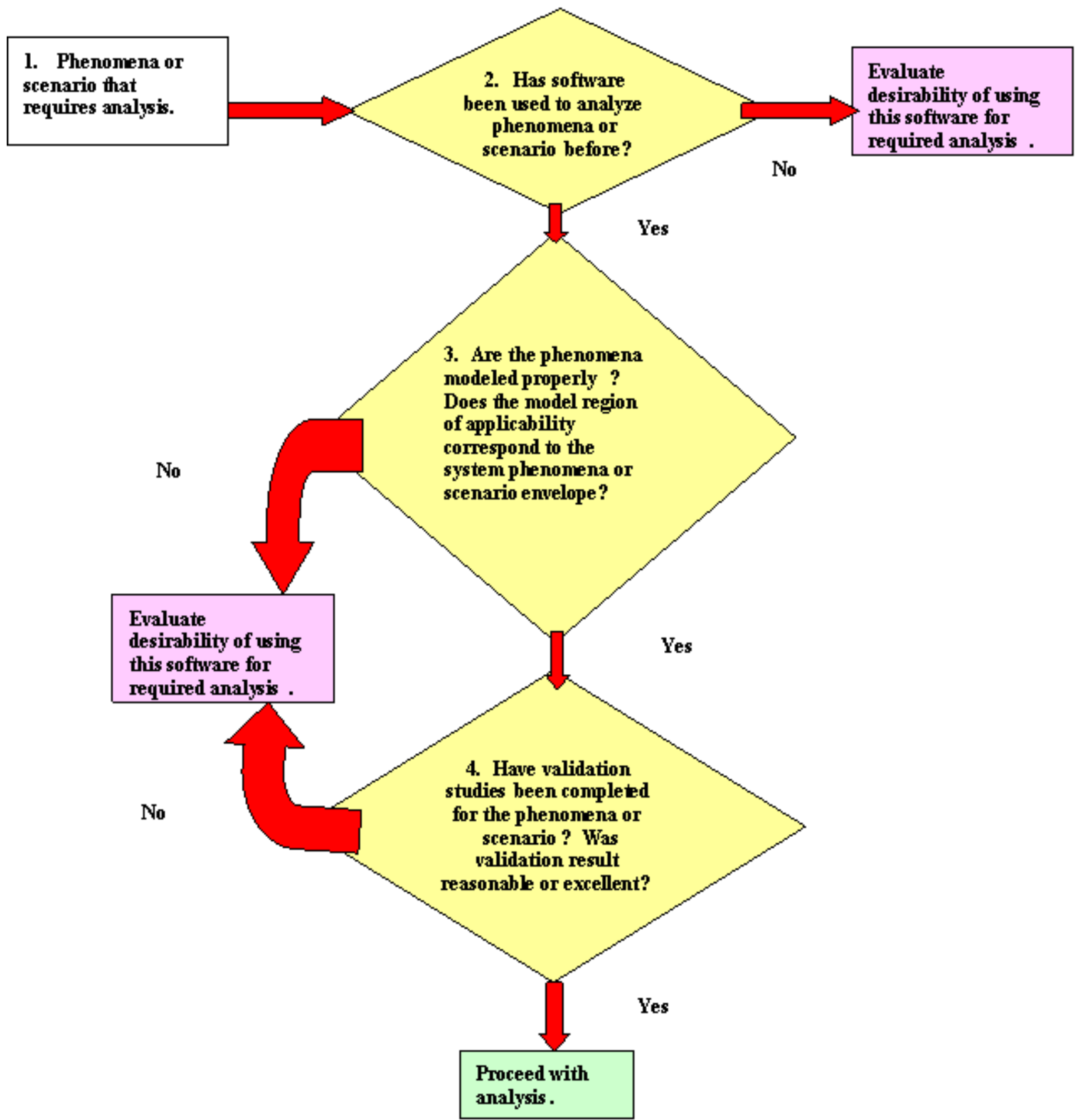

Figure A-3. Flow chart to evaluate applicability of analysis software.

\section{A-3.3 Software Quality Assurance}

As described and governed by PLN-2247, "General Software Management Plan for the VHTR TDO," (September 2009) all software used and developed for NGNP in accordance with the plan are subject to the software quality assurance requirements of LWP-13620, "Software Quality Assurance" and NQA-12000, "Quality Assurance Requirements for Nuclear Facility Applications," using a graded approach commensurate with the risk involved in developing and using the software. It applies to software used at 


\begin{tabular}{|c|lll|}
\hline NEXT GENERATION NUCLEAR PLANT & Identifier: & PLN-2498 & \\
METHODS TECHNICAL & Revision: & 3 & \\
PROGRAM PLAN & Effective Date: & $12 / 21 / 10$ & Page: 84 of 84 \\
\hline
\end{tabular}

the Idaho National Laboratory (INL) in support of the VHTR TDO and covers the development, acquisition, modification, maintenance, operation, and retirement of software designated as Quality Level (QL)-2 and QL-3.

Software excluded from this plan includes:

- Software included under contractual agreements, such as Work for Others and Cooperative Research and Development Agreements, including references or requirements to a specific documented SQA process other than this plan

- Static webpages, forms, and spreadsheets that do not generate/retrieve data or perform user-developed calculations

- Calculations used in support of analysis activities that are performed (for example, using a spreadsheet or programmable calculator) under the control of a single user, where verification of the results was performed by an independent reviewer or through alternate methods, and a technical report provides adequate information for reproducing the results

- Software that is a product of basic research

- Software used to generate information for input to a proposal during project initiation or project administration activities like budgeting, resource loading, periodic project reporting, or addressing "what if" scenarios

- Trial or evaluation copies of software if not used for data acquisition, reduction, or qualification, reactor licensing, or determination of the reactor safety envelope

- Software products and results used by only one VHTR TDO group or organization, which are not foreseen to expand beyond that organization, providing the organization's management assumes responsibility for the accuracy of calculations and validity of data produced through the use of the software, cyber security, and business continuity in the event of total loss of data/software

- Firmware that is acquired as a standard product that can only be user-modified by manufacturer updates after receipt, such as firmware used within cell phones, pagers, volt meters, etc., (nonsafety only).

\section{A-4. REFERENCES}

Freitas, C. J., U. Ghia, I. Celik, H. Coleman, P. Raad, and P. J. Roache, 2003, “ASME's Quest to Quantify Numerical Uncertainty," AIAA Paper 2003-0627, AIAA 41st Aerospace Sciences Meeting, Reno, NV, January.

Johnson, R. W., R. R. Schultz, P. J. Roache, I. B. Celik, W. D. Pointer, and Y. A. Hassan, 2006, Processes and Procedures for Application of CFD to Nuclear Reactor Safety Analysis, INL/EXT-06-11789, September.

Roache, P. J., 1998, Verification and Validation in Computational Science and Engineering, Hermosa Publishers, Albuquerque.

Schultz, R. R., 1993, "International Code Assessment and Applications Program: Summary of Code Assessment Studies Concerning RELAP5/MOD2, RELAP5/MOD3, and TRAC-B," NUREG/IA-0128, December. 